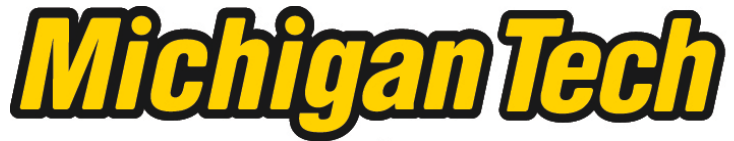 \\ Michigan Technological University Create the Future Digital Commons @ Michigan Tech
}

\section{EXPLORING CHANGES IN DETRITAL FLOCCULENT LAYER DYNAMICS DUE TO SHIFTS IN MACROPHYTE COMMUNITIES IN THE NORTHERN EVERGLADES}

Erin Leigh McKenney

Michigan Technological University

Follow this and additional works at: https://digitalcommons.mtu.edu/etds

Part of the Biogeochemistry Commons, and the Ecology and Evolutionary Biology Commons Copyright 2014 Erin Leigh McKenney

Recommended Citation

McKenney, Erin Leigh, "EXPLORING CHANGES IN DETRITAL FLOCCULENT LAYER DYNAMICS DUE TO SHIFTS IN MACROPHYTE COMMUNITIES IN THE NORTHERN EVERGLADES", Master's Thesis, Michigan Technological University, 2014.

https://doi.org/10.37099/mtu.dc.etds/876

Follow this and additional works at: https://digitalcommons.mtu.edu/etds

Part of the Biogeochemistry Commons, and the Ecology and Evolutionary Biology Commons 


\title{
EXPLORING CHANGES IN DETRITAL FLOCCULENT \\ LAYER DYNAMICS DUE TO SHIFTS IN MACROPHYTE COMMUNITIES IN THE NORTHERN EVERGLADES
}

\author{
By \\ Erin Leigh McKenney \\ A THESIS \\ Submitted in partial fulfillment of the requirements for the degree of \\ MASTER OF SCIENCE \\ In Biological Sciences \\ MICHIGAN TECHNOLOGICAL UNIVERSITY \\ 2014 \\ (C) 2014 Erin Leigh McKenney
}


This thesis has been approved in partial fulfillment of the requirements for the Degree of MASTER OF SCIENCE in Biological Sciences.

\title{
Department of Biological Sciences
}

\author{
Thesis Advisor: $\quad$ Dr. Michael Gretz \\ Committee Member: Dr. Charles Kerfoot \\ Committee Member: Dr. Brent Bellinger \\ Department Chair: Dr. Shekhar Joshi
}




\section{Table of Contents}

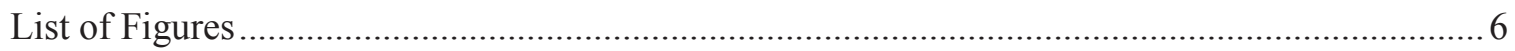

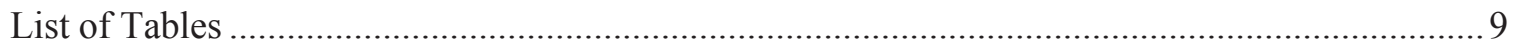

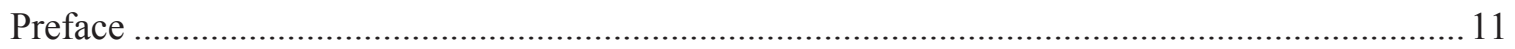

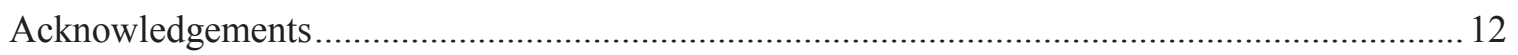

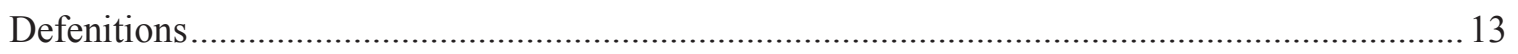

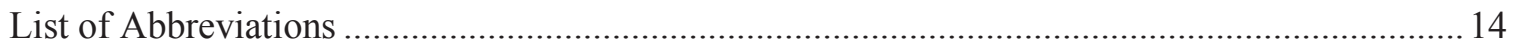

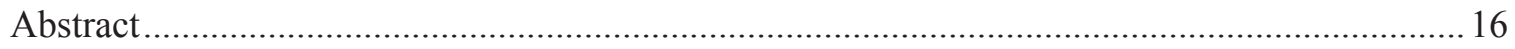

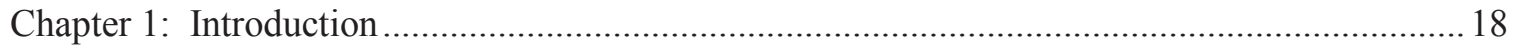

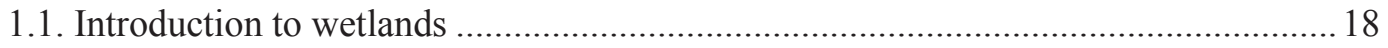

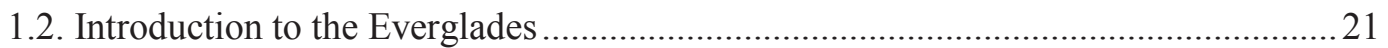

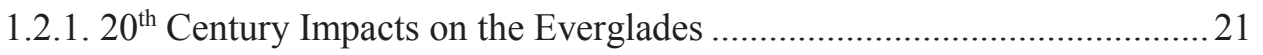

1.2.2. The Cattail Habitat Improvement Project ............................................... 23

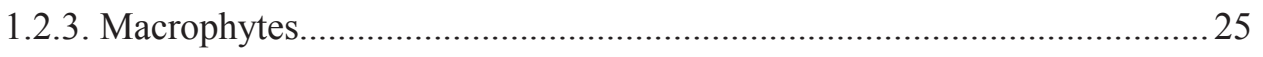

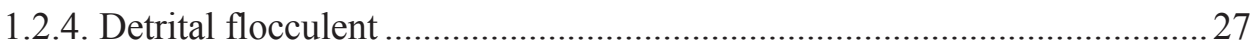

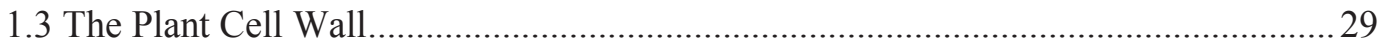

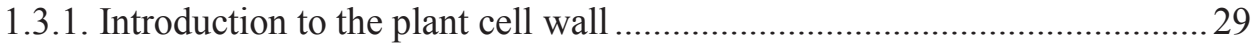

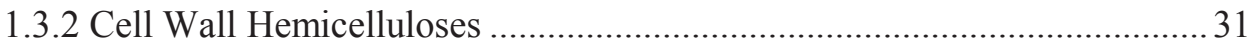

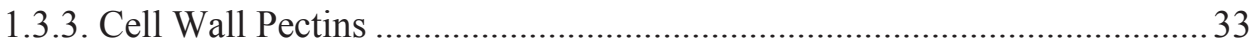

1.3.4 Cell Wall Proteins .................................................................................... 35

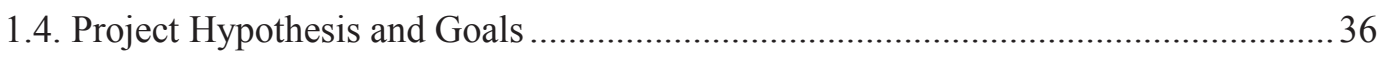

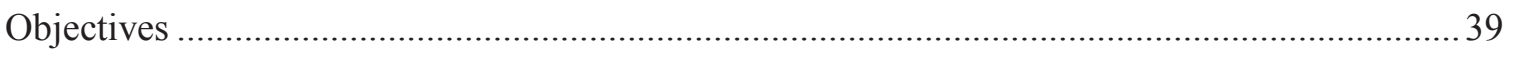

Chapter 2: Polymeric profiles of macrophytes and floc of WCA-2A ......................................... 40

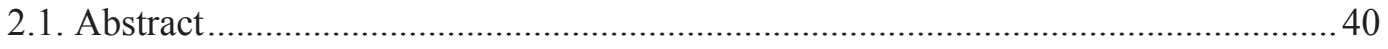

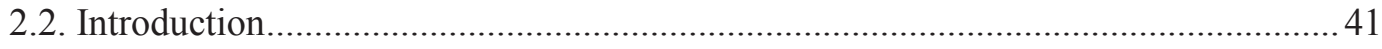

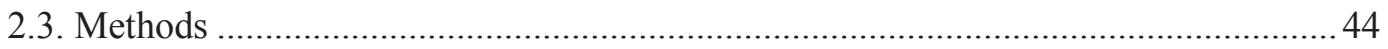

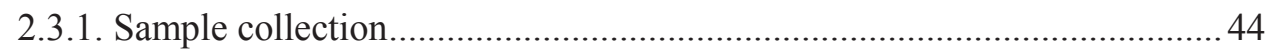

2.3.2. Visualization of collected macrophyte and floc....................................... 44

2.3.3. Visualization of Chara spp cell wall structure........................................... 45

2.3.4. Isolation and sequential extraction of the cell wall polymers .................... 45 
2.3.5. Presence of cell wall polymers in soluble extractions 47

2.3.6. Presence of cell wall polymers in unfractionated samples and residues.... 49

2.3.7. Presence of calcium in unfractionated samples and cell wall residues...... 49

2.4. Results. .50

2.4.1 Visualization and characterization of macrophyte and paired floc. .50

2.4.2. Visualization of Chara spp cell wall structure. .53

2.4.3. Isolation and sequential extraction of the cell wall polymers .....................54

2.4.4. Presence of cell wall polymers in isolated fractions 60

2.4.5. Presence of polymers in unfractionated samples and insoluble cell wall residues .68

2.4.6. Presence of $\mathrm{Ca}^{2+}$ in unfractionated samples and insoluble residues ..........76

2.5. Discussion. 79

2.5.1 Visualization and polysaccharide profile of macrophytes and paired floc .79

2.5.2. Biomarkers for macrophyte and paired floc sample differentiation .......... 81

2.5.3. Comparison of two methods of cell wall fractionation.............................. 83

Chapter 3: Chemical analysis of Everglades macrophytes and paired floc ................................. 85

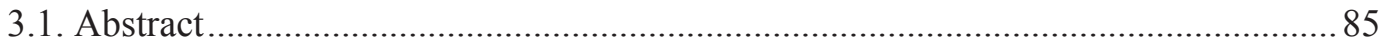

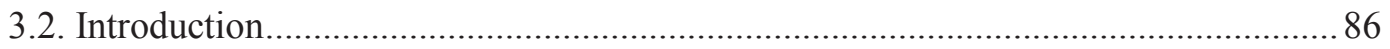

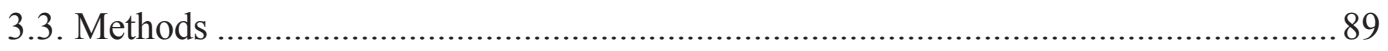

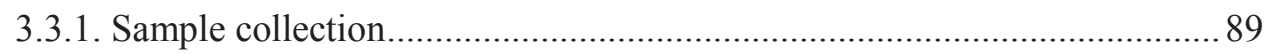

3.3.2. Isolation and sequential extraction of the cell wall polymers ....................90

3.3.5. Assay for total ester sulfate concentration .............................................. 92

3.3.4. Carbazole assay for total uronic acid concentration ................................. 92

3.3.3. Phenol-sulfuric assay for total carbohydrate concentration ...................... 93

3.3.6. Molybdenum blue method for determination of phosphorus..................... 93

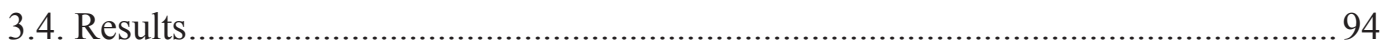

3.4.1. Chemical content of fractionation A samples .......................................... 94

3.4.2. Chemical content of fractionation B samples ...........................................97

3.4.3. Phosphorus content of macrophyte and paired floc samples .................. 104

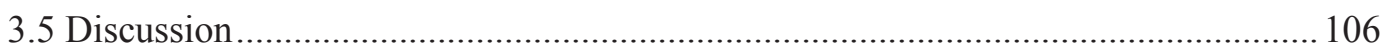

3.5.1. Chemical content of fractionation A samples ........................................ 106

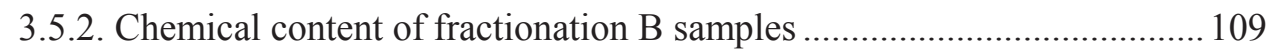




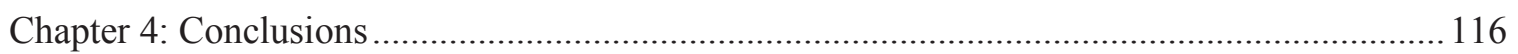

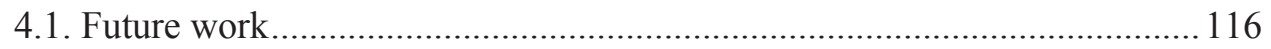

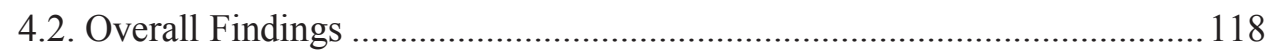

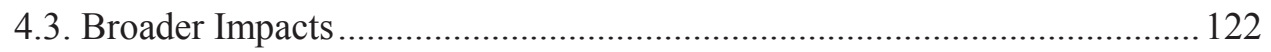

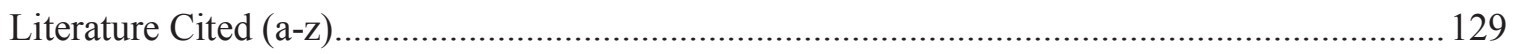

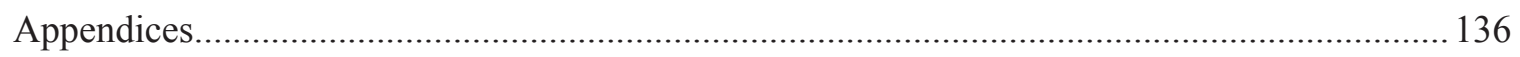

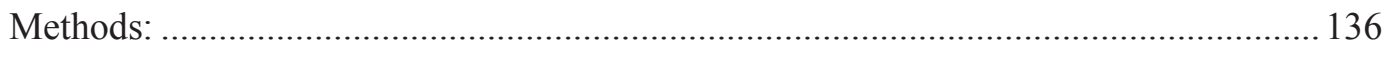

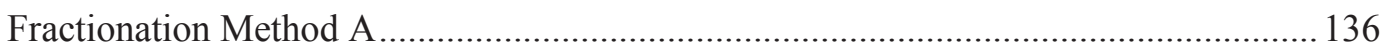

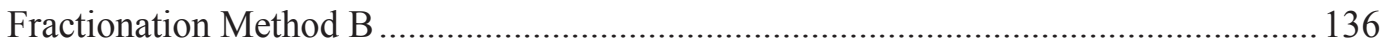

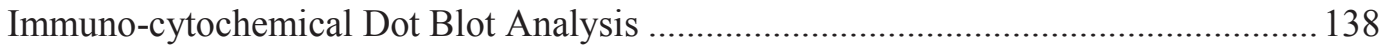

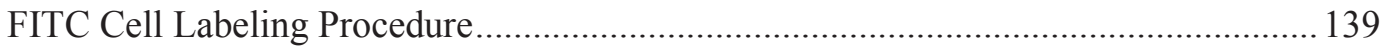

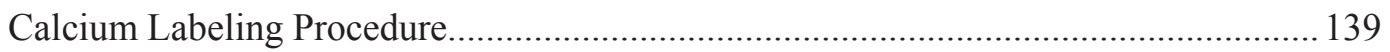

Phenol-sulfuric Assay for \% Total Carbohydrates (w/w) ........................................... 140

Carbazole Assay for \% Total Uronic Acid (w/w) ........................................................ 141

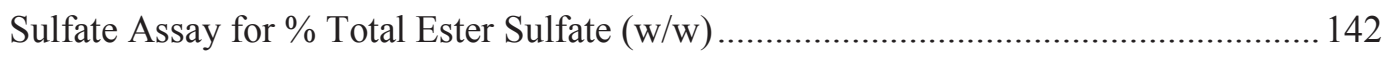

Sequential Fractionation of Soluble Phosphorus ............................................................ 143

Molybdenum Blue Method for \% Total Phosphorus (w/w) ........................................... 143

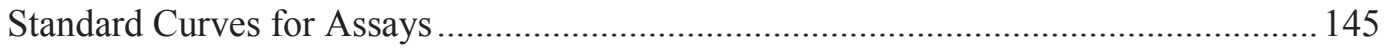




\section{List of Figures}

Figure 1.1: Densely populated urban areas border Water Conservation Areas

Figure 1.2: Basic polymer structure of cellulose

Figure 1.3: Basic polymer structure of xyloglucan

Figure 1.4: Basic polymer structure of xylan

Figure 1.5: Basic polymer Structure of homogalacturonan

Figure 1.6: Basic polymer structure of rhamnogalacturonan I

Figures 2.1 - 2.3: Initial, untreated images of collected Chara spp and paired floc samples EO1 and TO3 from WCA-2A

Figures 2.4 - 2.5: Initial, untreated images of collected T. domingensis and paired floc sample EC1 from WCA-2A.

Figures 2.6 - 2.7: Initial, untreated images of collected Cladium jamaicense and paired floc sample TC3 from WCA-2A.

Figures 2.8 - 2.9: SEM images of collected Chara spp samples from WCA-2A

Figures 2.10 - 2.11: SEM images of cultured Chara corallina

Figure 2.12: The percent of $\mathrm{HW}$ soluble material and $\mathrm{NaOH}$ soluble material from the total recovered soluble material from fractionation procedure $\mathrm{A}$

Figure 2.13: The percent of MeKOH soluble, DMSO soluble, HW soluble, CDTA soluble, $\mathrm{Na}_{2} \mathrm{CO} 3$ soluble, $1 \mathrm{M} \mathrm{KOH}$ soluble, $4 \mathrm{M} \mathrm{KOH}$ soluble and insoluble residue from the total recovered material after fractionation procedure $\mathrm{B}$

Figure 2.14: The percent recovered soluble material and insoluble residue (postfractionation method B) from the total original mass of plant material ( $\%$ dry weight after freeze drying)

Figures 2.15 - 2.16: Microscopic images of collected Chara spp sample from WCA-2A showing the nodal region labeled with monoclonal antibody LM20 to the methylesterified HG epitope under normal light (figure 2.15) and under fluorescence (figure 2.16).

Figures 2.17 - 2.18: Microscopic images of collected EO1 floc sample from WCA-2A showing labeling of detrital OM and algal species with monoclonal antibody LM15 to the xyloglucan epitope under normal light (figure 2.16) and under fluorescence (figure 2.17). 
Figures 2.19 - 2.20: Microscopic images of collected TO3 floc sample from WCA-2A showing labeling of detrital OM and algal species with monoclonal antibody LM11 to the xylan epitope under normal light (figure 2.19) and under fluorescence (figure 2.20).

Figures 2.21 - 2.22: Microscopic images of collected $T$. domingensis sample from WCA-2A showing labeling of the epidermal and mesophyll cell walls with monoclonal antibody LM11 to the xylan epitope under normal light (figure 2.21) and under fluorescence (figure 2.22).

Figures 2.23- 2.24: Microscopic images of collected EC1 floc sample from WCA-2A showing labeling of detrital OM and plant tissue with monoclonal antibody LM11 to the xylan epitope under normal light (figure 2.23) and under fluorescence (figure 2.24).

Figures 2.25 - 2.26: Microscopic images of collected Cladium jamaicense sample from WCA-2A showing labeling of the cell wall, intracellular region and cell surface with monoclonal antibody JIM5 to the unesterified HG epitope under normal light (figure 2.25) and under fluorescence (figure 2.26).

Figures 2.27 - 2.28: Microscopic images of collected TC3 floc sample from WCA-2A showing labeling of detrital OM and plant tissue with monoclonal antibody LM11 to the xylan epitope under normal light (figure 2.27) and under fluorescence (figure 2.28).

Figures 2.29 - 2.30: Microscopic images of unfractionated Chara spp sample from WCA-2A showing labeling of calcium on the cell surface with Fura-2 AM under normal light (figure 2.29) and under fluorescence (figure 2.30).

Figures 2.31 - 2.32: Microscopic images of unfractionated TO3 floc sample (paired floc sample to Chara spp) from WCA-2A showing ubiquitous labeling of calcium in detritus with Fura-2 AM under normal light (figure 2.31) and under fluorescence (figure 2.32).

Figures 2.33 - 2.34: Microscopic images of Cladium jamaicense residue (postfractionation A) showing no labeling of calcium with Fura-2 AM under normal light (figure 2.33) and under fluorescence (figure 2.34).

Figure 3.1: Mean carbohydrate, uronic acid and ester sulfate content of macrophyte and paired floc samples $(\% \mathrm{w} / \mathrm{w})$ in $\mathrm{HW}$ soluble and $\mathrm{NaOH}$ soluble fractions via fraction $\mathrm{A}$.

Figure 3.2: Mean carbohydrate and uronic acid concentration $(\% \mathrm{w} / \mathrm{w})$ of the DMSO soluble fraction of macrophytes and paired floc samples (fractionation B).

Figure 3.3: Mean carbohydrate and uronic acid concentration $(\% \mathrm{w} / \mathrm{w})$ of the HW soluble fraction of macrophytes and paired floc samples (fractionation B).

Figure 3.4: Mean carbohydrate and uronic acid concentration $(\% \mathrm{w} / \mathrm{w})$ of the CDTA soluble fraction of macrophytes and paired floc samples (fractionation B).

Figure 3.5: Mean carbohydrate and uronic acid concentration $(\% \mathrm{w} / \mathrm{w})$ of the $\mathrm{Na}_{2} \mathrm{CO}_{3}$ soluble fraction of macrophytes and paired floc samples (fractionation B). 
Figure 3.6: Mean carbohydrate and uronic acid concentration $(\% \mathrm{w} / \mathrm{w})$ of the $1 \mathrm{M} \mathrm{KOH}$ soluble fraction of macrophytes and paired floc samples (fractionation B).

Figure 3.7: Mean carbohydrate and uronic acid concentration $(\% \mathrm{w} / \mathrm{w})$ of the $4 \mathrm{M} \mathrm{KOH}$ soluble fraction of macrophytes and paired floc samples (fractionation B).

Figure 3.8: Mean phosphorus content of fractionation with $\mathrm{HW}, \mathrm{NaOH}$ and $\mathrm{HCl}$

Figure A.1: Standard curve obtained for carbazole assay (total \% uronic acid w/w) of fractionation A samples using glucuronic acid as a standard $n=3$

Figure A.2: Standard curve obtained for phenol assay (total $\%$ carbohydrate w/w) of fractionation A samples using glucose as a standard $n=3$

Figure A.3: Standard curve obtained for sulfate assay (total $\%$ ester sulfate $w / w$ ) of fractionation A samples using potassium sulfate as a standard $n=3$

Figure A.4: Standard curve obtained for phenol Assay (total \% glucose w/w) fractionation B samples using glucose as a standard $n=3$

Figure A.5: Standard curve for Carbazole Assay (total \% uronic acid w/w) fractionation B samples using glucuronic acid as a standard $n=3$

Figure A.6: Standard curve for phosphate assay (total \% phosphorus w/w) using potassium dihydrogen orthophosphate as a standard $n=3$ 


\section{List of Tables}

Table 2.1: Results of the immune-cytochemical dot blot analysis of fractionation procedure A.

Table 2.2: Results of the immuno-cytochemical dot blot analysis of fractionation procedure B.

Table 2.3: Results of the microscopic immuno-cytochemical fluorescence analysis of unfractionated macrophyte and paired floc samples after fractionation procedures $\mathrm{A}$ and B.

Table 2.4: Fura-2 AM immuno-fluorescence labeling of calcium in unfractionated and insoluble residue (post-fractionation A) of macrophyte and paired floc samples

Table 3.1: Mean (standard deviation) of chemical environment of surface water of study plots EC, EO, TC and TO as measured in Jan. 2007, Oct. 2008 and Oct. 2009 for dissolved oxygen content (DO), temperature, $\mathrm{pH}$ and floc total phosphorus (TP) $(\mathrm{n}=3)$. Data obtained from Sklar et al. 2008-2010.

Table 3.2: Two-way ANOVA (Soluble $\mathrm{P}$ content of $\mathrm{HW}, \mathrm{NaOH}$ and $\mathrm{HCl}$ fractions). Significant differences are shown in bold $F_{\text {critical }}=3.89 \mathrm{n}=3$.

Table 3.3: Mean phosphorus content ( $\mathrm{mg} / \mathrm{kg}$ dry weight) (standard deviation in parenthesis) of $\mathrm{HCl}$ soluble, organic and inorganic phosphorus (Jan, 2007) and $\mathrm{NaOH}$ and $\mathrm{HCl}$ soluble, organic and inorganic P (Jun. 2010). Jan. 2007 data obtained from (Sklar et al., 2008-2010) n=3

Table 4.1: Summary of overall results of unfractionated sample and fractionation A soluble and insoluble material.

Table 4.2: Summary of overall results of unfractionated sample and fractionation B soluble and insoluble material.

Table A.1: $\mu \mathrm{L}$ of glucose and $\mathrm{dH}_{2} \mathrm{O}$ for various concentrations for the glucose standard curve

Table A.2: $\mu \mathrm{L}$ of standard and $\mathrm{dH}_{2} \mathrm{O}$ for various concentrations for the uronic acid standard curve

Table A.3: $\mu \mathrm{L}$ of standard, $\mathrm{dH}_{2} \mathrm{O}$ and $2 \mathrm{M} \mathrm{HCl}$ for various concentrations for the ester sulfate standard curve 
Table A.4: $\mu \mathrm{L}$ of standard and $\mathrm{dH}_{2} \mathrm{O}$ for various concentrations for the phosphorus standard curve 


\section{Preface}

This thesis is an original work written by Erin L. McKenney. The work described in this thesis including data collection and analysis was performed by the author Erin L. McKenney. All microscopic images, tables and figures shown in this thesis were also

produced by the author. A portion of the preporatory lab work on samples (including weighing of samples and standards for colorimetric assays in chapter 3 and the preparation of nitrocellulose membranes for dot-blot analysis in chapter 2) was performed by undergraduate research assistants; Claire Higginbottom, Kate Pote and Kelsey Kox (of the Biological Sciences Department of Michigan Technological University) in 2010 and 2011. The field and labwork (including sample collection and fractionation procedure A) performed in June of 2010 reported in chapters 2 and 3 was conducted by the South Florida Water Management District (SFWMD). Data presented in chapters 2 and 3 are intended to be submitted for future publication as journal articles. 


\section{Acknowledgements}

I would first like to thank my advisor Dr. Michael Gretz for his advice and guidance as well as my committee members Dr. Brent Bellinger and Dr. Charles Kerfoot for their input and assistance in completion of this research and thesis. I would also like to thank my lab mates Dr. Sarah Kiemle, Claire Higginbottom, Kate Pote, Kelsey Kox, Jacob Jaszczak, Corey Momont for their support and assistance. I would also like to thank my parents Rodney and Nancy McKenney, and my husband Randall Enk for their help and support throughout the completion of my graduate degree!

I would like also to acknowledge the support of the South Florida Water Management District for providing sample material and partial funding for this research, the National Science Foundation for providing polysaccharide probes and supplies as well as the Biotech Research Center of Michigan Tech for their support and partial funding of this project. 


\section{Definitions}

Chara spp - A member of the charophycean green algae related to the progenitors of land plants macrophyte present in open areas of the Everglades

Cladium (C.) jamaicense - Common name sawgrass, native emergent aquatic monocot of Everglades

Detritus - made up of organic matter, extracellular polymers, and cellular debris from plants and algae and contribute to peat accumulation

Flocculent - Benthic layer made up of detritus and inorganic particulates, which support a complex community of microorganisms

Macrophyte - A plant that grows on or near water

Typha (T.) domingensis - Common name, cattail, rapidly spreading aquatic monocot of Everglades

Organic Phosphorus - Extractable phosphorus containing carbon bonds 


\section{List of Abbreviations}

1M KOH - 1 molar potassium hydroxide

4M KOH - 4 molar potassium hydroxide

$\mathrm{Ca}^{2+}$ - Calcium ion

Ca-bound P - Calcium bound phosphorus

CDTA - (1,2-cyclohexylenedi nitrilo)-tetraacetic acid

CERP - Comprehensive Everglades Restoration Plan

CHIP - Cattail Habitat Improvement Project

DMSO - Dimethyl sulfoxide

DO - dissolved oxygen

EAA - Everglades Agricultural Area

EC1 - Enriched Control 1, study site in WCA - 2A where T. domingensis is the dominant macrophyte

EO1 - Enriched Open 1, study site in WCA-2A where Chara spp is the dominant macrophyte

EPS - Extra-cellular polymeric substances

FITC - Fluorescein isothiocyanate conjugate

Floc - Flocculent, Benthic layer made up of detritus and inorganic particulates, which support a complex community of microorganisms

ha - Hectare $(10,000$ square meters $)$

HG - Homogalacturonan

HRP - Horseradish peroxidase 
HW - Hot Water

MeKOH - Methanolic potassium hydroxide

Mp/PBS - milk powder/phosphate buffered saline

$\mathrm{Na}_{2} \mathrm{CO}_{3}$ - Sodium carbonate

$\mathbf{O M}$ - Organic matter

PBS - Phosphate buffered saline

SAV - Submersed Aquatic Vegetation

SFWMD - South Florida Water Management District

TC3 - Transitional Control 3, study site in WCA-2A where $C$. jamaicense is the dominant macrophyte

TO3 - Transitional Open 1, study site in WCA-2A where Chara spp is the dominant macrophyte

TP - total phosphorus

WCA - Water Conservation Area 


\section{Abstract}

A shift in plant communities of the Water Conservation Areas (WCAs) within the Everglades has been linked to changes in hydrology and high levels of nutrient loading from surrounding agicultural areas. This has resulted in the encroachment of dense cattail stands (Typha domingensis) into areas that had previously been a ridge and slough landscape populated primarily by native sawgrass (Cladium jamaicense). In order to study ecological management solutions in this area, WCA-2A was broken into study plots; several of which became open water areas through the application of herbicide and burning regimens. The open water areas allowed for Chara spp (a submersed algal species) to replace Typha domingensis as the dominant macrophyte.

This study investigated the polymer and ionic profiles of Chara spp, Typha domingensis and Cladium jamaicense and their contributions to detrital flocculent (floc) in the study plots where they are the dominant macrophytes. Floc is not only an important food source for aquatic species; it also supports many algal, fungal and bacterial communities. Data gathered in this study indicated that the floc sample from a phosphorus enriched open water study plot (EO1) where Chara spp was the dominant macrophyte may contain cell wall polymers from sources other than Chara spp (most likely Typha domingensis), while the chemical and polymeric profile of the floc of the study plot where Typha domingensis is the dominant macrophyte (EC1) suggests that the floc layer has contributions from algal sources as well as Typha domingensis.

Additionally, monoclonal antibodies to Arabinoglalactan protein (AGP) and $(1,4)$ $\beta$-D galactan were identified as possible biomarkers for distinguishing algal dominated 
floc layers from layers dominated by emergent vegetation. Calcium labeling could be a useful tool for this as well because of the high amount of $\mathrm{Ca}^{2+}$ associated with Chara spp cell walls.

When looking into the soluble phosphorus content of the macrophytes and paired floc samples of WCA-2A, it was found that Chara spp may be contributing a greater amount of Ca-bound phosphorus to floc layers where it is the dominant macrophyte when compared to floc layers from study plots dominated by emergent macrophytes. Floc layers also appear to be acting as a nutrient sink for soluble phosphorus.

The findings of this study support the overall hypothesis that the shift from native emergent macrophyte communities to submersed macrophyte communities in study sites of the northern Everglades is affecting the polymeric/chemical profile and ionic content of detrital floc layers. The effects of this shift may contribute to changes in complex flocculent community dynamics. 


\section{Chapter 1: Introduction}

\subsection{Introduction to wetlands}

Freshwater wetlands are a unique and valuable resource constituting about $6 \%$ of the land surface on Earth. They sustain a multitude of unique biological species and provide high levels of primary productivity (Graham \& Mendelssohn, 2010). Compared to other natural environments, plant primary productivity in wetland ecosystems is among the highest known (Benner et al., 1984). Wetlands serve essential ecological functions which provide many important services to human society. Flood mitigation and water filtration are essential services provided by wetlands. Water storage by wetlands can slow down water's momentum and reduce erosion in surrounding areas, as well as reduce flood heights, support groundwater recharge and contribute water to other systems during dry periods. In addition to these benefits, wetlands have high biological productivity. Thirty-one percent of the plant species of the United States are found in wetlands. About half of the bird species in North America depend on wetlands for either feeding or nesting. Wetlands are also able support commercial shellfish and fishing industries as well as ecotourism activities (such as fishing, bird watching, hunting and photography) that bring in billions of dollars to the national economy annually (Mitsch \& Gosselink, 2000). However, the value of freshwater wetlands has historically been overlooked.

Over half of the estimated 220 million acres of wetland that existed in the United States in the 1600 s have now been drained or converted to other uses. Although wetland loss is now decreasing in the United States, between the years 1986 and 1997 alone, an estimated 58,500 acres of wetland were lost each year. Some factors that may now be 
contributing to the recent decreases in wetland loss in the United States are the discontinuation of some wetland drainage incentives, enforcement of wetland recreation and enforcement acts, protection and monitoring of costal systems and more education and public outreach about the value and importance of wetland ecosystems (Dahl, 2000). There has also been significant degradation to many extant wetland systems.

Alterations such as eutrophication in wetland ecosystems can lead to extensive shifts in vegetative communities and as a result, can either directly or indirectly impact environmental conditions and functions. Vegetation, both submersed and emergent serves many functions within a wetland ecosystem. Wetland vegetation can have many positive benefits to the ecosystem including forage and habitat for fish and fowl, buffering against runoff and storms, and improvement to water quality. Additionally, it provides a source of organic matter (OM) from which detrital flocculent may be derived.

Habitat loss, changes in substrate, water quality, and loss of invertebrate organisms impact $\mathrm{OM}$ availability and composition as well as native plant communities (Corstanje et al., 2007). Shifts in microorganism communities can also affect important biogeochemical processes such as nutrient cycling (carbon, nitrogen, and phosphorous availability), decomposition rates, $\mathrm{pH}$ control, $\mathrm{O}_{2}$ concentrations, eutrophication, heavy metal deposition, and food sources for higher organisms (Cole, 1988; Gutknecht et al., 2006). Greater concentrations of aquatic microbes can cause anoxic conditions when phytoplankton sinks to the bottom layers of a wetland, increasing the usage of oxygen. This can cause the death of benthic wetland plant communities and degradation of benthic OM by anaerobic microbes, the bi-products of which can lead to an increase in 
greenhouse gasses, as well as economic losses due to water fouling and corrosion (Webster \& Benfield, 1986; Bhaskar \& Narayan, 2005; Reddy \& DeLaune, 2008). In many wetland systems, complex microbial communities active in these processes are present in detritus and unconsolidated benthic flocculent made up of plant tissues, bacteria, zooplankton, soil and other organic materials. Such communities are important in adding otherwise organically bound nutrients to the soil thus controlling nutrient cycling and supporting primary production (Reddy \& Duluane, 2008). Soil microorganisms help to regulate processes such as nitrification, de-nitrification, and methanogenesis in a wetland ecosystem (Gutknecht et al., 2006). Studies have indicated that the benthic detrital/flocculent layer in the Everglades as well as similar wetland systems is one of the most active zones of nutrient accumulation and cycling (Richardson \& Marshall, 1986; Reddy, 1999;). Environmental factors and resource availability are controlling factors in the physiology and processes of microbial communities (Bellinger et al., 2012). Investigating variable factors such as detrital floc composition and their associated microbial communities could provide important information to be used when considering management options for these systems.

Recent efforts have sought to formulate sustainable management strategies for wetland use and management. In order to do this effectively, wetland ecosystems must be evaluated and monitored consistently to characterize change. 


\subsection{Introduction to the Everglades}

\subsubsection{0 ${ }^{\text {th }}$ Century Impacts on the Everglades}

Positioned in Florida south of Lake Okeechobee is the largest freshwater wetland in the United States, the Florida Everglades. Containing a diverse array of species unique to the area, the Everglades are home to a mixture of tropical and temperate vegetation, large megafauna (e.g., Florida Panther, American alligator), and almost 300 species of wading and migratory birds (Davis \& Ogden, 1994; Lodge, 2010). Once over 8 million acres, the Everglades ecosystem were historically a vast marshland connected to the Kissimmee River system and Lake Okeechobee (Sklar et al., 2008-2013; Lodge, 2010). Constant alteration to this complex wetland ecosystem due to human activity has caused numerous shifts in hydrology, water quality, and has resulted in dramatic ecological effects. Rapid increases in agriculture and urban expansion in South Florida have resulted in drastic changes to native vegetation, wildlife, and wildlife habitat in just a century. Before human influence, the ridge and slough portion of the Everglades was characterized by low-velocity sheet flow, long hydroperiods, and organic soils (McCormick \& O’Dell, 1996). There were periodic fires and low nutrient (phosphorous) levels (Chiang et al., 2000). Since the early 1900s, the construction of canals, dikes, and levees for flood control has greatly altered the hydrology of the Everglades (Davis \& Ogden, 1994). Also, since the 1950s, there has been a significant increase in agricultural run-off which has in turn, increased water and nutrient loading (Davis, 1991) Prior to its alteration, the ridge and slough area was dominated by stands of $C$. jamaicense (Ogden, 
2005), submersed aquatic vegetation (SAV) periphyton, and tree islands (Steward \& Ornes, 1975).

Today, the Everglades have been reduced to about 2 million acres, yet remain the largest sub-tropical wetlands in the United States (Zedler \& Kercher, 2005). The Everglades now consists of wildlife management areas, national parks, and water conservation areas (WCAs), the latter being shallow water impoundments which lie south of the Everglades Agricultural Area (EAA). The Everglades National Park was dedicated by President Truman in 1947. Between 1954 and 1959, a system of levees, canals and pumps were constructed to create the 700,000 acre EAA. Soon after (between 1960 and 1963) the remaining Everglades north of the Everglades National Park were diked and fragmented creating three WCA impoundments (Lodge, 2010). The WCAs store and control water levels as well as provide recreational areas and supply heavily populated areas in the lower coast with water. Additionally, the WCAs are meant to support a complex ecology and habitat for a unique assortment of wildlife and vegetation (Ogden, 2005; Lodge, 2010). The water levels and flows of the WCA impoundments are highly regulated in in order to balance environmental needs with the requirements of the surrounding communities. To summarize, changes to the Everglades ecosystem caused by human activity in the past century have been dramatic; including great spatial reductions and alterations to fundamental ecosystem processes such as the hydrology of the wetland, fire regimes, and nutrient cycling. As a result these changes have negatively impacted and changed populations of native species including plants, wading birds and fish populations. Since the 1980s, there has been an effort towards conservation and 
restoration of the Everglades to how it had functioned at the turn of the century. The creation of the Save Our Everglades Program in 1983, the Florida Preservation 2000 Act in 1990 (which provided funding for land acquisition for conservation and recreation), the Comprehensive Everglades Restoration Plan (CERP) of 1992 (which re-examined previously implemented flood control practices), and the Everglades Investment Act of 2000 (which committed Florida to a 50\% cost share for Everglades restoration), have been some of the recent legislation efforts made to study, conserve and restore the Everglades (Lodge, 2010).

\subsubsection{The Cattail Habitat Improvement Project}

As discussed earlier, there has recently been a shift in ecosystem community structure and function in the WCAs, due to intensive management practices such as the removal of dense emergent macrophyte stands of cattail (Typha domingensis) and sawgrass (Cladium jamaicense). The Cattail Habitat Improvement Project (CHIP) was a large-scale study of fifteen 6.5 hectare test plots focused on designing an effective cattail control method in WCA-2A (an impoundment severely impacted by nutrient loading by the neighboring agricultural area). The objectives of the CHIP project were to assess the alteration to trophic dynamics that may be caused by creating openings in areas of dense cattail growth, and to compare the functions of newly created, open areas to the functions of the non-eutrophic Everglades (Sklar et al., 2008-2013).

The plots within WCA-2A were burned in July 2006 and herbicide (glyphosate) was applied in May of 2006 to create open plots in areas dominated by emergent 
macrophytes. This study uses samples obtained in July of 2010, four years after the creation of the open water plots. With the removal of cattail stands, open areas were created where the macroalgae Chara spp became the dominant vegetation. In these open areas, the plots showed an increase in microbial activity, higher decomposition rates and a reduction in detritivore biomass. In addition, an increase in wading bird foraging was observed in created open plots compared to cattail-dominated control plots (Sklar et al., 2008-2013).

This study focuses on four of the fifteen 6.5 hectare study plots of WCA-2A; EC1, TC3, EO1, TO3. Plot EC (Enriched Control) is characterized by high phosphorous levels and is dominated by cattail (T. domingensis; mean of $696 \mathrm{~g}$ dry weight $[\mathrm{DW}] / \mathrm{m}^{2}$ ) with moderate biomass of sawgrass (Cladium jamaicense; mean of 173 $\mathrm{g} \mathrm{DW} / \mathrm{m}^{2}$. In contrast, Plot $\mathbf{T C}$ (Transitional Control) is characterized by moderate phosphorous and mixed, dense stands of sawgrass (C. jamaicense, mean of $495 \mathrm{~g}$ $\mathrm{DW} / \mathrm{m}^{2}$ ) and cattail (T. domingensis, mean of $\left.264 \mathrm{~g} \mathrm{DW} / \mathrm{m}^{2}\right)$. Paired treatment plots include EO (Enriched Open) and TO (Transitional Open), which have been managed and maintained as open water areas. Management has resulted in development of submersed algal and emergent macrophyte plots (dominated by Chara spp, but also including Utricularia spp) due to removal of emergent macrophytes shading the water column (Grimshaw et al., 1997). 


\subsubsection{Macrophytes}

Emergent macrophytes: Cladium jamaicense and Typha domingensis are native to the Everglades and are classified as flowering monocots in the order Poales. Both species may reproduce by seeds and vegetative propagation from persistent rhizomes (Miao \& Sklar, 1998).

One reason for the replacement of native $C$. jamaicense by $T$. domingensis in areas of the Everglades is the changing water and soil chemistry. Since the turn of the century, the Everglades have been affected by alterations to hydrology including increased nutrient loading, increased water depths and extended hydroperiods, to which the historical plant community structure is not accustomed. In the WCA impoundments as well as other areas of the Everglades, it is evident that these alterations are facilitating the proliferation of $T$. domingensis stands in areas that were previously dominated by $C$. jamaicense since the two species have differing growth requirements (SFWMD, 1992; Richardson \& Vaithiyanathan, 1995). In a mesocosm enclosure study, Newman et al. (1996) found that over a 2 year period, $T$. domingensis had a 60\% increase in biomass at increased water depths $(30 \mathrm{~cm})$, while $C$. jamaicense showed no increase in biomass. Also, with the Everglades being historically P limited, plant communities evolved in response to low nutrient conditions with $C$. jamaicense as the dominant macrophyte (Loveless, 1959; Davis, 1994; Newman et al., 1997;). In a similar microcosm study as above, by Newman et al. (1996), it was shown that T. domingensis has a $45 \%$ increase in biomass over a 2 year period with elevated water nutrients while $C$. jamaicense showed no growth increase (Newman et al., 1996). The growth of cattail species often indicates 
disturbed environments high in nutrients (Dykyjova \& Kvet, 1978; Newman et al., 1996).

Studies have indicated that Typha is able to better take advantage of high nutrient conditions $t$ to increase photosynthesis and growth, which may allow it to out-compete sawgrass (Chiang et al., 2000). This is true for the historically $C$. jamaicense dominated ridge and slough landscape of the northern Everglades. As described in Hagerthy et al. (2008), an abrupt shift in vegetation and soil phosphorus content of was observed along the surface water TP (total phosphorus) gradient of WCA-2. Cladium was shown to remain the dominant emergent vegetation until the surface water TP exceeded $15 \mu \mathrm{g} / \mathrm{L}$ and $1100 \mathrm{mg} / \mathrm{kg}$ in the floc and soil when it abruptly declined. At this point the areal extent of Typha was observed to increase. The areal extent of Typha was also observed to increase after the decline of the open water slough areas when TP levels reached $10 \mu \mathrm{g}$ $\mathrm{P} / \mathrm{L}$ and floc and soil $(0-10 \mathrm{~cm}) \mathrm{TP}$ exceeded $500 \mathrm{mg} \mathrm{P} / \mathrm{kg}$ (Hagerthey et al., 2008).

Another trait difference that may contribute to the encroachment of $T$. domingensis into $C$. jamaicense habitat is differences in seed production and germination. Lorenzen et al. (2000) found the incubation period needed for T. domingensis seeds to germinate was 1.1-19.5 days. This is a relatively short incubation period when compared to $C$. jamaicense which was 26-46 days. Additionally, the percentage of seeds which germinated was also much higher in $T$. domingensis (85\%) than in $C$. jamaicense (42\%). Production differed in that $T$. domingensis produced a large number of small seeds however these seeds could not germinate if covered by sediment, while $C$. jamaicense produced a smaller amount of large seeds which were able to germinate when covered by a thin layer of sediment or detritus (Lorenzen et al. 2000). 
Submersed macrophyte: Chara is a macrophytic alga. Its morphology consists of intricately-woven networks of branched filaments (Cook et al., 1998). Chara is a member of the charophycean green algae (CGA) and in the order Charales. The order Charales consists of six extant genera which display the greatest morphological complexity within the CGA and are related to the progenitors of land plants (Mattox \& Stewart, 1984). While the CGA are less complex in their morphological structures than those of land plants, many of the cell-wall polymers found in the CGA are similar (Cook et al., 1998; Domozych, 2007;).

The members of the order Charales are known to have abundant calcium carbonate encrustations bound to un-esterified homogalacturonans (HG) in their cell walls (Hutchinson, 1957; Siong \& Asaeda, 2009). Marl, a thick benthic layer of clay-like calcium carbonate and aggregate mineral deposits, is frequently found beneath areas of dense Chara growth, contributing to long-term calcium deposition (Siong \& Asaeda, 2009). There is also evidence that calcium carbonate binding may affect phosphorous cycling in Chara-dominated environments. Phosphate can bind to calcite, creating hydroxyapatite $\left(\mathrm{CaCO}_{3}-\mathrm{PO}_{4}\right)$ which may be deposited in sediments (Siong \& Asaeda, 2006).

\subsubsection{Detrital flocculent}

Flocculent material (floc) is made up of detritus and inorganic particulates such as clays and silts, which support a complex community of microorganisms including bacteria, fungi and algal species (Webster \& Benfield, 1986; Belicka et al., 2012). 
Detritus is comprised of dead OM, extracellular polymers, and cellular debris from plants and algae and contribute to peat accumulation and is an important food source for invertebrates and fish (McCormick et al., 2000; Neto et al., 2006). Variations in detrital floc composition could thus alter food webs and OM accumulation rates, and (as different plants have differing nutrient requirements) potentially influence plant community assemblages (Zak et al., 2005; Neto et al., 2006). Detritus can have two sources of OM, that which is generated locally (autochthonous), or that which is generated elsewhere and imported to a system or area (allochthonous) (Webster \& Benfield, 1986).

Macrophytes are broken down in three main ways. Initial loss of soluble inorganic and organic materials due to leaching from immersion in water can decrease dry weight of plant material by up to $25 \%$ in the first 24 hours depending on factors such as fragmentation of the sample, water temperature, type of plant material, and turbulence of the water (causing disruption of the benthic layer) (Webster \& Benfield, 1986). After initial leaching, detritus goes through a period of microbial conditioning and decomposition by fungi and bacterial species, many of which produce enzymes for hydrolyzing plant cell wall components (Suberkropp \& Klugg, 1980; Chameir, 1985; Webster \& Benfield, 1986). A third way vascular plant can be broken down in a wetland is through fragmentation via grazing by primary consumers such as fish or invertebrates, or through other disturbances such as water turbulence (Webster \& Benfield, 1986). 


\subsection{The Plant Cell Wall}

\subsubsection{Introduction to the plant cell wall}

Plant cells are surrounded by robust walls which function in the mediation of cell growth and expansion, tissue cohesion and adhesion, ion exchange, cell protection, and intercellular communication (Fry, 2000; Cosgrove, 2005; Popper, 2008). After the formation of the cell plate, the primary plant cell wall is deposited and continues to expand throughout cell growth. Primary cell walls are strong, yet resilient extracellular layers, fundamentally made up of cellulose microfibrils with embedded cross-linking glycans, within a complex, hydrated matrix of polysaccharides and structural proteins which can vary in composition considerably (Fry, 2000; Cosgrove, 2005). Some cell types or species of plant contain secondary cell walls. Typically they are found only in vascular plants (Fry, 2000; Popper, 2008). Secondary cell walls are composed of mostly cellulose (the basic polymer structure of which is found in figure 1.1), with xylan, lignin and also glucomannan (Popper, 2008). The secondary cell wall can make up the bulk of a mature plant and is sometimes hard to distinguish from the primary cell wall (Fry, 2000). In grasses, the secondary wall makes up about $50 \%$ of the cell wall mass of the stems and leaves in mature plants. Lignin is abundant within the secondary cell wall, constituting about $20 \%$ of the secondary cell wall of the grasses. The middle lamella creates a boundary between two daughter nuclei after mitosis. It is a thin layer responsible for holding two cells together, rich in pectin. The middle lamella is often difficult to distinguish from the primary cell wall as well. Based on the diverse array of cell wall morphology and structure that can be found between different species and even 
between different types of cell within the same plant, it has become evident that not all cell walls are made up of the same polymers, or configuration of polymers (Popper, 2008; Verhertbruggen et al., 2009). Algal species have differing cell walls from emergent macrophytes and thus may be a more labile carbon complex. The ecological significance of this may include increased decomposition rates of organic substrates (Sklar et al., 2008-2013).

While the Charophycean green algae shows characteristics which may distinguish them from land plants and are less complex in their morphological structures, many cell wall polymers are similar (Mattox \& Stewart, 1984; Cook et al., 1998; Domozych et al., 2007) including the basic framework of cellulose microfibrils and cross-linking matrix (Carpita \& Gibeaut, 1993). Many recent studies have focused on cell wall structure of the charophycean green algae in order to further study plant origins. Two such studies compared cell wall polymers in the Charophytes and embryophytes thus giving insight into the origin of land plants. Domozych et al. (2012) concluded that the cell walls of the later divergent Charophycean green algae contain similar cellulose, pectins, hemicelluloses, arabinogalactan proteins (AGPs), extensin, and lignin polymer assemblages to embryophytes. Sorensen et al. (2011) describes that the ability of Charophytes to produce these similar cell wall polymer assemblages was an important factor in the pre-adaptation that allowed for the success of the first land plants. The chemical profile and structure of these cell walls can vary dramatically during different stages of cell wall development as well (Cosgrove, 2005). The cellulose microfibrils formed by cross-linking glycans differ between plant families. For example, linking 
polymers associated with dicots are xyloglucans, while the linking polymers associated with the monocots (and subclass Poales) are dominated by glucuronoarabinoxylans (Carpita \& Gibeaut 1993; Carpita, 1996; Cosgrove, 2000).

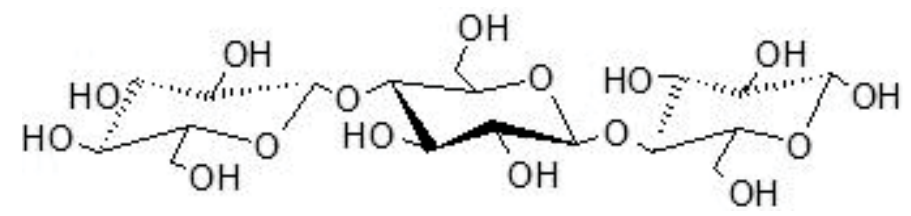

Figure 1.1: Basic polymer structure of cellulose (figures created with ChemSketch)

\subsubsection{Cell Wall Hemicelluloses}

The hemicelluloses, also called cross-linking glycans, are an abundant group of complex polysaccharides which have a backbone that consists of $(1,4)-\beta-\mathrm{D}$ glycans similar to that of cellulose (Cosgrove, 2005). The hemicellulose group includes polysaccharides such as xyloglucans, xylans and manans. Of the hemicelluloses, this study focuses on xyloglucans and xylans which are discussed in depth below.

Xyloglucans: Xyloglucans (shown in figure 1.2) are an abundant hemicellulose group in the primary cell wall, making up about $20 \%$ of the primary cell wall of dicots, and about 1-5\% (significantly less) in the grasses (Vogel, 2008). They have a backbone identical to that of cellulose, consisting of a linear $\beta-(1-4)$-D-glucan. They function in creating a matrix which maintains the strength of the cell wall by linking cellulose microfibrils together through hydrogen bonding. This matrix also mediates cell wall growth and expansion (Marcus et al., 2008). There is controversy as to the relative abundance of xyloglucan present within the charophycean green algae. In one study by 
Popper and Fry (2003), xyloglucan was not found to be present in significant amounts in the charophytes which were investigated. The charophytes investigated included Klebsoridum flaccidium, Coleochaete scuata, and Chara corallina, (Popper \& Fry, 2003). This however, conflicts with other studies which show xyloglucan to be present in significant amounts in several of the charophytes including Chara corallina (Domozych et al., 2009; Kiemle, 2010).

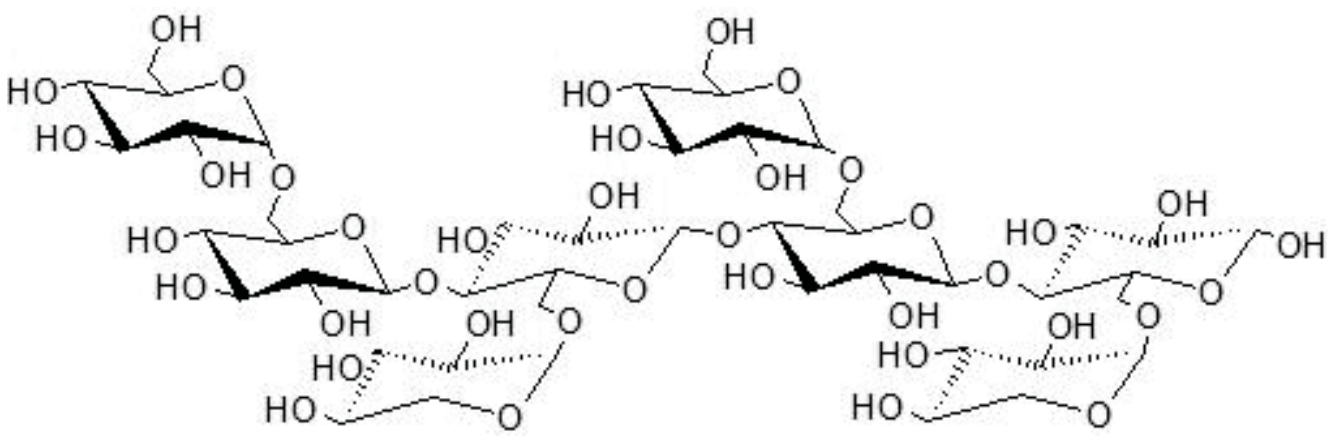

Figure 1.2: Basic polymer structure of Xyloglucan (figures created with ChemSketch)

Xylan: Xylan (shown in figure 1.3) is a branched highly variable hemicellulosic polymer containing a $\beta-(1,4)$-D xylose backbone and side chains which may include arabinose or glucuronic acids (which give the polysaccharides a net negative charge). Xylans can act as a structural polymer such as cellulose in some species (Cosgrove, 2005). Xylans make up about $20 \%$ of the primary cell wall of the grasses, as well as about $20 \%$ of the secondary cell walls of grasses and dicots. Because of their potential ability to self-aggregate/and or bind to cellulose by H-bonds, xylans in vascular plant species may indicate an acquired advantage over non-vascular plants allowing them to achieve larger sizes, efficient mechanical and vascular tissues and growth in areas where 
water is a limiting factor (as in wetlands where water depth may be greatly varied) (Fry, 2000; Popper 2008).

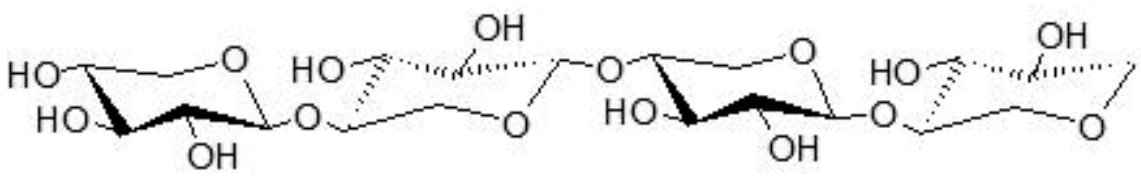

Figure 1.3: Basic polymer structure of Xylan (figures created with ChemSketch)

\subsubsection{Cell Wall Pectins}

Pectins are abundant polymers within the cell walls and lamelle of all land plants. They are a structurally complex group rich in galacturonic acid (Knox, 2008) that creates a hydrated 3-D matrix in the cell wall. This matrix contributes to the pliability of the cell wall. Pectins have many functions including cell pliability, expansion, adhesion, cell wall porosity, signaling, and ionic and $\mathrm{pH}$ control of the cell wall (however, additional roles of pectins in the cell wall are not fully realized (Willats et al., 1998). Galacturonic acid occurs in the backbone of the major domains of pectins and is thought to be present in all plant species. These major structural domains include homogalacturonan (HG), rhamnogalacturonan-I (shown in figure 1.5), rhamnogalacturonan-II, and xylogalactruonan (a linear chain of galacturonic acid residues modified by xylose branches) all of which may be covalently bonded together within the cell wall (Willats et al., 2001; Cosgrove, 2005). Neutral arabinans and arabinogalactans are linked to acidic pectins and are useful in promoting wall flexibility. They may also may occur bound to cellulose (Cosgrove, 2005; Zywinkska et al., 2005). 
Homogalacturonan: Homogalacturonan (HG) (shown in figure 1.4) is a major structural domain of the backbone of pectin with diverse functions within the primary cell wall. HG aids in cell wall assembly, cell growth, matrix porosity, and cell defense (Verhertbruggen et al., 2009). HG is a homopolymer made up of repeating $\alpha-(1-4)$ galacturonic acid which can be methyl esterified at the O-6 unit, or acetyl-esterified at the O-2 or O-3 unit. Methoxylated $\mathrm{HG}$ gel at low $\mathrm{pH}$, while in neutral $\mathrm{pH}$, the galactuonic acid units may be ionized leading to formation of salt bridges and the chelation of metals such as calcium. This increases rigidity in the matrix of the cell wall (Zykwinkska et al., 2007; Mohnen et al., 2008).

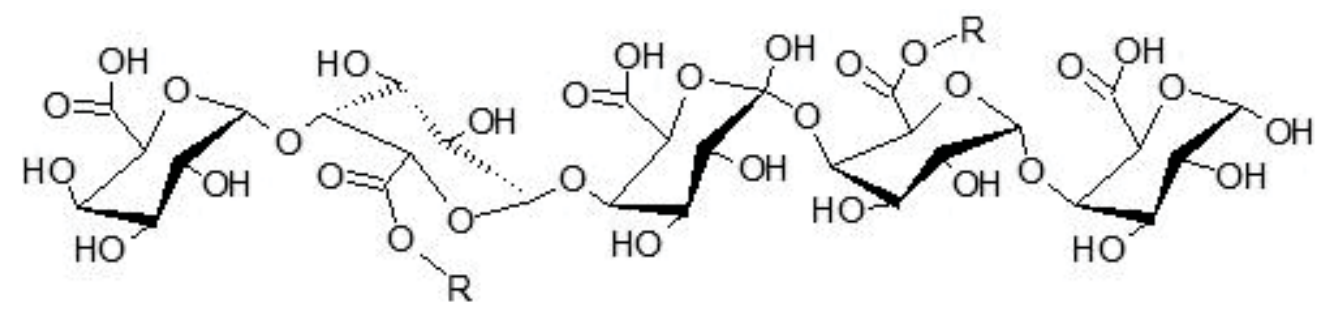

Figure 1.4: Basic polymer Structure of Homogalacturonan (figures created with ChemSketch)

Arabinan: The arabinans occur as one of the most abundant neutral sugar side chains which are thought to play a role in the flexibility of the cell wall (Cosgrove 2005; Zywinkska et al., 2005). The arabinans occur in small amounts relative to the other major pectic domains and can be present in many different parts of a plant. This study focuses on (1-5)- $\alpha-\mathrm{L}$ arabinan which is a structural feature on the side chains of pectins, or can be present within the cell wall as an unattached polymer (Willats et al., 1998).

Rhamnogalacturonan-I: Rhamnogalacturonan-I (shown in figure 1.5) contains residues of alternating rhamnose and galactruonic acid with side chains of other pectic 
domains. It binds specifically to cellulose and may have a role in the structural support of the cell wall (Cosgrove, 2005).

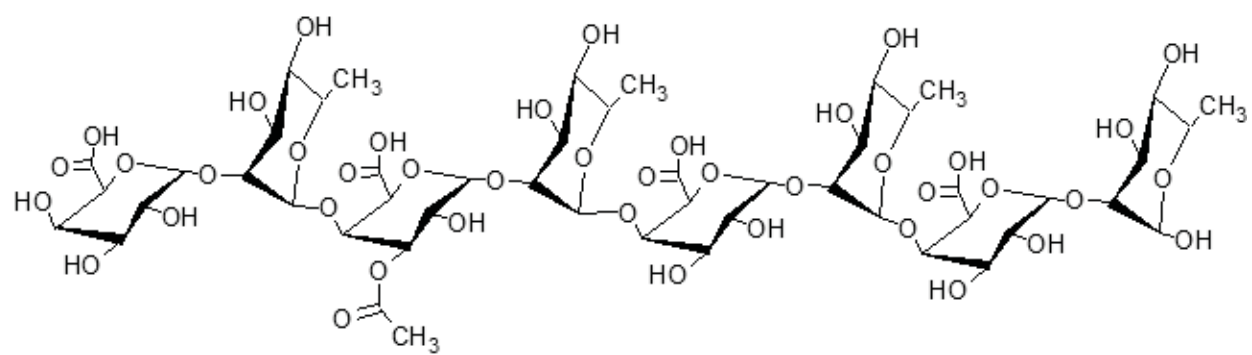

Figure 1.5: Basic polymer structure of Rhamnogalacturonan I (figures created with ChemSketch)

Rhamnogalacturonan-II: Rhamnoglacturonan-II is a complex, modified HG containing eleven different sugar residues with a galacturonic acid rich core (Cosgrove, 2005; Fry, 2000). It plays a role in cell wall strength as it forms borate-ester cross links (Fry, 2000). Rhamnogalacturonan-II is also associated with the formation of lignified cell walls and the formation of upright stems (Popper, 2008). It is found throughout the land plants but not in significant amounts in the bryophytes, which suggests its development early in the evolutionary history of the cell wall of land plants (Caprita \& McCann, 2000; Popper, 2008).

\subsubsection{Cell Wall Proteins}

Cell walls contain an assortment of proteins including the hydroxyproline-rich glycoproteins which incorporate the extensins (found in the primary cell walls of dicots and the grasses) and the arabinogalactan proteins (AGPs) (found throughout the cell walls of most plant tissues) (Fry, 2000). The extensins are wall proteins that enable turgor- 
driven cell expansion through modifying the mechanical properties of the cell wall. They are thought to be important to the evolution of the cell wall as they play a role in the development of xylem. Numerous studies have indicated that the AGPs are present in all land plants and charophytes (Cassab, 1998; Popper, 2008). Varied structure of the AGPs contributes to functional differences in different plant species (Popper, 2008). The AGPs are thought to have roles in plant growth and development at the cell surface. In land plants, AGPs are found in leaves, stems, roots, flowering tissues, and in xylem (Showalter, 2001). AGPs aid in cell wall expansion, cell adhesion, defense, reproduction and is believed to be involved in programmed cell death (Cassab, 1998; Showalter, 2001). The structure of the AGPs is highly diverse as well, and can vary considerably in length and complexity based on arabinogalactan structure and varying side chains. There are two types of AGPs. One type of AGP, consisting of (1-4) $\beta$-D-galactan units with tarabinan side-chains are only associated with pectins, while the other type consists of short (1-3) or (1-6) $\beta$-D-galactan units, the backbone of which is linked to arabinose and smaller amounts of glucuronic acid, galacturonic acid, mannose and rhamnose (Seifert \& Roberts, 2007).

\subsection{Project Hypothesis and Goals}

I hypothesized that the shift from native emergent macrophyte communities to submersed macrophyte communities in study sites of the northern Everglades were affecting the ionic content and polymeric/chemical profile of detrital flocculent layers derived from these macrophytic communities, which may in turn cause changes in 
complex flocculent community dynamics. The goals of this research were to determine whether floc in created open plots with was linked with SAV communities, and specifically Chara spp, or if the detrital OM present was primarily derived from surface peat derived from the remnant $T$. domingensis and Cladium jamaicense communities. Distinguishing source plant material was tested by examining polysaccharide content and application of fluorescence markers specific to cell wall polymers potentially distinct between the CGA and emergent monocots. Chemical assessments were carried out on intact Chara spp, T. domingensis and Cladium jamaicense in addition to floc collected from the respective created open and control plots. Successful identification and application of distinguishing cell wall probes could lead to future studies tracking the selective removal of specific cell wall components by microbial decomposition.

Additionally, it is unknown the extent to which calcium and phosphorus contents of Chara spp differ from vascular macrophytes. This is in part due to a lack of description in literature as to whether cell wall calcite was removed prior to chemical analysis (Kufel \& Kufel, 2002). In Chara spp dominated freshwater systems it is thought that calcite encrustations aid in the sequestration and precipitation of phosphate and other cations in flocculent layers (Siong \& Asaeda, 2006). The amount of phosphorous and calcium being contributed to benthic peat layers of WCA-2A had not yet been explored. This knowledge may lead to a better understanding of Chara spp calcium and phosphorous cycling in relation to detrital floc. This information is important not only in terms of potential long-term binding and burial of phosphorus, but combined with the differing cell wall structure of Chara spp, may play a role in rates of microbial activity 
and decomposition. In wetland systems, the decomposition of dead plant tissue is typically a slow process. This can result in a thick detrital floc layer and accumulation of organic peat (Debusk \& Reddy, 1998).

This research fills mechanistic gaps in the knowledge of plant-detrital-nutrient pathways. Cattail stands have been expanding throughout the water conservation areas due to an increase in phosphorous input from neighboring agricultural sources, and active management will be necessary in the enhancement and potential rehabilitation of these areas. Understanding all of the biogeochemical implications of emergent macrophyte removal and subsequent growth of submersed macrophytes is therefore essential in predicting local and downstream effects of management. As of now, there is little known about the effects of alterations to polymeric and ionic contributions to floc layers by algal communities due to emergent macrophyte removal. This knowledge will also contribute to understanding of process measurements of microbial activity within floc as related to OM composition. 


\section{Objectives}

\section{Overall objective of this study}

To broaden the current understanding of the effects of shifting macrophytic communities on polymeric and ion contributions to floc layers due to extensive plant community management in freshwater wetland ecosystems such as the Florida Everglades. From this, we may gain understanding of how management techniques may be influencing complex floc community dynamics.

\section{Specific objectives of this study}

1. To determine if floc layers in newly Chara spp dominated study plots are indeed derived from Chara spp.

2. To determine effective polysaccharide polymer and calcium probes for use as biomarkers for distinguishing macrophytic algal-dominated areas from native, emergent plant-dominated areas.

3. To determine polysaccharide polymer profile and chemical analysis in Chara spp and paired floc in treatment plots, for comparison with emergent plant-dominated areas and paired floc.

4. To quantify loosely bound phosphorous in the cells walls of Chara spp, $T$. domingensis and Cladium jamaicense in addition to paired floc layers derived from each study plot 


\section{Chapter 2: Polymeric profiles of macrophytes and floc of}

\section{WCA-2A ${ }^{1}$}

\subsection{Abstract}

Little is known about how the shift from emergent plant communities to open water areas dominated by SAV may affect the polymeric and calcium content of floc layers in the WCAs of the Everglades.

Potential differences in cell wall polysaccharides are thought to occur within a family of structural polysaccharides, as well as in the hemicellulosic material usually present in land plant cell walls but typically absent in the alga. We used immuno-cytochemical dotblot assay analysis and immuno-fluorescence labeling as well as $\mathrm{Ca}^{2+}$ labeling to investigate possible polysaccharide biomarkers for distinguishing emergent and submersed macrophytes. The higher plants present in the Everglades, Typha domingensis and Cladium jamaicense, showed the presence of several structural polysaccharides including (1,4)- $\beta$-D galactan, xyloglucan, xylan, unesterified HG, arabinan and esterified HG, as well as AGP. Chara spp showed the presence of the polymers xyloglucan, unesterified HG, esterified HG, xyloglucan, xylan, and AGP. Similar results were seen in Chara spp and paired floc samples EO1 and TO3; including the presence of AGP, $(1,4)$ $\beta$-D galactan, xyloglucan, unesterified HG, and xylan. Several similarities in the polymer profile of EO1 and EC1 were seen as well; in that they both contained AGP, xyloglucan,

\footnotetext{
${ }^{1}$ The material contained in this chapter is intended to be submitted for publication.
} 
xylan and esterified $\mathrm{HG}$, while $(1,4)-\beta-\mathrm{D}$ galactan, unesterified $\mathrm{HG}$, and arabinan were either shown to be absent or in present in insignificant amounts. This suggests that there are macrophytes other than Chara spp contributing to the EO1 study site, most likely from Typha domingensis.

Immuno-fluorescence microscopy results indicate that it may be possible to utilize several monoclonal antibodies (such as AGP and (1,4)- $\beta$-D galactan) to differentiate Chara spp and paired floc study plots from Typha domingensis, Cladium jamaicense and paired study plots. Our data also suggests that Cladium jamaicense structural polymers may be more difficult to extract from the cell wall than in Typha domingensis.

Fura-2 AM appears to be a promising biomarker for differentiating Chara spp dominated flocculent from Cladium jamaicense and Typha domingensis dominated flocculent. Strong fluorescent labeling indicated that Chara spp contributed a significant amount of calcium to associated flocculent layers while Cladium jamaicense and Typha domingensis contributed less calcium.

\subsection{Introduction}

In the last century, agriculture and urban expansion in South Florida has resulted in drastic changes to native vegetation, wildlife, hydrology and ecology of the Everglades, the largest freshwater wetland in the United States. A major shift in the plant communities due to nutrient loading and the resulting encroachment of cattail species has diminished the native sawgrass stands and loss of historical ridge and slough landscapes (Davis, 1991; Newman et al. 2008-2010). Between 1991 and 2003, monotypic stands of 
T. domingensis in WCA-2A (an impounded northern Everglades marsh) increased from 442 ha to 1979 ha (an astounding 469\% in just a little over a decade (Hagerthey, 2008)). In order to gain insight into the best ecological management solutions in WCA-2A, as well as other areas of the Everglades, the Cattail Habitat Improvement Project (CHIP) was started as a large-scale investigation of fifteen 6.5 ha test plots focused on designing effective control methods for $T$. domingensis as well as a large scale ecosystem restoration program. CHIP created open areas in dense monotypic stands of $T$. domingensis through burn regimens and the application of the herbicide glyphosate. (Sklar et al., 2008-2013). In the newly created open areas, Chara spp (a submersed, macrophytic algae) became the dominant vegetation.

Plant tissues which are introduced into aquatic systems undergo extensive fragmentation and decomposition by groups of bacteria, fungi and grazing invertebrates, thus plant tissue found in detrital floc is mostly made up of the cell walls, (Webster \& Benfield, 1986) the characterization of which (in Everglades plant and floc samples) will be the main focus of this study. Changes to the composition of the detrital floc layers (an important substrate and food source for microorganisms, invertebrae and fungal communities) in WCA-2A may occur due to shifting plant communities as well.

Methods used for the characterization and analysis of the cell walls of emergent and submersed macrophytes and floc samples included sequential extraction and fractionation, immuno-cytochemical dot blot analysis, and $\mathrm{Ca}^{2+}$ labeling with Fura-2 AM. The sequential extraction and fractionation of polymers of is a useful tool for the characterization and comparison of plant and algal cell walls in that it isolates materials 
of interest (cell wall polymers) from the complex and diverse mix of other plant cell tissues and materials. Immuno-cytochemical dot blot analysis is the immobilization of macromolecules on a porous substrate (in this case nitrocellulose membrane). Plant pectins, hemicelluloses and other anionic cell wall compounds attach to strongly cationic substrates and can therefore be immobilized and labeled for detection (Jeffree, 1993).

The presence of calcium in floc layers may be an effective biomarker in determining if Chara spp cell walls are present in floc layers through the use of microscopy and calcium labeling techniques. This is due to an interesting characteristic of the cell wall of the macroalgae Chara spp which has the ability to sequester calcium which binds to un-esterified homogalacturonans $(\mathrm{HG})$ on the cell wall surface to form calcite $\left(\mathrm{CaCO}_{3}\right)$ encrustations (Hutchinson, 1957; Siong \& Asaeda, 2009). ). The calcite encrustations of the cell wall of Chara may also bind to anions such as phosphate. This aspect of Chara will also be investigated in this study in regards to if phosphorous is present in higher levels in Chara dominated floc layers as it may sequester higher amounts of phosphorous than other dominant macrophytes. To determine the presence of $\mathrm{Ca}^{2+}$ in untreated as well as insoluble residue from macrophyte and floc samples, the calcium probe Fura-2 AM was used. 


\subsection{Methods}

\subsubsection{Sample collection}

Sample collection was carried out in study plots EC1, which contain monotypic stands of $T$. domingensis, plot TC3 which contain a mix of $T$. domingensis and Cladium jamaicense, and paired treatment plots $\mathrm{EO} 1$ and $\mathrm{TO} 3$ which have been maintained as open water and are now dominated by Chara spp. The pourable floc samples were collected from above the consolidated sediments. Stems of $T$. domingensis and Cladium jamaicense were collected by random grab sampling of 5-7 stems in EC1 and TC3, respectively. Chara spp was also collected by random grab sampling from plots EO1 and TO3. Sample collection was performed by the SFWMD during the summer (June) of 2010.

\subsubsection{Visualization of collected macrophyte and floc}

Freeze dried macrophyte and paired floc samples were received in July of 2010. Upon arrival, samples were coarsely ground and allowed to hydrate in distilled water at room temperature for several hours. Slides of the samples were prepared and viewed with a Zeiss Axioskop microscope to observe the structure of the macrophyte tissue and characterize the floc samples. Several microscopic images were taken of each sample and documented with digital photography using Leica DFC295 digital camera. 


\subsubsection{Visualization of Chara spp cell wall structure}

Based on methods presented by Chandler and Robertson (2009) collected Chara spp samples from WCA-2A were desiccated and placed on an aluminum stub held in place with carbon tape. The samples were then sputter-coated with platinum and analyzed using JEOL JSM-6400 SEM and documented using digital photography.

Chara corallina samples were collected from a freshwater wetland in Porter Corners, NY (USA) and cultured at Skidmore College. The cultures were made axenic using a commercial anti-biotic/anti-mycotic cocktail (Sigma Chemical, St. Louis, MO, USA). Cells were treated for 24 hours in the anti-biotic/anti-mycotic cocktail, washed thoroughly in sterile Woods Hole Medium (WHM) (Nichols, 1973) and then cultured in the same media per the manufacturer's instructions. After several days of growth, samples were determined to be axenic by microscopic analysis. Samples were collected and freeze-dried after being allowed to grow for several more weeks. These samples were visualized using SEM in order to see general cell structure and features and calcite encrustations, or "scales" (see above method).

\subsubsection{Isolation and sequential extraction of the cell wall polymers}

Two methods were used to isolate the cell walls and soluble fractions of samples received from Florida, modified from methods from Fry (2000). Fractionation method A is a simple fractionation method used to isolate three fractions: a $\mathrm{HW}$ soluble, $\mathrm{NaOH}$ soluble, and insoluble residue fraction. . Fractionation B is a more thorough fractionation of cell wall polymers. Soluble fractions isolated were: methanolic $\mathrm{KOH}(\mathrm{MeKOH})$, 
dimethyl sulfoxide (DMSO), hot water (HW), (1,2-cyclohexylenedi nitrilo)-tetraacetic acid (CDTA), $\mathrm{Na}_{2} \mathrm{CO}_{3}, 1 \mathrm{M} \mathrm{KOH}, 4 \mathrm{M} \mathrm{KOH}$. Insoluble residue fractions from fractionation B were also analyzed.

Fractionation Method A: This fractionation was performed by the SFWMD in June of 2010. In brief, approximately $1 \mathrm{~g}$ (dry weight) of sample was ground under liquid nitrogen. Fifty milliliters of distilled water was added and the sample was then placed in a $95^{\circ} \mathrm{C}$ water bath for 1 hour. The sample was cooled and the supernatant was collected. This step was repeated two more times. The collected supernatant was the HW soluble fraction. The supernatant was then dialyzed, and freeze-dried. The resulting pellet was then treated with $6 \mathrm{M} \mathrm{NaOH}$ for 1 hour at $21^{\circ} \mathrm{C}$ three times. The resulting supernatant was then collected, dialyzed and freeze-dried. This was the $\mathrm{NaOH}$ (alkali) soluble fraction. The insoluble pellet was then washed extensively with water until neutral and then freeze-dried. The resulting pellet was the insoluble residue fraction.

Fractionation Method B: Untreated, freeze-dried samples were ground to a fine powder. To clean and isolate the cell wall of samples, they were defatted using methanolic $\mathrm{KOH}(\mathrm{MeKOH}) . \mathrm{MeKOH}$ was added approximately $0.5 \mathrm{~g}$ (dry weight) of sample and placed in a $90^{\circ} \mathrm{C}$ water bath for 15 minutes. The supernatant was collected and the step repeated three more times yielding the $\mathrm{MeKOH}$ soluble fraction. The resulting pellet was washed extensively with distilled water until neutral. The pellet was then suspended in a solution of $90 \%$ DMSO in ethanol for approximately 16 hours at $25^{\circ} \mathrm{C}$. The supernatant was collected giving the DMSO soluble fraction. The resulting pellet was washed extensively with distilled water then suspended in 50mM CDTA 
solution ( $\mathrm{pH}$ adjusted to 7.5 ) and stirred for approximately 6 hours at $21^{\circ} \mathrm{C}$, and the supernatant was collected. This step was repeated two times and the collected supernatants were pooled for the CDTA fraction. The pellet was then washed extensively with distilled water. The resulting pellet was then re-suspended in $0.05 \mathrm{M} \mathrm{Na}_{2} \mathrm{CO}_{3} / 20 \mathrm{mM}$ $\mathrm{NaBH}_{4}$ solution and left to sit in a $1^{\circ} \mathrm{C}$ ice bath for approximately 16 hours. The supernatant was collected giving the $\mathrm{Na} 2 \mathrm{CO} 3$ soluble fraction. The pellet was washed extensively and then re-suspended in $1 \mathrm{M} \mathrm{KOH} / 20 \mathrm{mM} \mathrm{NaBH}_{4}$ solution in a $1^{\circ} \mathrm{C}$ ice bath for 2 hours. This step was repeated two times and the supernatant was collected for the $1 \mathrm{M} \mathrm{KOH}$ soluble fraction. The resulting pellet was then suspended in $4 \mathrm{M} \mathrm{KOH} / 20 \mathrm{mM}$ $\mathrm{NaBH}_{4}$ solution in a $1^{\circ} \mathrm{C}$ ice bath for 2 hours. This step was repeated two times and the supernatant was collected giving a $4 \mathrm{M} \mathrm{KOH}$ soluble fraction). The resulting pellet was washed extensively with distilled water and acetic acid until neutral. The pellet was then freeze-dried and represents the insoluble residue. Soluble fractions were neutralized to pH 6-7, dialyzed against distilled water (CDTA soluble fraction was dialyzed against $0.5 \mathrm{M}$ imidazole) for approximately 72 hours at $3-5^{\circ} \mathrm{C}$, then freeze-dried. The pore size of dialysis tubing (from Sigma-Aldrich) used for all samples for both fractionation methods A and B was 12,000 Da.

\subsubsection{Presence of cell wall polymers in soluble extractions}

All soluble cell wall fractions were analyzed using a suite of monoclonal antibodies to determine the presence of cell wall polymers by the immuno-cytochemical dot blot analysis using the methods of Knox et al. (1990). The monoclonal antibodies 
used were: LM5 (1-4- $\beta$-D galactan (Rat IgG)), LM11 (xylan/arabinoxylan (Rat IgM)), LM19/JIM5 (unesterified homogalacturonan (Rat IgM)), LM20/JIM7 (esterified homogalacturonan (Rat IgM)), LM2 (arabinogalactan protein (Rat IgM)), LM6 (1-5- $\alpha$-L arabinan Rat IgG)) and LM15 (xyloglucan (Rat IgG2c)). The monoclonal antibodies were from Plant Probes (Paul Knox Cell Wall Lab at the University of Leeds, England). A 5-fold serial dilution in phosphate buffered saline solution (PBS) was prepared from the fractions, as well as a negative control (soluble starch solution) and positive control (polymer being tested for). $1 \mu \mathrm{l}$ aliquots were then applied to a nitrocellulose membrane grid. The nitrocellulose grids were then dried under Drierite for approximately 16 hours at $21^{\circ} \mathrm{C}$. The membranes were incubated in $5 \%$ milk powder (MP)/PBS) for one hour to block binding sites, and then for 1.5 hours in a primary antibody $\left(1^{\circ}\right)$ solution containing 1/10 diluted monoclonal antibody in MP/PBS. The membranes were then washed extensively in distilled water and PBS and then incubated in secondary antibody solution $\left(2^{\circ}\right)$ which was an anti-rat horseradish peroxidase conjugate (purchased from Sigma), diluted $1 / 1000$ in $5 \% \mathrm{MP} / \mathrm{PBS}$. The membrane was again washed extensively in distilled water and PBS. Development was produced by incubation for approximately 10 minutes

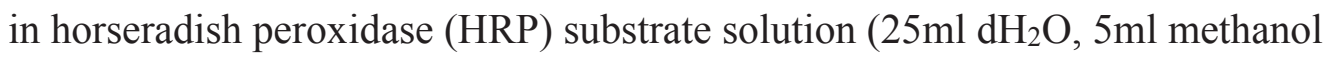
containing 10mg/ml 4-chloro-l-napthol, 30ul 6\% (w/w) $\mathrm{H}_{2} \mathrm{O}_{2}$ ). The membranes were then observed for labeling. 


\subsubsection{Presence of cell wall polymers in unfractionated samples and residues}

Immuno-fluorescence microscopic methods were used to analyze cell wall polymer content. Procedures described in Domozych et al. (2007) and Wustman et al. (1997) were utilized for this. The same suite of monoclonal antibodies as in the procedure for immuno-cytochemical dot blot analysis (above) was used in this investigation. In short, $50 \mu 1$ of sample was incubated in MP/PBS for one hour to block binding sites. The sample was then washed extensively in PBS and distilled water. The sample was then incubated in $1^{\circ}$ antibody for 1.5 hours diluted 10 -fold at room temperature and washed again with PBS and distilled water. The sample was then incubated in the appropriate $2^{\circ}$ antibody (FITC conjugate) diluted 1000-fold in MP/PBS for 1.5 hours at room temperature, covered to prevent photo-bleaching. After being washed again in PBS and distilled water, the sample was then viewed using fluorescence microscopy using a Zeiss Axioskop microscope and documented with digital photography using a Leica DFC295 digital camera.

\subsubsection{Presence of calcium in unfractionated samples and cell wall residues}

Untreated and insoluble residue samples were labeled with Fura-2 AM calcium indicating dye and viewed using fluorescence microscopy using the techniques outlined in Grynkiewicz et al. (1985). In short, $50 \mu 1$ of sample was placed in a micro-centrifuge 
tube and incubated in a $1 \mathrm{~mm}$ stock solution of Fura-2 AM in DMSO for one hour at $25^{\circ} \mathrm{C}$. The sample was then washed extensively with PBS and distilled water several times and viewed under epifluorescence using a Zeiss Axioskop microscope to determine the presence of calcium, and documented with digital photography using Leica DFC295 digital camera. Fura-2 AM is a sensitive calcium indicator dye which excites at $340 / 380 \mathrm{~nm}$ with high selectivity for Ca2+ ions). Fura-2 AM is a fluorescein isothiocyanate conjugated (FITC) molecule which chelates the calcium in samples, allowing them to be viewed under ultra-violet (UV) light (Grynkiewicz et al. 1986).

\subsection{Results}

\subsubsection{Visualization and characterization of macrophyte and paired floc}

Unfractionated Chara spp sample appeared to have heavily calcite encrusted, elongated cell walls. Nodal regions and branching were visible. Some diatom species were seen attached to the cell surface (shown in figure 2.1). The EO1 floc sample (paired floc sample to Chara spp) appeared as indistinguishable detritus, as well as cyanobacteria (circular with and without mucilage sheaths, colonial, and filamentous), as well as filamentous algal species and species of desmids Chara spp oogonium and antheridium structures were also present in the floc (shown in figure 2.3). The TO3 floc sample (also a paired floc sample to Chara spp) appeared much the same as EO1 but also included species of diatom and remnant plant and cell wall material present in the floc (shown in

figure 2.2). The unfractionated T. domingensis sample appeared as large, smooth, 
rectangular epidermal cells arranged between bundles of vascular tissue. There were also areas of exposed mesophyll and spongy mesophyll cells which appeared ovular and smaller than the epidermal cells (shown in figure 2.4). EC1 (paired floc sample to $T$. domingensis) appeared as undistinguishable detritus, with remnant plant tissue and cell wall materials as well as some species of filamentous green algae and diatoms (shown in figure 2.5). Unfractionated Cladium jamaicense appeared to have epidermal cells larger than that of $T$. domingensis and with rough interlocking edges. The vascular tissue, which was visible beneath the epidermal cells appeared to be tightly bundled, more so than was observed in the $T$. domingensis sample. The exposed mesophyll cells appeared larger and more elongated than in the T. domingensis sample as well (shown in figure 2.6). Untreated TC3 (paired floc sample to $C$. jamaicense) appeared as dense detritus with remnant plant and cell wall tissues. There were not many algal species visible in the TC3 floc sample (shown in figure 2.7). 

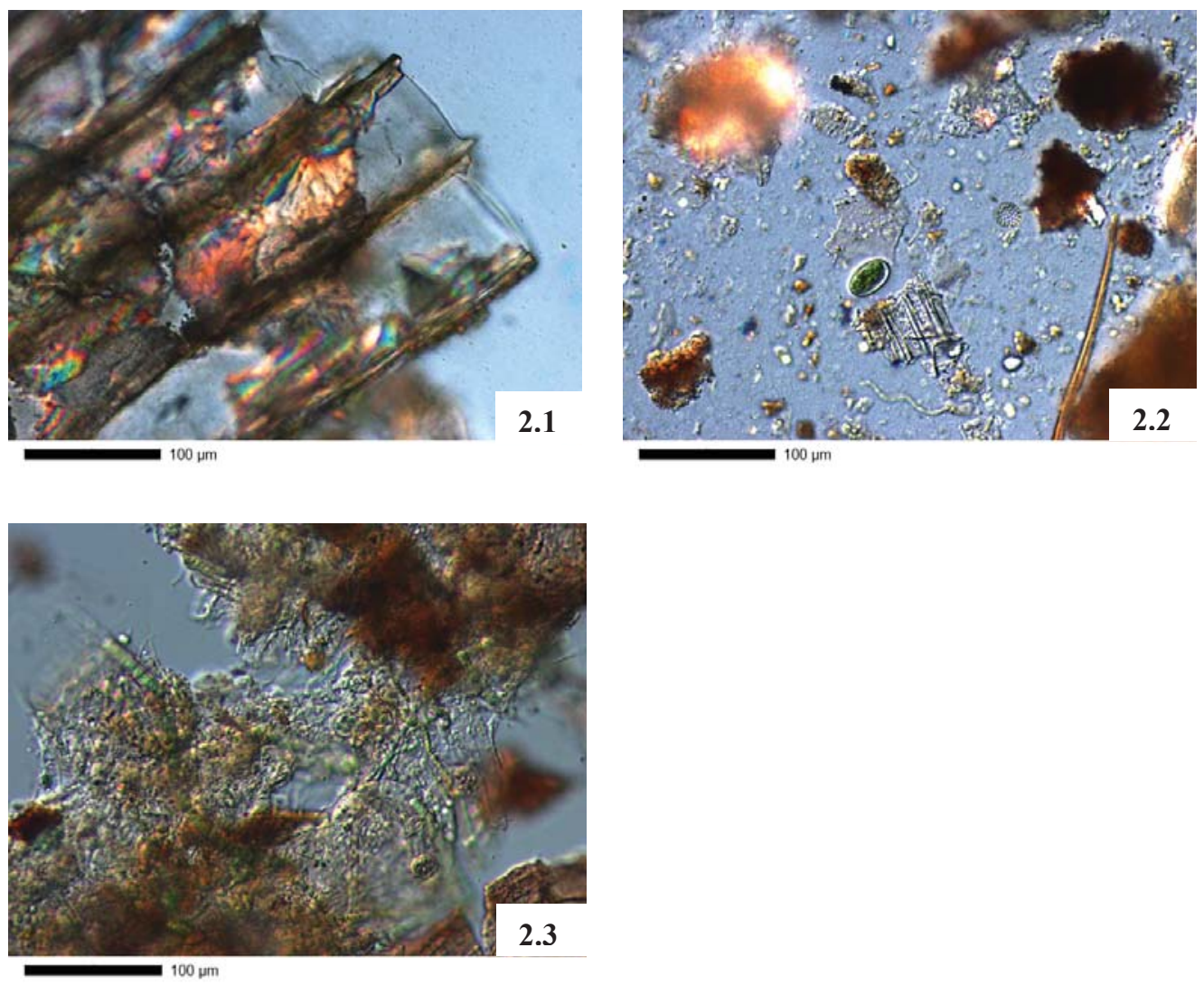

Figures 2.1 - 2.3: Initial, untreated images of collected Chara spp and paired floc samples EO1 and TO3 from WCA-2A. Chara spp (figure 2.1) shows cell walls heavily encrusted with calcite, exposed cell walls, cellular structure and intra-cellular regions. Floc samples TO3 (figure 2.2) and EO1 (figure 2.3) shows detritus, cell wall remnants, cyanobacteria, filamentous algae and other algal species. (Scale bar $=100 \mu \mathrm{m})$.
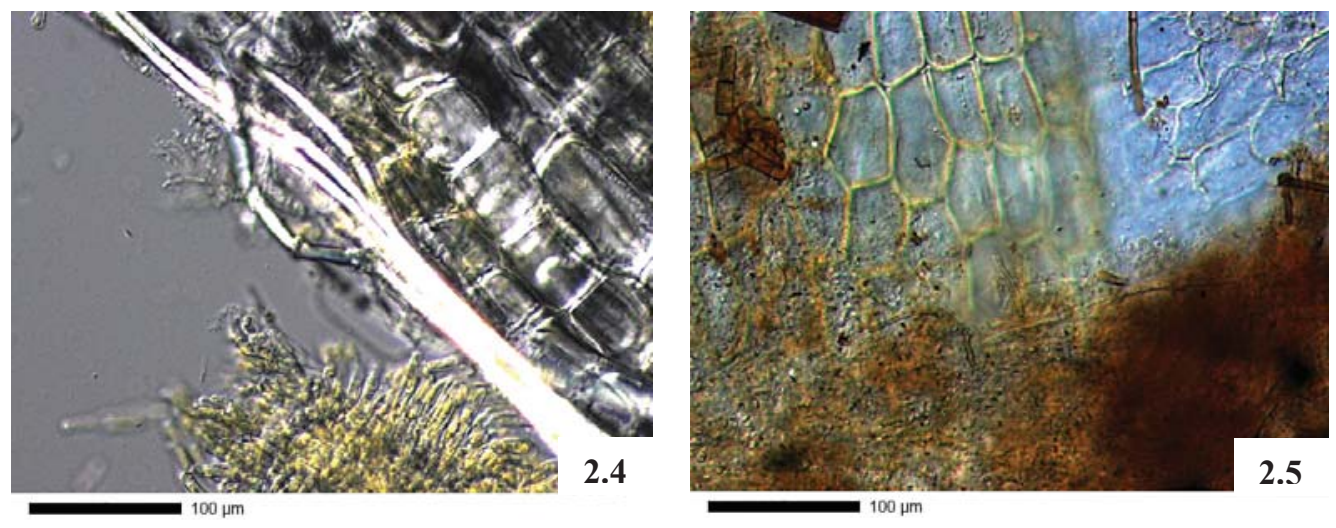

Figures 2.4 - 2.5: Initial, untreated images of collected T. domingensis and paired floc sample EC1 from WCA-2A. T. domingensis (figure 2.4) shows epidermal cells, vascular tissue, exposed mesophyll, cellular structure and intra-cellular regions. Floc sample EC1 (figure 2.5) shows dense detritus, and remnant plant tissues. $\quad($ Scale $b a r=100 \mu \mathrm{m})$. 

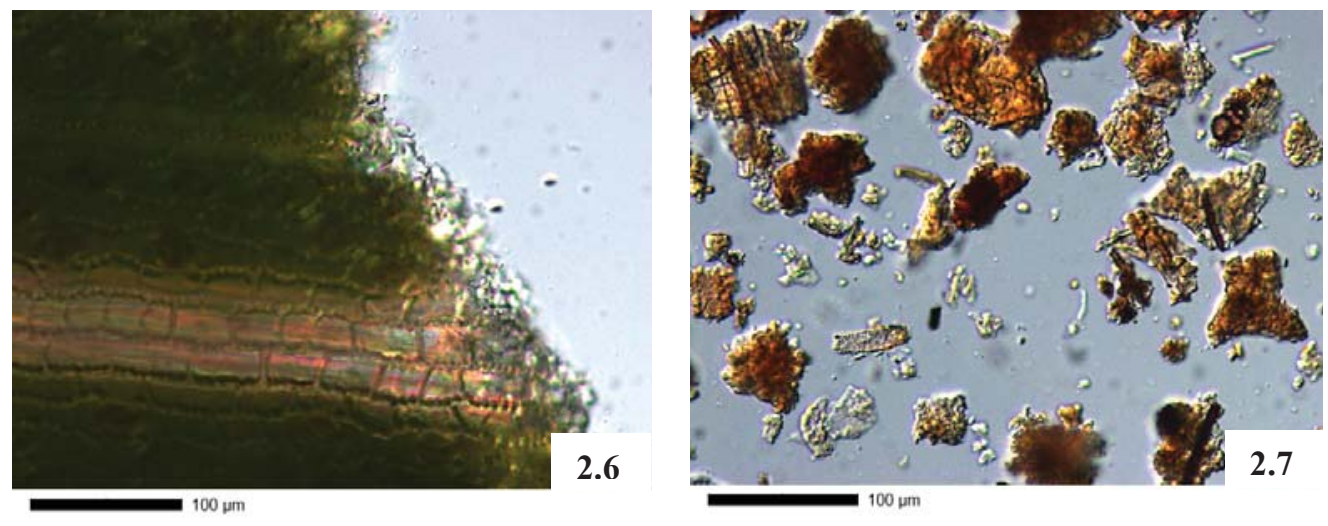

Figures 2.6 - 2.7: Initial, untreated images of collected $C$. jamaicense and paired floc sample TC3 from WCA-2A. C. jamaicense (figure 2.6) shows epidermal cells, vascular tissue, cellular structure and intracellular regions. Floc sample EC1 (figure 2.7) shows dense detritus, and remnant plant tissues. (Scale bar $=100 \mu \mathrm{m})$.

\subsubsection{Visualization of Chara spp cell wall structure}

Cell wall-bound calcite of Chara spp appeared to be ubiquitous throughout the cell walls when visualized using SEM. Larger branches of the macrophyte appeared more heavily encrusted and homogenous (figure 2.8), while the smaller branches appeared to have more cell wall-bound calcite in the intra-cellular regions (figure 2.9). The cultured Chara corallina (shown in figures 2.10) seemed to have less extra-cellular debris than the environmental samples from WCA-2A, with heavily calcite encrusted cell walls. Upon viewing the interior of the cell, calcite appeared to have been forming along the cell wall pores as well (shown in figure 2.11). These observations were consistent with what was seen using calcium indicating dye under fluorescence microscopy. 

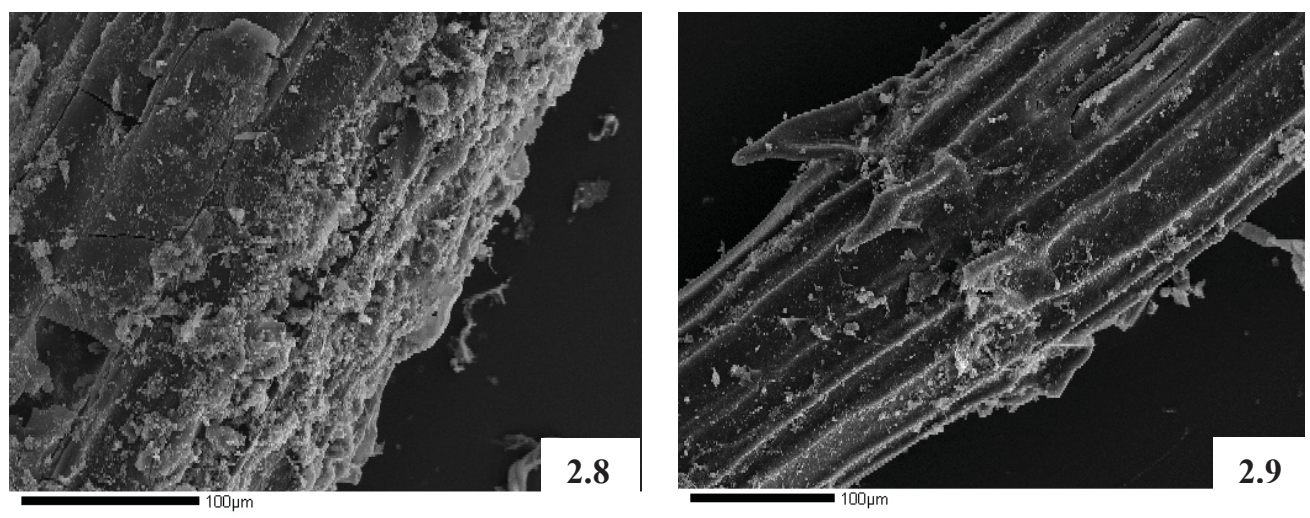

Figures 2.8 - 2.9: SEM images of collected Chara spp samples from WCA-2A showing cell walls heavily encrusted with calcite (fig. 2.8) and general features including whorled branching (fig. 2.9) cellular structure and intra-cellular regions. (Scale bar $=100 \mu \mathrm{m})$
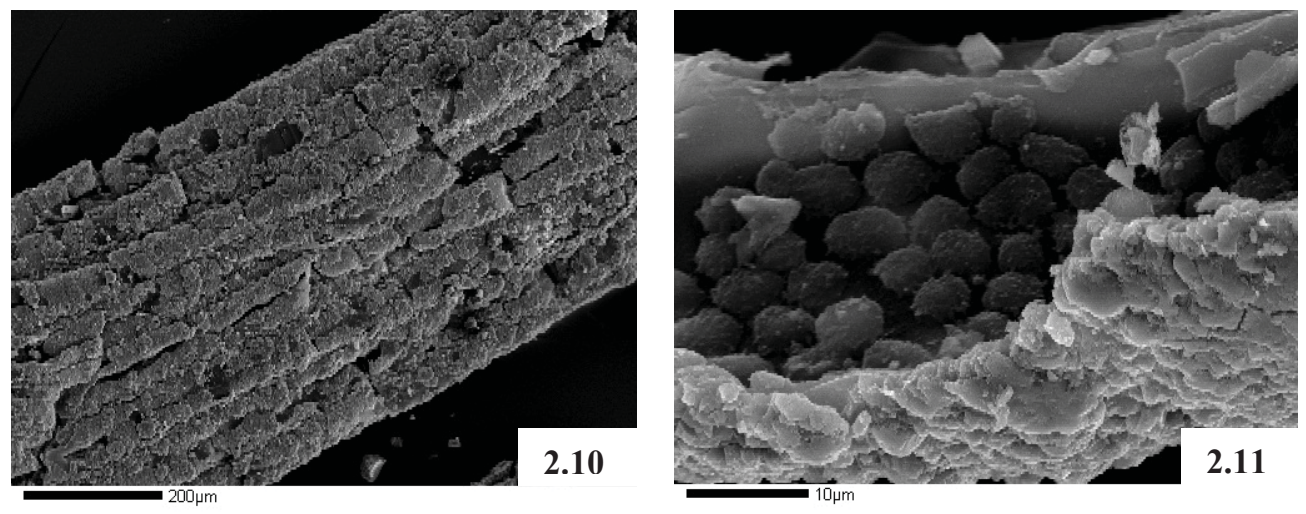

Figures 2.10 - 2.11: SEM images of cultured Chara corallina (source: Skidmore college) showing heavily calcite encrusted cell walls that appear ubiquitous (fig. 2.10) and calcite encrustations formed on the inside of the cell in the region of the cell wall pores (fig. 2.11). (Scale bars $=200 \mu \mathrm{m} / 10 \mu \mathrm{m}$ )

\subsubsection{Isolation and sequential extraction of the cell wall polymers}

Method A: The results of Fractionation method A are shown in Figure 2.12. The results from fractionation method A showed a correlation between Chara spp and Chara spp paired floc samples, and the emergent macrophyte samples $T$. domingensis and Cladium jamaicense and paired floc samples EC1 and TC3. The emergent macrophyte samples T. domingensis and C. jamaicense and their paired floc samples EC1 and TC3 
yielded similar results, with the samples containing about 50\% HW soluble material and $50 \% \mathrm{NaOH}$ soluble material of their total recovered soluble fractions. The percent of recovered $\mathrm{HW}$ soluble material and $\mathrm{NaOH}$ soluble material appear to be almost even in amount, except in the case of the samples gathered from the open area sites (EO3 and TO3). In the EO3 site sample, the HW soluble fraction from the floc sample is greater than samples from the other sites and macrophyte samples. The $\mathrm{NaOH}$ soluble material recovered from the $\mathrm{TO} 3$ site was also higher than the other $\mathrm{NaOH}$ soluble material recovered from floc samples in the other sites.

Method B: The results of the expanded fractionation method B are shown in Figure 2.13. The amount of soluble material and insoluble residue is shown for each dominant macrophyte as well as floc material from paired sample sites as percentage of total recovered material after the fractionation. The expanded results of fractionation B strengthen the correlation between macrophytes and their paired floc samples identified from fractionation $\mathrm{A}$. In the $\mathrm{MeKOH}$ soluble fractions of the macrophytes and paired floc samples Chara spp, T. domingensis and Cladium jamaicense contained substantially lesser amounts of MeKOH soluble material than their paired floc samples.

Extraction with HW showed that the Chara spp sample and paired floc samples EO1 and TO3 all contained over 4\% HW soluble material while the macrophytes $T$. domingensis and Cladium jamaicense contained less than 2\% HW soluble material. Their paired floc samples (EC1 and TC3) contained slightly greater amounts of HW soluble material. 
The results of the CDTA extraction where somewhat inconsistent, with Chara spp only having $2.5 \%$ CDTA soluble material of the total recovered material, and the paired floc sample EO1 having $1 \%$, and the other paired floc sample containing about $3.5 \%$. Possible reasons for this may be that the $\mathrm{Ca}^{2+}$ was either removed during the initial MeKOH defatting method (which seems to be the case in the floc samples), or not entirely removed by CDTA and present in the insoluble residue which is likely what happened in the Chara spp sample.

In the $\mathrm{Na}_{2} \mathrm{CO}_{3}$ extraction, which removes pectins and hemicelluloses, all samples were found to contain similar amounts of $\mathrm{Na}_{2} \mathrm{CO}_{3}$ soluble material (between 1.5 and $3 \%$ of their total recovered material.

Extraction with stronger alkalis $1 \mathrm{M} \mathrm{KOH}$ and $4 \mathrm{MKOH}$ yielded interesting results. The $1 \mathrm{M} \mathrm{KOH}$ soluble fraction of Chara spp was found to be significantly greater than the $1 \mathrm{M} \mathrm{KOH}$ soluble material of Chara spp paired floc samples. This shows that most of the alkali soluble hemicelluloses in Chara spp were removed with a weaker base than in the Chara spp paired floc samples. The greater amount of insoluble residue in Chara spp and paired floc samples in conjunction with the alkali extraction data, may indicate resistant hemicellulose and $\mathrm{Ca} 2+$ present in the insoluble residue of Chara spp that may have been more liable to removal by strong alkali extraction in the Chara spp paired floc samples.

The alkali extraction and insoluble residue results from the emergent macrophytes and their paired floc samples showed differing results from that of Chara spp and paired floc samples. T. domingensis had very a small $1 \mathrm{M} \mathrm{KOH}$ soluble fraction (much less than 
that of Chara spp and Cladium jamaicense) and a greater 4M KOH soluble fraction and $14 \%$ insoluble residue while the paired floc sample, with paired floc sample EC1 showing similar results. T. domingensis and paired floc sample EC1 also had similar levels of insoluble residue.

The alkali extraction results from C. jamaicense and paired floc sample TC3 showed that $1 \mathrm{M} \mathrm{KOH}$ was able to extract a greater amount of soluble material from $C$. jamaicense, than in paired floc TC3. This result may be due to weak alkali soluble material already having been extracted during initial treatment with MeKOH. $C$. jamaicense and Chara spp had a similar amount of $1 \mathrm{M} \mathrm{KOH}$ soluble material but Cladium jamaicense had a much greater yield of $4 \mathrm{M} \mathrm{KOH}$ soluble material. This suggests a greater diversity of hemicellulose within the walls of $C$. jamaicense, than in Chara spp as well as $T$. domingensis (in which most alkali soluble hemicellulose was removed with 4M KOH rather than $1 \mathrm{M} \mathrm{KOH})$. Cladium jamaicense and paired floc sample TC3 contained similar amounts of 4MKOH soluble material and insoluble residue. The percent of total recovered soluble and insoluble material from the original dry mass of the plant material is presented in figure 2.14. The total percentage of recovered material were above $60 \%$ in each sample. 


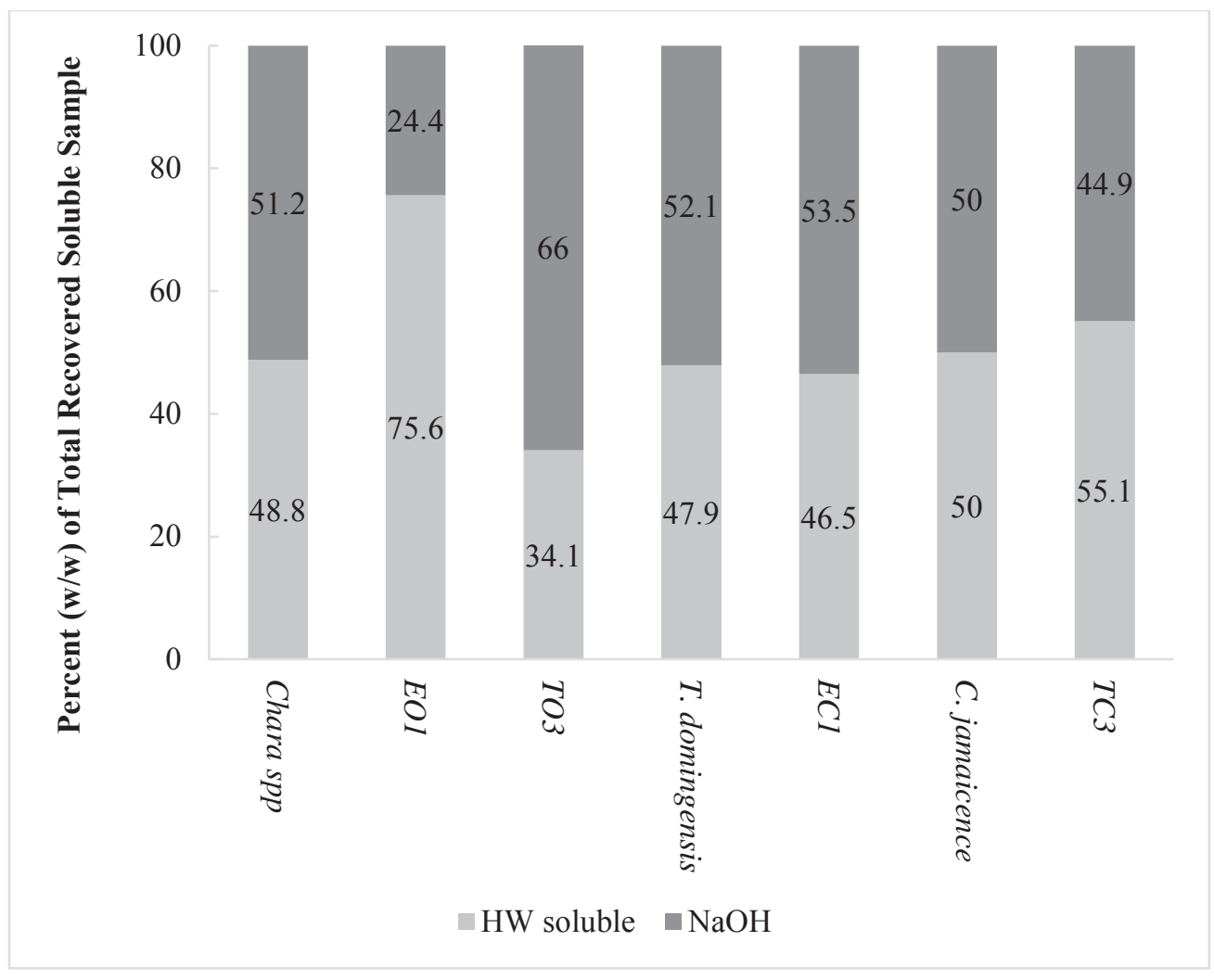

Figure 2.12: The percent of $\mathrm{HW}$ soluble material and $\mathrm{NaOH}$ soluble material from the total recovered soluble material from fractionation procedure A, presented as percent dry weight after freeze-drying. 


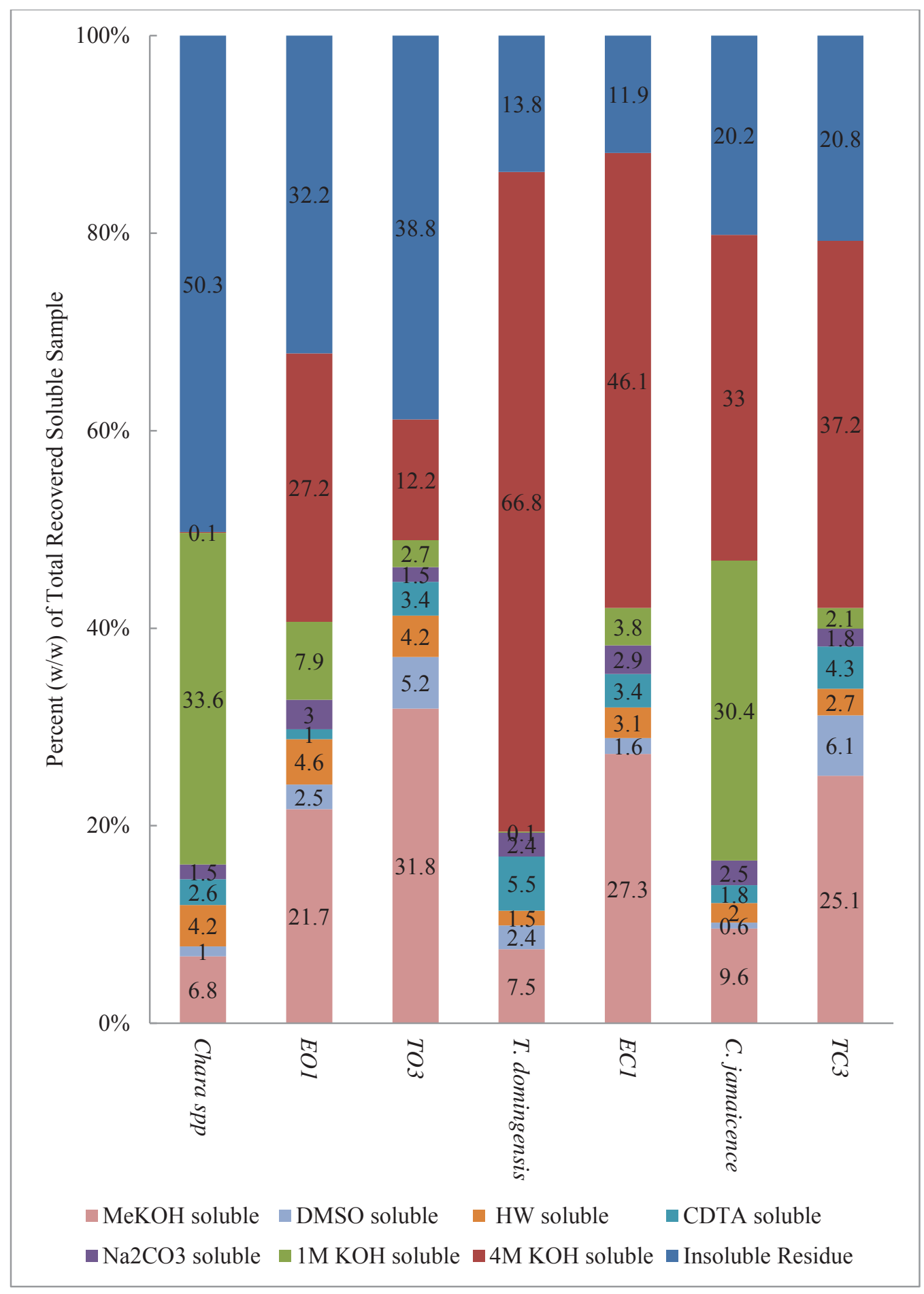

Figure 2.13: The percent of MeKOH soluble, DMSO soluble, $\mathrm{HW}$ soluble, CDTA soluble, $\mathrm{Na}_{2} \mathrm{CO} 3$ soluble, $1 \mathrm{M} \mathrm{KOH}$ soluble, $4 \mathrm{M} \mathrm{KOH}$ soluble, and insoluble residue from the total recovered material after fractionation $\mathrm{B}$, presented as percent dry $\mathrm{w} / \mathrm{w}$ after freeze-drying. 


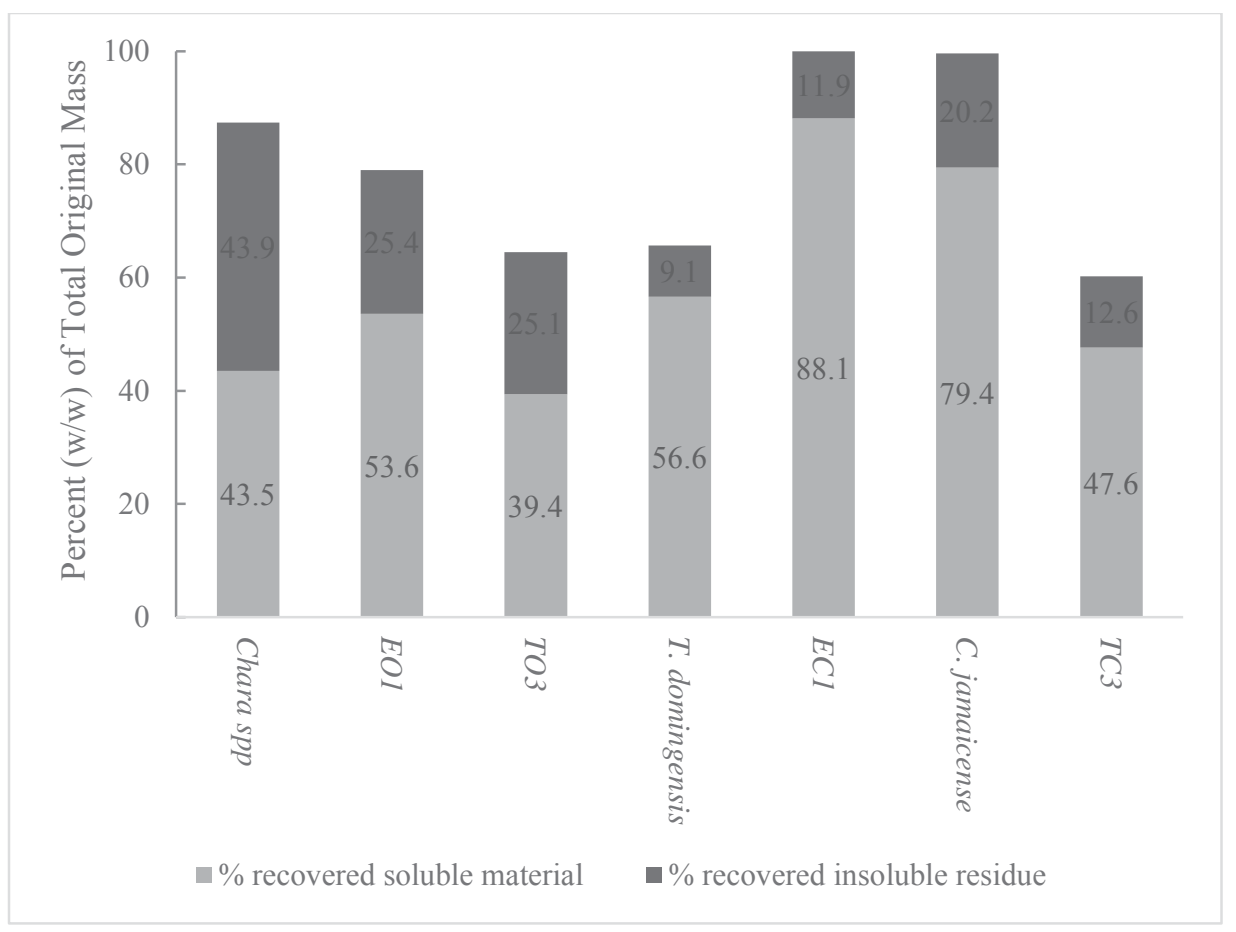

Figure 2.14: The percent recovered soluble material and insoluble residue (post-fractionation method B) from the total original mass of plant material (\% dry weight after freeze drying)

\subsubsection{Presence of cell wall polymers in isolated fractions}

The results of the polymers found in the soluble material extracted from coarsely ground macrophyte and paired floc samples post fractionation method A are shown in table 2.1. The dot blot analysis of Chara spp indicated that an extraction with HW removed a significant amount of xylan which was present in the HW soluble fraction, however significant amounts of $(1,4)-\beta$-D galactan, unesterified HG, esterified HG, AGP, arabinan and xyloglucan were not found to be present. Extraction with $\mathrm{NaOH}$ indicated that significant amounts of xylan and xyloglucan were removed and present in the $\mathrm{NaOH}$ soluble fraction. 
The dot blot analysis of floc sample EO1 (paired floc sample to Chara spp) indicated that the HW soluble fraction removed xylan, methyl-esterified HG, and AGP, while $(1,4)-\beta-\mathrm{D}$ galactan, unesterified HG and arabinan were not found present in amounts detectible via dot-blot analysis. Xylan AGP and xyloglucan were detected in the $\mathrm{NaOH}$ soluble fraction of EO1, as well as methyl-esterified HG.

The dot blot analysis results of fractionation method A on the floc sample from site TO3 was very similar to that of paired macrophyte Chara spp. The HW soluble fraction indicated the presence of xylan in moderate amounts and the absence of $(1,4)-\beta$ D galactan, unesterified HG, esterified HG, AGP, arabinan and xyloglucan in significant amounts. The analysis of the $\mathrm{NaOH}$ soluble fraction indicated the presence of xylan and xyloglucan in significant amounts.

The dot blot analysis of macrophyte sample $T$. domingensis indicated the presence of xylan in a significant amount, as well as the presence of (1,4)- $\beta$-D galactan, methylesterified $\mathrm{HG}$, and AGP in moderate amounts in the $\mathrm{HW}$ soluble fraction. In the $\mathrm{NaOH}$ soluble fraction of $T$. domingensis, xylan, AGP and xyloglucan was found present in significant amounts.

In the floc sample EC1 (paired floc sample to T. domingensis) xylan, AGP and arabinan were found present in significant amounts, and unesterified HG was found to be present in moderate amount. In the $\mathrm{NaOH}$ soluble fraction of $\mathrm{EC} 1 \mathrm{floc}$, the monoclonal antibodies for xylan AGP and xyloglucan epitopes labeled strongly, whereas unesterified HG labeled weakly. 
The HW fraction of Cladium jamaicense labeled strongly for the xyloglucan epitope, and weakly for the (1,4)- $\beta$-D galactan, xylan, and esterified HG. AGP and arabinan epitopes were strongly labeled for in the $\mathrm{NaOH}$ soluble fraction. Strong labeling during dot blot analysis also indicated the presence of $(1,4)-\beta$-D galactan, xylan, esterified $\mathrm{HG}$ and xyloglucan epitopes in the $\mathrm{NaOH}$ soluble fraction.

The dot blot analysis results of paired floc sample to $C$. jamaicense, TC3 was very similar to that of $C$. jamaicense. The HW soluble fraction of TC3 was found to label strongly for methyl-esterified HG epitope. Xylan, AGP and arabinan epitopes were weakly labeled for in the HW soluble fraction of TC3 floc as well. The (1,4)- $\beta$-D galactan epitope was weakly labeled for in the dot blot analysis of the $\mathrm{NaOH}$ soluble fraction.

Table 2.2 describes the dot blot analysis of the expanded fractionation method B of macrophytes and their paired floc samples from WCA-2A. The various soluble fractions of the samples were labeled with a suite of monoclonal antibodies to common plant and algal polymers to determine differences in polymer content and solubility. Chara spp was found to weakly label for the xyloglucan epitope in the MeKOH, HW, $1 \mathrm{M} \mathrm{KOH}$ and $4 \mathrm{M} \mathrm{KOH}$ soluble fractions indicating the removal of xyloglucan with these extractions. Chara spp was also found to weakly label for the unesterified HG epitope in the HW, CDTA, and $\mathrm{Na}_{2} \mathrm{CO}_{3}$ soluble fractions. The Xylan epitope strongly was labeled for in the $\mathrm{MeKOH}, \mathrm{HW}, \mathrm{Na}_{2} \mathrm{CO}_{3}, 1 \mathrm{M} \mathrm{KOH}$ and $4 \mathrm{M} \mathrm{KOH}$ soluble fractions in the Chara spp samples. 
The paired floc sample to Chara spp, EO1 labeled strongly for the xylan epitope in the MeKOH, DMSO and CDTA soluble fractions and weakly in the HW, $1 \mathrm{M} \mathrm{KOH}$ and $4 \mathrm{M} \mathrm{KOH}$ soluble fractions. EO1 also labeled for the xyloglucan epitope strongly in the $1 \mathrm{M} \mathrm{KOH}$ soluble fraction, and weakly in the $\mathrm{MeKOH}$ and $\mathrm{HW}$ soluble fractions weakly. Methyl-esterified HG was also found present in the dot blot analysis of EO1. Methyl-esterified HG labeled weakly in the CDTA soluble fraction.

The dot blot analysis results of the soluble fractions of paired floc sample to Chara spp TO3, was somewhat similar to the soluble fractions of both Chara spp and $T$. domingensis. AGP was found to be present in the $\mathrm{HW}, \mathrm{Na}_{2} \mathrm{CO}_{3}, 1 \mathrm{M} \mathrm{KOH}$ and $4 \mathrm{M} \mathrm{KOH}$ soluble fractions of TO3 in small amounts indicated by the weak labeling in these fractions in the dot blot analysis. The arabinan epitope also labeled weakly during dot blot analysis in the DMSO soluble fraction of TO3. In the MeKOH, HW, $1 \mathrm{M} \mathrm{KOH}$ and 4M KOH soluble fractions, the epitope for xylan labeled strongly, while the CDTA soluble fraction labeled weakly. Xyloglucan was also found to be present in the TO3 floc sample and was indicated by the strong labeling in the $\mathrm{MeKOH}$ and $4 \mathrm{M} \mathrm{KOH}$ soluble fractions, as well as weak labeling in the $\mathrm{HW}$, CDTA, and $1 \mathrm{M} \mathrm{KOH}$ soluble fractions. There was strong labeling of the unesterified HG epitope in the HW soluble fraction, as well as weak labeling for the methyl-esterified epitope.

The $\mathrm{HW}, \mathrm{Na}_{2} \mathrm{CO}_{3}, 1 \mathrm{M} \mathrm{KOH}$ and $4 \mathrm{M} \mathrm{KOH}$ soluble fractions of $T$. domingensis weakly labeled for the AGP epitope. The (1,4)- $\beta$-D galactan epitope labeled strongly in the DMSO, HW and 4M KOH soluble fractions and weakly in the MeKOH, CDTA, $\mathrm{Na}_{2} \mathrm{CO}_{3}$ and $1 \mathrm{M} \mathrm{KOH}$ soluble fractions. The arabinan epitope was indicated in the 
$\mathrm{Na}_{2} \mathrm{CO}_{3}$ soluble fraction as well, which labeled strongly. The dot blot analysis of $T$. domingensis also revealed that it contained a high amount of xylan, as the epitope labeled strongly in every soluble fraction. The xyloglucan epitope labeled strongly in the $\mathrm{MeKOH}, \mathrm{DMSO}, \mathrm{HW}, 1 \mathrm{M} \mathrm{KOH}$ and $4 \mathrm{M} \mathrm{KOH}$ soluble fractions, and weakly in the CDTA and $\mathrm{Na}_{2} \mathrm{CO}_{3}$ soluble fractions. Unesterified $\mathrm{HG}$ and methyl-esterified $\mathrm{HG}$ were also found to be present, with strong labeling for the unesterified HG epitope in the HW soluble fraction, and weak labeling for the unesterified and methyl-esterified HG epitopes in the CDTA soluble fraction.

Xylan and xyloglucan epitopes were the only polymers indicated in the dot blot analysis of T. domingensis paired floc sample EC1. The HW soluble fraction of EC1 labeled strongly for the xylan epitope and the $\mathrm{MeKOH}, \mathrm{DMSO}$, CDTA and $1 \mathrm{M} \mathrm{KOH}$ soluble fractions labeled weakly for the xylan epitope. The MeKOH, DMSO, HW and $1 \mathrm{M} \mathrm{KOH}$ soluble fractions labeled weakly for the xyloglucan epitope.

C. jamaicense was shown to label weakly for the AGP epitope in the $\mathrm{Na}_{2} \mathrm{CO}_{3}$ and $4 \mathrm{M} \mathrm{KOH}$ soluble fractions. The $(1,4)-\beta-\mathrm{D}$ galactan epitope was indicated in $\mathrm{MeKOH}$, $\mathrm{HW}$, and CDTA soluble fractions which labeled weakly, and the $\mathrm{Na}_{2} \mathrm{CO}_{3}$ and $4 \mathrm{M} \mathrm{KOH}$ soluble fractions which labeled strongly. The arabinan epitope also showed strong labeling in the $\mathrm{HW}$ and $1 \mathrm{M} \mathrm{KOH}$ soluble fractions of $C$. jamaicense. The xylan epitope was found to label strongly in all soluble fractions of $C$. jamaicense. The xyloglucan epitope labeled for in the $\mathrm{HW}, \mathrm{CDTA}, \mathrm{Na}_{2} \mathrm{CO}_{3}$ and $1 \mathrm{M} \mathrm{KOH}$ soluble fractions weakly, and the $\mathrm{MeKOH}$ and $4 \mathrm{M} \mathrm{KOH}$ soluble fractions strongly. Unesterified $\mathrm{HG}$ was indicated as present by the weak labeling of the unesterified HG epitope in the HW and CDTA 
soluble fractions. The esterified HG showed weak labeling in the CDTA soluble fraction as well.

The results of the dot blot analysis of the $C$. jamaicense paired floc sample TC3 similar to those of $C$. jamaicense, however TC3 did not label for the arabinan epitope while $C$. jamaicense did. The AGP epitope labeled for weakly in the HW soluble fraction of TC3. Also in the HW soluble fraction, the $(1,4)-\beta$-D galactan epitope labeled strongly. The xylan epitope labeled for weakly in the CDTA soluble fraction and strongly in the $\mathrm{MeKOH}, \mathrm{HW}, 1 \mathrm{M} \mathrm{KOH}$ and 4M KOH soluble fractions. The xyloglucan epitope was labeled for as well, weakly indicated in the CDTA and $1 \mathrm{M} \mathrm{KOH}$ soluble fractions and strongly indicated in the $\mathrm{MeKOH}, \mathrm{HW}$ and $4 \mathrm{M} \mathrm{KOH}$ soluble fractions. Unesterified HG was weakly labeled for in the HW soluble fraction, while methyl-esterified HG was labeled for weakly in the CDTA soluble fraction.

Table 2.1: Results of the immuno-cytochemical dot blot analysis of fractionation procedure A. $(++)$ indicates strong labeling and a significant amount of the polymer being tested for in a sample. $(-+)$ indicates moderate labeling and the possible presence of the polymer being tested for in a sample. ( $(-)$ indicates no labeling and the absence of the polymer being tested for in the sample.

\begin{tabular}{|c|c|c|c|c|c|c|c|}
\hline & $\begin{array}{c}\text { AGP } \\
(\mathrm{LM} 2)\end{array}$ & $\begin{array}{c}(1,4)-\beta-\mathrm{D} \\
\text { galactan } \\
(\mathrm{LM})\end{array}$ & $\begin{array}{l}\text { Arabinan } \\
\text { (LM6) }\end{array}$ & $\begin{array}{c}\text { Xylan } \\
\text { (LM11) }\end{array}$ & $\begin{array}{c}\text { Xyloglucan } \\
\text { (LM15) }\end{array}$ & $\begin{array}{c}\mathrm{HG} \\
\text { (JIM5) }\end{array}$ & $\begin{array}{c}\mathrm{HG} \\
(\mathrm{JIM} 7)\end{array}$ \\
\hline \multirow{2}{*}{$\begin{array}{l}\text { Chara spp } \mathrm{HW} \\
\text { Chara spp } \mathrm{NaOH}\end{array}$} & -- & -- & -- & ++ & -- & -- & -- \\
\hline & -- & -- & - & ++ & ++ & - & -- \\
\hline EO1 HW & -+ & - & - & ++ & -- & -- & -+ \\
\hline EO1 NaOH & ++ & -- & -- & ++ & ++ & - & -+ \\
\hline TO3 HW & - & -- & - & -+ & - & -- & -- \\
\hline TO3 NaOH & -- & -- & -- & ++ & ++ & - & -- \\
\hline \multirow{3}{*}{$\begin{array}{r}\text { T. domingensis } \mathrm{HW} \\
\text { T. domingensis } \\
\mathrm{NaOH}\end{array}$} & -+ & -+ & - & ++ & -- & - & -+ \\
\hline & & & & & & & \\
\hline & ++ & -- & -- & ++ & ++ & -- & -- \\
\hline EC1 HW & ++ & -- & ++ & ++ & - & -+ & -- \\
\hline
\end{tabular}




\begin{tabular}{|c|c|c|c|c|c|c|c|}
\hline EC1 NaOH & ++ & -- & -- & ++ & ++ & -+ & - \\
\hline \multicolumn{8}{|l|}{ Cladium jamaicense } \\
\hline HW & -- & -+ & -- & -+ & ++ & -- & -+ \\
\hline \multicolumn{8}{|l|}{ Cladium jamaicense } \\
\hline $\mathrm{NaOH}$ & ++ & ++ & ++ & ++ & ++ & - & ++ \\
\hline TC3 HW & -+ & -- & -+ & -+ & -- & -- & ++ \\
\hline TC3 NaOH & ++ & -+ & ++ & ++ & ++ & - & - \\
\hline
\end{tabular}

Table 2.2: Results of the immuno-cytochemical dot blot analysis of fractionation procedure B. $(++)$ indicates strong labeling and a significant amount of the polymer being tested for in a sample. $(-+)$ indicates moderate labeling and the possible presence of the polymer being tested for in a sample. $(--)$ indicates no labeling and the absence of the polymer being tested for in the sample.

\begin{tabular}{|c|c|c|c|c|c|c|c|}
\hline & $\begin{array}{c}\text { AGP } \\
(\mathrm{LM} 2)\end{array}$ & $\begin{array}{c}(1,4)-\beta- \\
D \\
\text { galactan } \\
(\text { LM5) }\end{array}$ & $\begin{array}{l}\text { Arabinan } \\
\text { (LM6) }\end{array}$ & $\begin{array}{l}\text { Xylan } \\
\text { (LM11) }\end{array}$ & $\begin{array}{l}\text { Xyloglucan } \\
\text { (LM15) }\end{array}$ & $\begin{array}{c}\text { HG } \\
\text { (JIM5) }\end{array}$ & $\begin{array}{c}\mathrm{HG} \\
(\mathrm{JIM} 7)\end{array}$ \\
\hline Chara spp $\mathrm{MeKOH}$ & - & - & - & ++ & - & - & - \\
\hline Chara spp DMSO & - & - & - & - & - & - & - \\
\hline Chara spp HW & - & - & - & ++ & - & - & - \\
\hline Chara spp CDTA & - & - & - & - & - & -+ & - \\
\hline Chara spp $\mathrm{Na}_{2} \mathrm{CO}_{3}$ & - & - & - & ++ & - & -+ & - \\
\hline Chara spp $1 \mathrm{M} \mathrm{KOH}$ & - & - & - & ++ & - & - & - \\
\hline Chara spp 4M KOH & - & - & - & ++ & -+ & - & - \\
\hline EO1 MeKOH & - & - & - & ++ & - & - & - \\
\hline EO1 DMSO & - & - & - & ++ & - & - & - \\
\hline EO1 HW & - & - & - & -+ & -+ & - & - \\
\hline E01 CDTA & - & - & - & ++ & - & - & - \\
\hline $\mathrm{EO} 1 \mathrm{Na}_{2} \mathrm{CO}_{3}$ & - & - & - & - & - & - & - \\
\hline EO1 1M KOH & - & - & - & -+ & - & - & - \\
\hline EO1 4M KOH & - & - & - & -+ & ++ & - & - \\
\hline TO3 MeKOH & - & - & - & ++ & ++ & - & - \\
\hline TO3 DMSO & - & - & -+ & - & - & - & - \\
\hline TO3 HW & - & - & - & ++ & -+ & ++ & - \\
\hline TO3 CDTA & - & - & - & -+ & -+ & - & -+ \\
\hline $\mathrm{TO} 3 \mathrm{Na}_{2} \mathrm{CO}_{3}$ & - & - & - & - & - & - & - \\
\hline TO3 1M KOH & - & - & - & ++ & - & - & - \\
\hline
\end{tabular}




\begin{tabular}{|c|c|c|c|c|c|c|c|}
\hline TO3 4M KOH & - & - & - & ++ & ++ & - & - \\
\hline T. domingensis $\mathrm{MeKOH}$ & - & - & - & ++ & ++ & - & - \\
\hline T. domingensis DMSO & -+ & ++ & - & ++ & ++ & - & - \\
\hline T. domingensis HW & - & ++ & - & ++ & ++ & ++ & - \\
\hline T. domingensis CDTA & - & -+ & - & ++ & - & - & - \\
\hline T. domingensis $\mathrm{Na}_{2} \mathrm{CO}_{3}$ & - & -+ & ++ & ++ & -+ & - & - \\
\hline T. domingensis $1 \mathrm{M} \mathrm{KOH}$ & - & -+ & - & ++ & ++ & - & - \\
\hline T. domingensis 4M KOH & - & ++ & - & ++ & ++ & - & - \\
\hline EC1 MeKOH & - & - & - & -+ & - & - & - \\
\hline EC1 DMSO & - & - & - & -+ & - & - & - \\
\hline EC1 HW & - & - & - & ++ & -+ & - & - \\
\hline EC1 CDTA & - & - & - & -+ & - & - & - \\
\hline $\mathrm{EC} 1 \mathrm{Na}_{2} \mathrm{CO}_{3}$ & - & - & - & - & - & - & - \\
\hline EC1 $1 \mathrm{M} \mathrm{KOH}$ & - & - & - & -+ & - & - & - \\
\hline EC1 4M KOH & - & - & - & - & - & - & - \\
\hline $\begin{array}{r}\text { Cladium jamaicense } \\
\text { MeKOH }\end{array}$ & - & - & - & ++ & ++ & - & - \\
\hline $\begin{array}{r}\text { Cladium jamaicense } \\
\text { DMSO }\end{array}$ & - & - & - & ++ & - & - & - \\
\hline Cladium jamaicense HW & - & -+ & ++ & ++ & -+ & -+ & - \\
\hline $\begin{array}{r}\text { Cladium jamaicense } \\
\text { CDTA }\end{array}$ & - & -+ & - & ++ & -+ & - & -+ \\
\hline $\begin{array}{r}\text { Cladium jamaicense } \\
\mathrm{Na}_{2} \mathrm{CO}_{3}\end{array}$ & - & ++ & - & ++ & -+ & - & - \\
\hline $\begin{array}{r}\text { Cladium jamaicense } 1 \mathrm{M} \\
\mathrm{KOH}\end{array}$ & - & - & ++ & ++ & - & - & - \\
\hline $\begin{array}{r}\text { Cladium jamaicense 4M } \\
\mathrm{KOH}\end{array}$ & - & ++ & - & ++ & ++ & - & - \\
\hline TC3 MeKOH & - & - & - & ++ & ++ & - & - \\
\hline TC3 DMSO & - & - & - & - & - & - & - \\
\hline TC3 HW & -+ & ++ & - & ++ & ++ & - & - \\
\hline TC3 CDTA & - & - & - & -+ & -+ & - & -+ \\
\hline TC3 $\mathrm{Na}_{2} \mathrm{CO}_{3}$ & - & - & - & - & - & - & - \\
\hline $\mathrm{TC} 31 \mathrm{M} \mathrm{KOH}$ & - & - & - & ++ & - & - & - \\
\hline $\mathrm{TC} 34 \mathrm{M} \mathrm{KOH}$ & - & - & - & ++ & ++ & - & - \\
\hline
\end{tabular}




\subsubsection{Presence of polymers in unfractionated samples and insoluble cell wall residues}

The results of the polymers found in the unfractionated and insoluble residues of material extracted from ground macrophyte and paired floc samples are shown below in table 2.3. Unfractionated Chara spp sample showed strong labeling for the xylan, xyloglucan, unesterified HG, and methyl-esterified HG epitopes, as well as weak labeling for the AGP and $(1,4)-\beta$-D galactan epitopes. Arabinan was not indicated as being present in the untreated Chara spp sample, or in any soluble or insoluble fractions of Chara spp. Labeling for the $(1,4)-\beta$-D galactan epitope was visible on the cell wall surface as well as intracellular regions. The AGP epitope was visible in the intracellular regions as well. The xylan epitope showed visible labeling on the cell wall surface of unfractionated Chara spp, as well as the insoluble residue from fractionation A. The unesterified HG epitope labeled ubiquitously on the cell wall surface as well as on the calcite encrustations of the cell wall of unfractionated Chara spp as well as in the insoluble residues from fractionations A and B. The methyl-esterified HG epitope was observed to be present in the intracellular regions, as well as the nodal regions of Chara spp as well as in the insoluble residue of fractionations A and B. Microscopic images of Chara spp showing the nodal region labeled with monoclonal antibody LM20 to the methyl-esterified HG epitope are shown below in figures 2.15-2.16. While the xyloglucan epitope was not seen in the unfractionated or insoluble residues of the Chara spp sample during immuno-fluorescence microscopy analysis, it was labeled for in the soluble fractions of both fractionation method A and fractionation method B. This indicates that 
the xyloglucan present in the Chara spp cell wall was bound tightly within the cell wall and not detectable with immuno-fluorescence microscopy, but was removed with fractionation methods $\mathrm{A}$ and $\mathrm{B}$, and therefore detectable in the soluble material, but not the insoluble residue.

EO1, The paired floc sample to Chara spp, strongly labeled for xyloglucan epitope visible in the unfractionated sample. Microscopic images of EO1 floc showing labeling of detrital OM and algal species with monoclonal antibody LM15 to the xyloglucan epitope are shown in figures 2.17-2.18. Strong labeling was also visible for the xylan epitope which appeared ubiquitous on the cell surface. AGP, $(1,4)-\beta-D$ galactan, unesterified $\mathrm{HG}$, and methyl-esterified $\mathrm{HG}$ were also present in the untreated EO1 sample, and indicated by areas of weak labeling of organic detritus. Weak labeling of the insoluble residue of EO1, post-fractionation A, indicates that the unesterified $\mathrm{HG}$ present in the floc was not completely removed via fractionation method A.

The immuno-cytochemical fluorescence microscopy analysis results of TO3 was showed weak labeling of the arabinan epitope in the unfractionated TO3 sample, as well as in the insoluble residue of fractionation A. In the unfractionated TO3 sample, labeling of the arabinan epitope was ubiquitous, while weaker labeling occurred in the detritus. Unesterified HG was not visible in the unfractionated TO3 sample, but found present in the soluble material of fractionation $\mathrm{B}, \mathrm{AGP},(1,4)-\beta-\mathrm{D}$ galactan, xylan, xyloglucan and methyl-esterified HG had strong labeling visible in detrital and cell wall matter during the immuno-cytochemical fluorescence microscopy analysis. Microscopic images of TO3 floc showing labeling of detrital OM and algal species with monoclonal antibody LM11 
to the xylan epitope are shown in figures 2.19-2.20. Weak labeling of detrital OM and cell wall tissue for the AGP, and xylan epitopes in the insoluble residues of fractionation A and B were observed. Strong labeling of the methyl-esterified HG epitope was also visible in the insoluble residue of fractionation $\mathrm{A}$.

The immuno-cytochemical fluorescence microscopy analysis of T. domingensis yielded interesting results. $(1,4)-\beta$-D galactan, xylan, xyloglucan and methyl-esterified HG epitopes were seen to label strongly in the unfractionated sample, visible in the intracellular and vascular regions of the macrophyte. Microscopic images of $T$. domingensis showing labeling of the epidermal and mesophyll cell walls with monoclonal antibody LM11 to the xylan epitope are shown in figures 2.21-2.22. The methyl-esterified HG epitope was also visibly labeled for on the cell wall surface. Unesterified HG was seen to label weakly in the insoluble residue of fractionation A. Xylan, which labeled weakly, was also found to be present in the insoluble residue of fractionation A. Although AGP and arabinan were not indicated as present in the immuno-fluorescence microscopy analysis, they were found present in the soluble fractions of $T$. domingensis.

In the immuno-cytochemical fluorescence microscopy analysis of EC1 floc sample, xylan and xyloglucan were seen to label strongly and appeared ubiquitous in the OM of the sample and AGP, arabinan and unesterified HG were seen to label weakly in small areas of organic matter and remnant plant tissue. Microscopic images of EC1 floc showing labeling of detrital OM and plant tissue with monoclonal antibody LM11 to the xylan epitope are shown in figures 2.23-2.24. AGP was present in the insoluble residue 
of fractionation A and B. Arabinan and unesterified $\mathrm{HG}$ also labeled weakly in the insoluble residue of fractionation B in small areas of remnant plant tissue.

Unfractionated Cladium jamaicense was found to label strongly in the intracellular and vascular regions for AGP, $(1,4)-\beta-\mathrm{D}$ galactan, arabinan, xyloglucan, unesterified $\mathrm{HG}$, and methyl-esterifed epitopes. Microscopic images of $C$. jamaicense showing labeling of the cell wall, intracellular region and cell surface with monoclonal antibody JIM5 to the unesterified HG epitope are shown in figures 2.25-2.26. AGP, $(1,4)-\beta-D$ galactan and xylan epitopes were also observed to label for on the cell wall surface. Xylan labeled for weakly in the unfractionated sample and in the insoluble residue of fractionation $\mathrm{A}$, and strongly in the insoluble residue of fractionation $\mathrm{B}$. This suggests that much of the xylan present in $C$. jamaicense was not fully exposed until after the expanded fractionation method B. The AGP epitope labeled for strongly in the insoluble residues of fractionations A and B. The $(1,4)-\beta-\mathrm{D}$ galactan, xyloglucan, unesterified HG and methyl-esterified HG epitopes labeled for weakly in the insoluble residues of fractionation $\mathrm{A}$.

The results of the immuno-cytochemical fluorescence microscopy analysis of floc sample TC3 was similar to that of $C$. jamaicense except that unesterified HG was not found present in unfractionated $\mathrm{TO} 3$, or in the insoluble residue of fractionations $\mathrm{A}$ or $\mathrm{B}$. Strong labeling of $(1,4)-\beta-D$ galactan, arabinan, xylan, xyloglucan and methyl-esterified HG epitopes were visible in detrital OM and remnant plant tissue in the unfractionated sample TC3. Microscopic images of TC3 floc showing labeling of detrital OM and plant tissue with monoclonal antibody LM11 to the xylan epitope are shown in figures 2.27- 
2.28. Weak labeling of the AGP epitope was visible in unfractionated TC3, as well as in the insoluble residue of fractionation A. The xylan epitope was shown to label weakly in the insoluble residue of fractionation $\mathrm{B}$, while it was not seen to label in the insoluble residue of fractionation A. This result was also seen in the xylan labeling of $C$. jamaicense. This suggests that much of the xylan present in $C$. jamaicense as well as TC3 was not fully exposed and able to be labeled with a monoclonal antibody within the cell wall until after expanded fractionation method B.

Table 2.3: Results of the microscopic immuno-cytochemical fluorescence analysis of unfractionated macrophyte and paired floc samples and samples after fractionation procedures A and B (insoluble residue (IR)). (+) indicates labeling and a significant amount of the polymer being tested for in a sample. $(+-)$ indicated small, concentrated areas of labeling or weak labeling of the sample being tested. $(-)$ indicates no labeling visible or labeling that was indistinguishable from auto fluorescence naturally occurring in the sample, however the polymer epitope being tested for may still be present bound tightly within the cell wall

\begin{tabular}{|c|c|c|c|c|c|c|c|}
\hline & $\begin{array}{c}\text { AGP } \\
\text { (LM2) }\end{array}$ & $\begin{array}{c}(1,4)-\beta-\mathrm{D} \\
\text { galactan } \\
(\mathrm{LM} 5)\end{array}$ & $\begin{array}{l}\text { Arabinan } \\
\text { (LM6) }\end{array}$ & $\begin{array}{c}\text { Xylan } \\
\text { (LM11) }\end{array}$ & $\begin{array}{l}\text { Xyloglucan } \\
\text { (LM15) }\end{array}$ & $\begin{array}{c}\mathrm{HG} \\
(\mathrm{LM} 19)\end{array}$ & $\begin{array}{c}\mathrm{HG} \\
(\mathrm{LM} 20)\end{array}$ \\
\hline Chara spp unfrac. & +- & +- & - & + & - & + & + \\
\hline Chara spp IR A & - & - & - & + & - & + & + \\
\hline Chara spp IR B & - & & - & +- & - & +- & +- \\
\hline EO1 unfrac. & +- & +- & - & + & + & +- & +- \\
\hline EO1 IR A & - & - & - & - & - & +- & - \\
\hline EO1 IR B & - & & - & - & - & - & - \\
\hline TO3 unfrac. & + & + & +- & + & + & - & + \\
\hline TO3 IR A & +- & + & +- & +- & - & - & + \\
\hline TO3 IR B & +- & & - & +- & - & - & - \\
\hline $\begin{array}{r}\text { T. domingensis } \\
\text { unfrac. }\end{array}$ & - & + & - & + & + & - & + \\
\hline T. domingensis IR A & - & - & - & +- & - & +- & + \\
\hline T. domingensis IR B & - & & - & + & - & - & - \\
\hline EC1 unfrac. & +- & - & +- & + & + & +- & - \\
\hline
\end{tabular}




\begin{tabular}{|c|c|c|c|c|c|c|c|}
\hline $\begin{array}{l}\text { EC1 IR A } \\
\text { EC1 IR B }\end{array}$ & $\begin{array}{l}+- \\
+-\end{array}$ & - & $\begin{array}{l}+- \\
-\end{array}$ & $\begin{array}{l}- \\
-\end{array}$ & $\begin{array}{l}- \\
-\end{array}$ & $\begin{array}{l}+- \\
-\end{array}$ & - \\
\hline $\begin{array}{r}\text { Cladium jamaicense } \\
\text { unfrac. } \\
\text { Cladium jamaicense } \\
\text { IR A } \\
\text { Cladium jamaicense } \\
\text { IR B }\end{array}$ & $\begin{array}{l}+ \\
+\end{array}$ & + & - & $\begin{array}{l}+- \\
+- \\
+\end{array}$ & $\begin{array}{l}+ \\
-\end{array}$ & + & + \\
\hline $\begin{array}{r}\text { TC3 unfrac. } \\
\text { TC3 IR A } \\
\text { TC3 IR B }\end{array}$ & $\begin{array}{l}+- \\
+- \\
-\end{array}$ & + & $\begin{array}{l}+ \\
- \\
-\end{array}$ & $\begin{array}{l}+ \\
- \\
+-\end{array}$ & $\begin{array}{l}+ \\
- \\
-\end{array}$ & $\begin{array}{l}- \\
- \\
-\end{array}$ & $\begin{array}{l}+ \\
- \\
-\end{array}$ \\
\hline
\end{tabular}
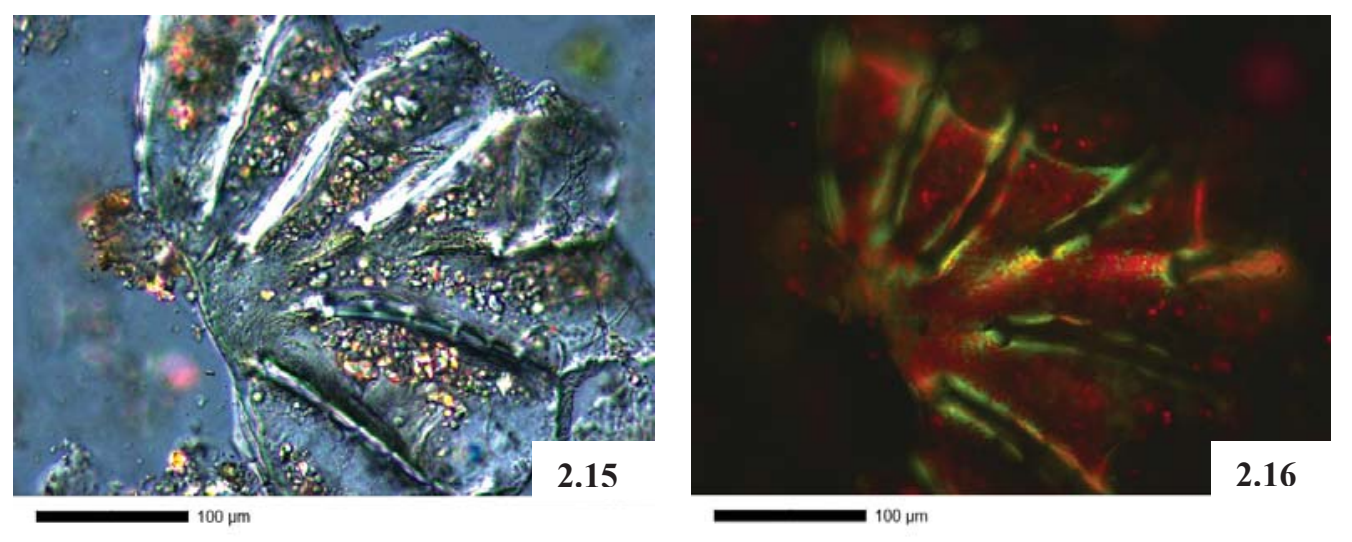

Figures 2.15 - 2.16: Microscopic images of collected Chara spp sample from WCA-2A showing the nodal region labeled with monoclonal antibody LM20 to the methyl-esterified HG epitope under normal light (figure 2.15) and under fluorescence (figure 2.16). $\quad($ Scale bar $=100 \mu \mathrm{m})$ 

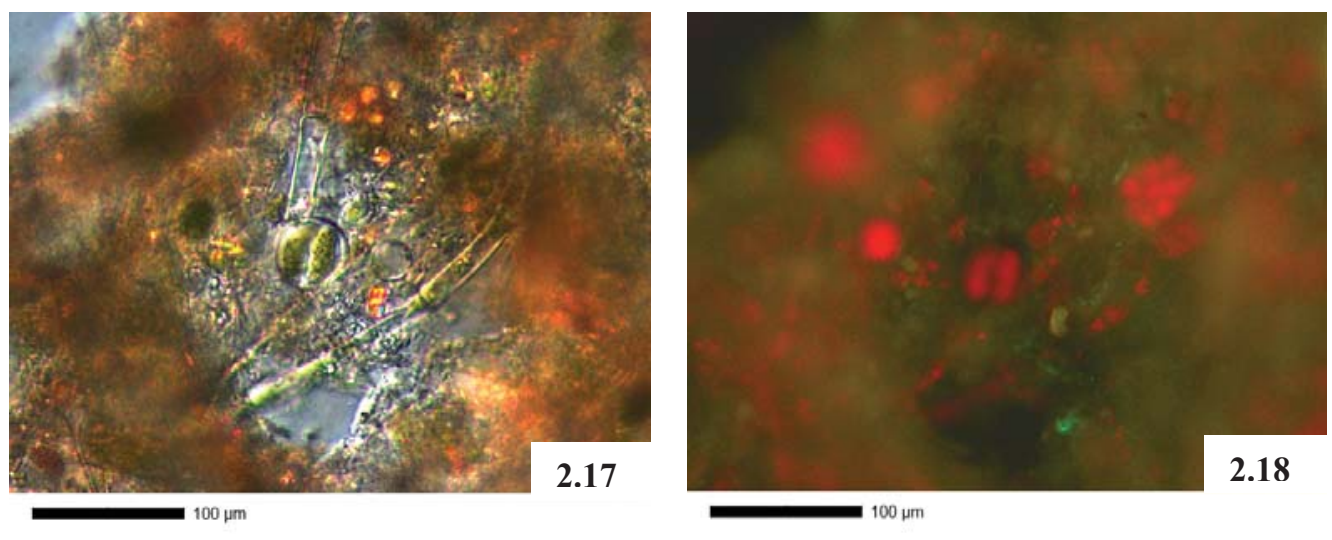

Figures 2.17 - 2.18: Microscopic images of collected EO1 floc sample from WCA-2A showing labeling of detrital OM and algal species with monoclonal antibody LM15 to the xyloglucan epitope under normal light Note - most labeling of EO1 with LM15 was seen in mucilage of microscopic algal species.(figure $2.17)$ and under fluorescence (figure 2.18). (Scale bar $=100 \mu \mathrm{m})$
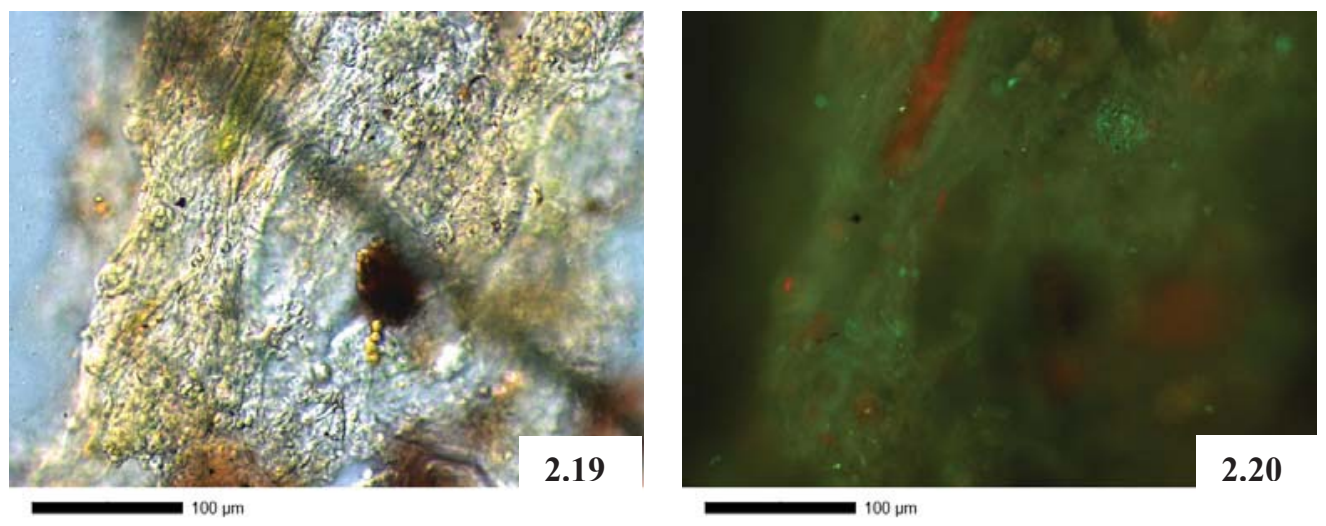

Figures 2.19 - 2.20: Microscopic images of collected TO3 floc sample from WCA-2A showing labeling of detrital OM and algal species with monoclonal antibody LM11 to the xylan epitope under normal light (figure 2.19) and under fluorescence (figure 2.20). $\quad($ Scale bar $=100 \mu \mathrm{m})$
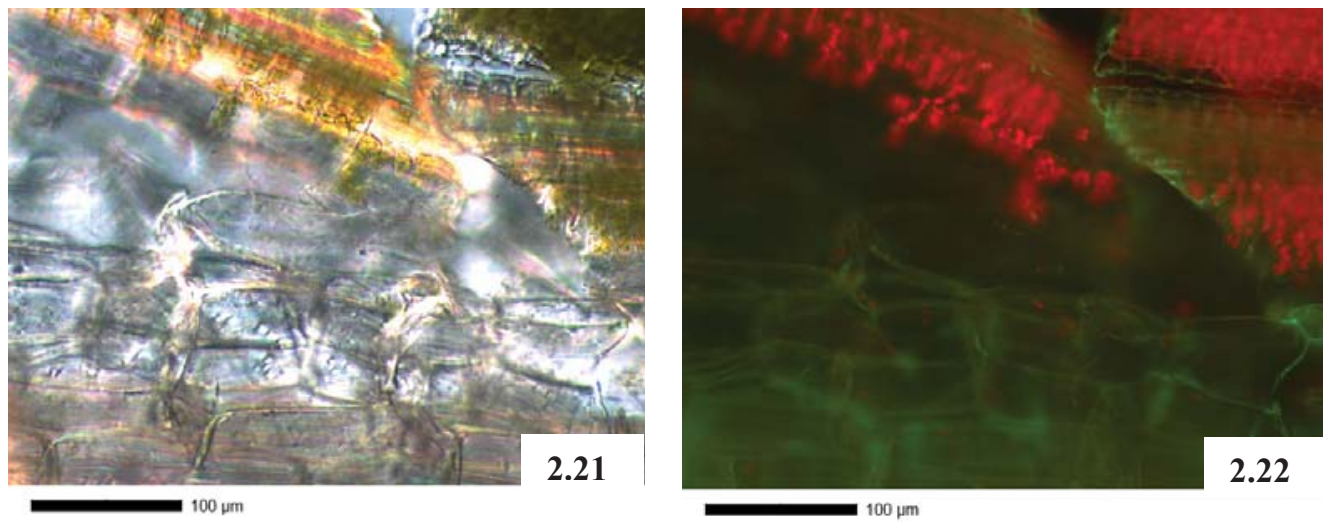
Figures 2.21 - 2.22: Microscopic images of collected T. domingensis sample from WCA-2A showing labeling of the epidermal and mesophyll cell walls with monoclonal antibody LM11 to the xylan epitope under normal light (figure 2.21) and under fluorescence (figure 2.22). (Scale bar $=100 \mu \mathrm{m})$
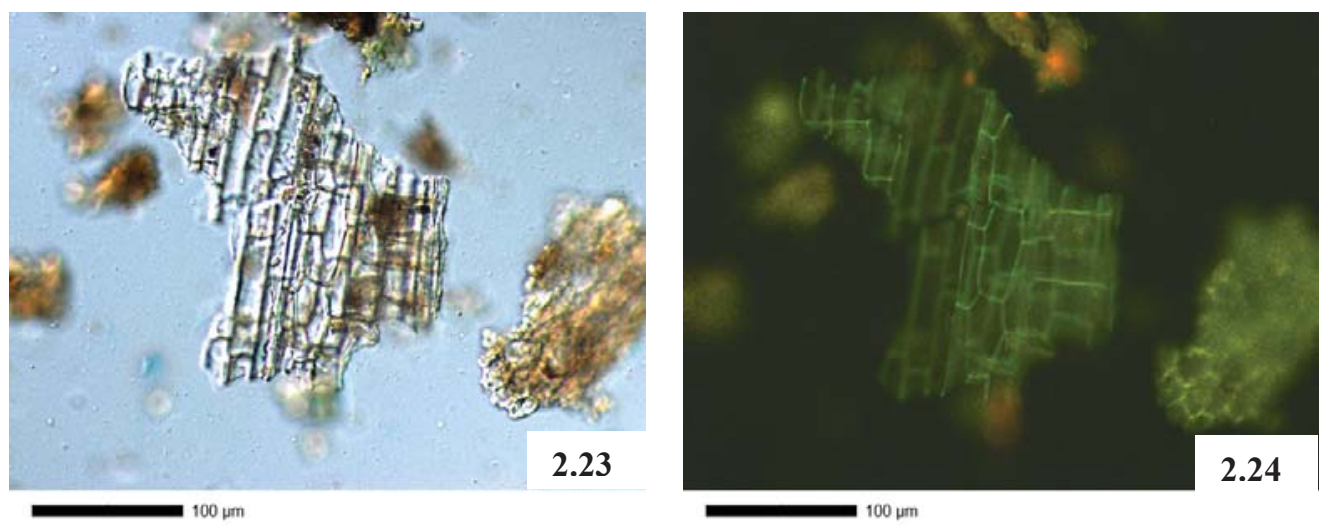

Figures 2.23 - 2.24: Microscopic images of collected EC1 floc sample from WCA-2A showing labeling of detrital OM and plant tissue with monoclonal antibody LM11 to the xylan epitope under normal light (figure 2.23) and under fluorescence (figure 2.24). (Scale bar $=100 \mu \mathrm{m})$
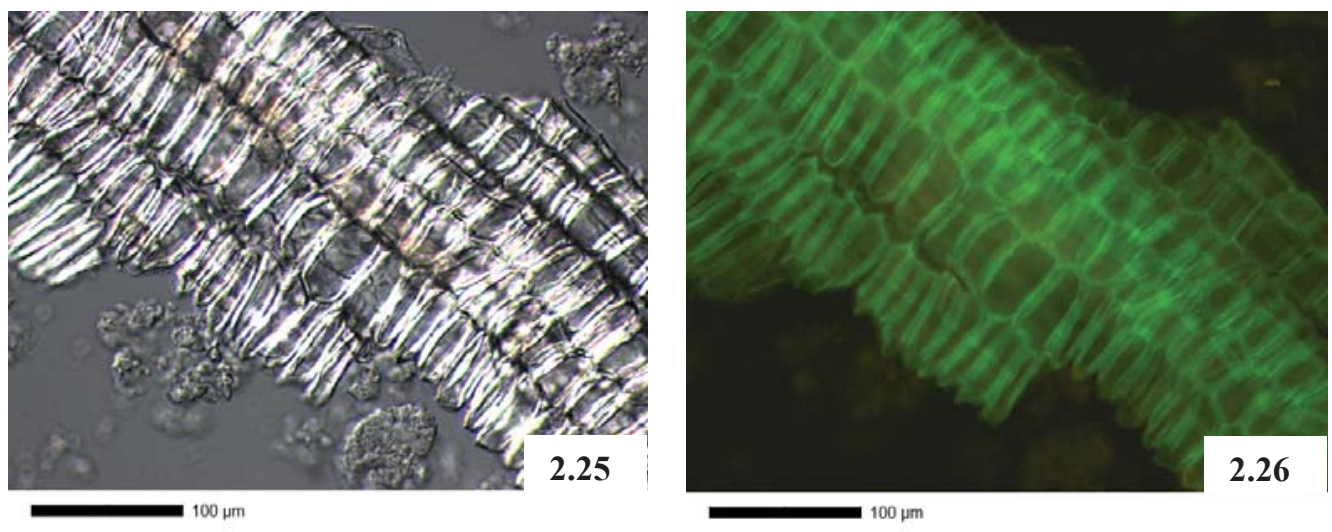

Figures 2.25 - 2.26: Microscopic images of collected Cladium jamaicense sample from WCA-2A showing labeling of the cell wall, intracellular region and cell surface with monoclonal antibody JIM5 to the unesterified HG epitope under normal light (figure 2.25) and under fluorescence (figure 2.26). (Scale bar $=100 \mu \mathrm{m}$ ) 

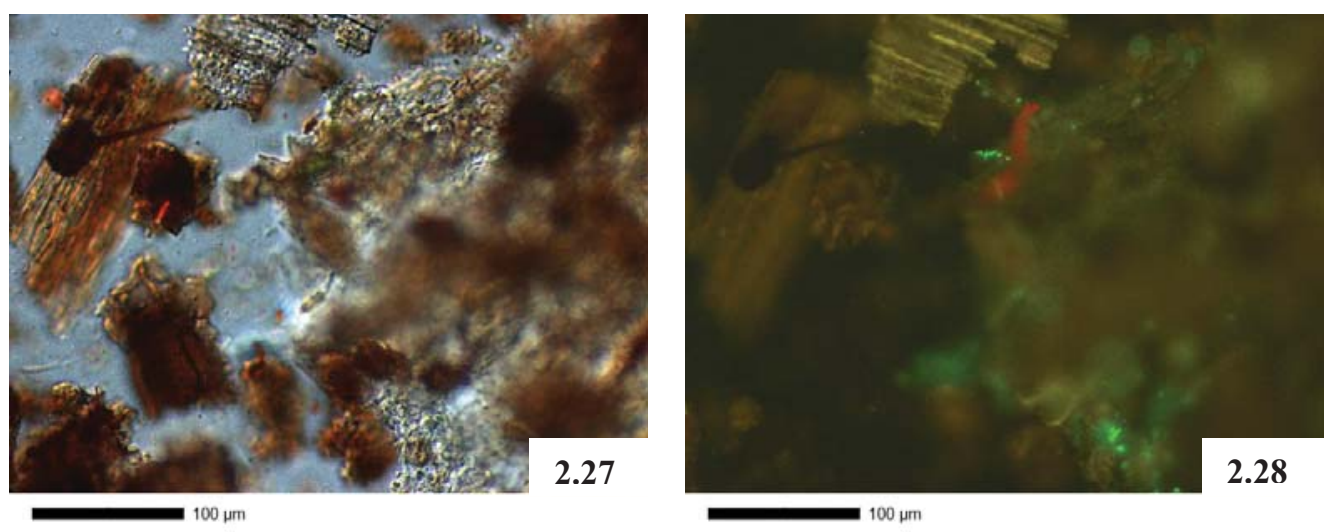

Figures 2.27 - 2.28: Microscopic images of collected TC3 floc sample from WCA-2A showing labeling of detrital OM and plant tissue with monoclonal antibody LM11 to the xylan epitope under normal light (figure 2.27) and under fluorescence (figure 2.28). (Scale bar $=100 \mu \mathrm{m}$ )

\subsubsection{Presence of $\mathrm{Ca}^{2+}$ in unfractionated samples and insoluble residues}

To indicate the presence of calcium in untreated as well as insoluble residue after fractionation A from macrophyte and floc samples, samples were labeled with the calcium indicating probe Fura-2 AM. The results of this analysis are shown in table 2.4. Select images are shown below as well in figures $2.28-2.33$. In the unfractionated Chara spp sample as well as the post-fractionation A insoluble residue, strong, ubiquitous labeling of calcium was observed on the cell surface. This suggests that the calcite encrustations present on the cell surface of the Chara spp sample was not fully removed after fractionation A. In the unfractionated samples EO1 and TO3 (paired floc samples to Chara spp), ubiquitous labeling of detritus was observed while in the post-fractionation A insoluble residues, no labeling was visible. This suggests that fractionation method A removed the calcium present in the EO1 and TO3 floc samples. In the T. domingensis sample, there was some minor calcium labeling evident in the intracellular regions and vascular region. There was no labeling evident in T. domingensis post-fractionation A 
insoluble residue. In the paired floc sample to $T$. domingensis, EC1, weak, ubiquitous labeling of the detritus was visible. No calcium labeling was observed in the postfractionation A insoluble residue of floc sample EC1. In the unfractionated Cladium jamaicense sample, calcium labeling was visible on the cell wall surface as well as the intracellular regions. In the TC3 floc sample (paired floc sample to $C$. jamaicense), small concentrated areas of weak labeling were visible, and no labeling was visible in the postfractionation A insoluble residue.

Table 2.4: Fura-2 AM Immuno-fluorescence labeling of calcium in unfractionated and insoluble residue (post-fractionation A) of macrophyte and paired floc samples. (+) indicates labeling and a significant amount of the polymer being tested for in a sample. $(+-)$ indicated small, concentrated areas of labeling or weak labeling of the sample being tested. (-) indicates no labeling visible or labeling indistinguishable from auto fluorescence naturally occurring in the sample.

\begin{tabular}{|rc|}
\hline & $\begin{array}{c}\text { Calcium } \\
\text { (Fura-2 AM) }\end{array}$ \\
Chara spp unfractionated & + \\
Chara spp residue A & + \\
EO1 unfractionated & + \\
EO1 residue A & - \\
TO3 unfractionated & + \\
TO3 residue A & - \\
T. domingensis unfractionated & +- \\
T. domingensis residue A & - \\
EC1 unfractionated & +- \\
EC1 residue A & - \\
Cladium jamaicense unfractionated & +- \\
Cladium jamaicense residue A & - \\
TC3 unfractionated & +- \\
TC3 residue A & - \\
\hline
\end{tabular}



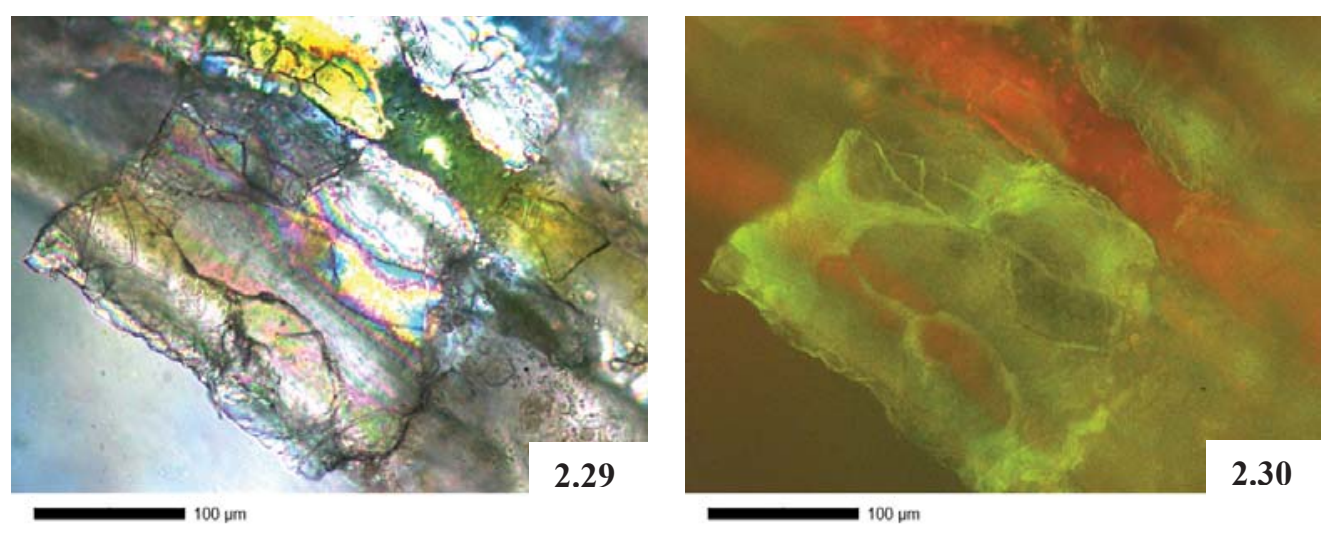

Figures 2.29 - 2.30: Microscopic images of unfractionated Chara spp sample from WCA-2A showing labeling of calcium on the cell surface with Fura-2 AM under normal light (figure 2.29) and under fluorescence (figure 2.30). (Scale bar $=100 \mu \mathrm{m})$
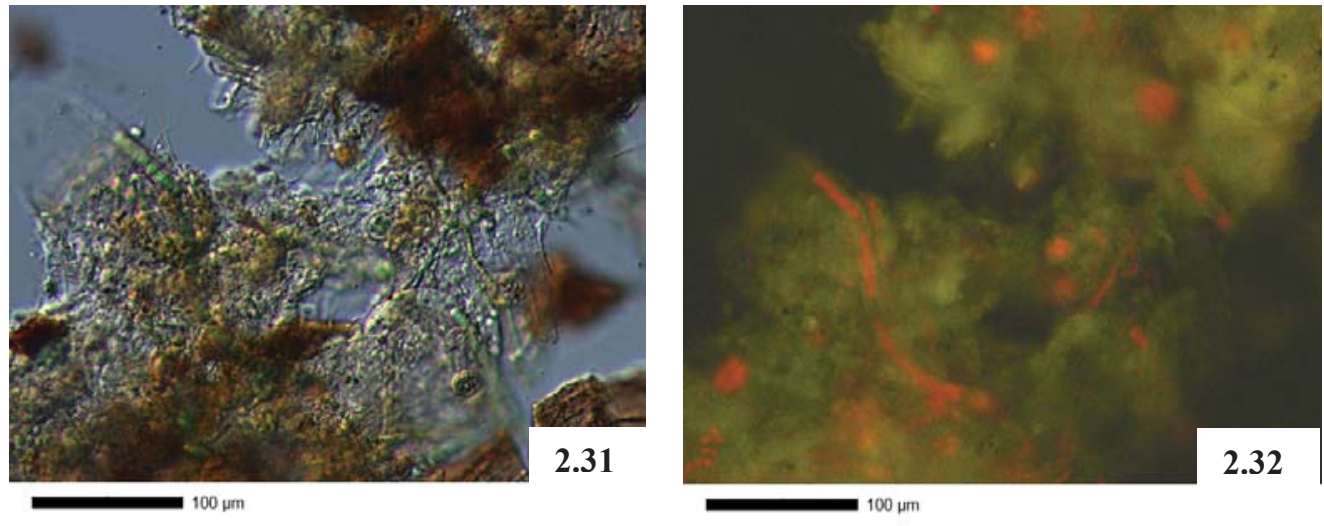

Figures 2.31 - 2.32: Microscopic images of unfractionated TO3 floc sample (paired floc sample to Chara spp) from WCA-2A showing ubiquitous labeling of calcium in detritus with Fura-2 AM under normal light (figure 2.31) and under fluorescence (figure 2.32). (Scale bar $=100 \mu \mathrm{m})$ 

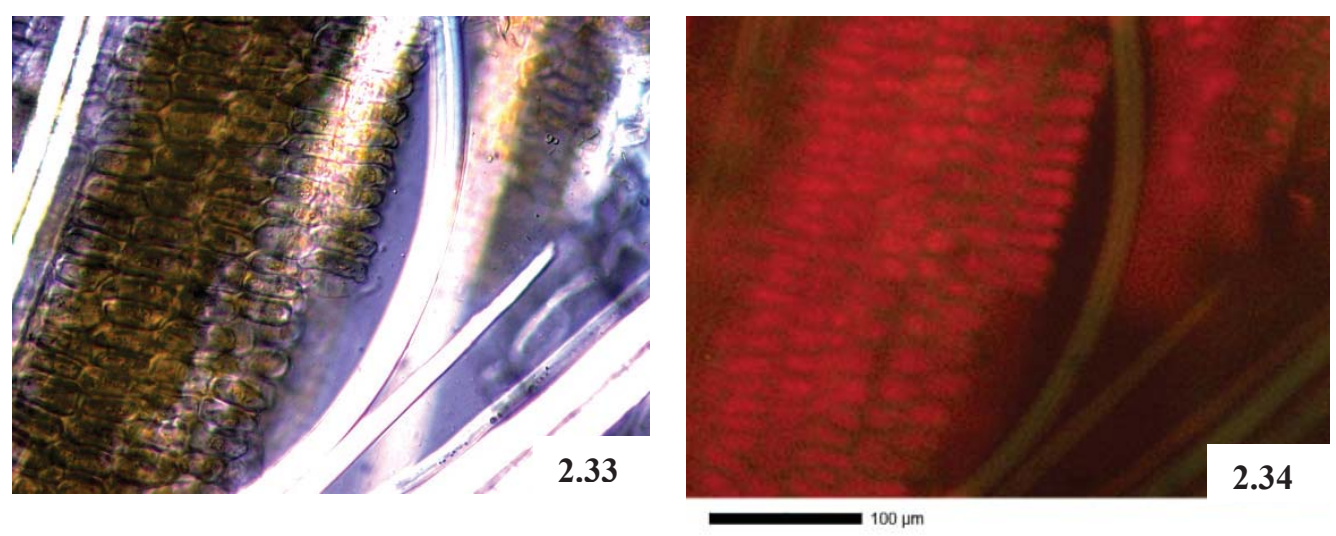

Figures 2.33 - 2.34: Microscopic images of Cladium jamaicense residue (post-fractionation A) showing no labeling of calcium with Fura-2 AM under normal light (figure 2.33) and under fluorescence (figure 2.34). $($ Scale bar $=100 \mu \mathrm{m})$

\subsection{Discussion}

\subsubsection{Visualization and polysaccharide profile of macrophytes and paired floc}

Initial visualization of the floc samples also showed the changes to OM and algal communities that occurred with the shift from emergent to submersed aquatic vegetation. While control floc samples contained vascular plant tissue, some types of filamentous green algae and diatoms, open plot floc contained OM, species of cyanobacteria, as well as filamentous and desmid species. Chara spp reproductive structures were also visible in open plot floc samples indicating the presence of remnant Chara spp tissues.

Due to this shift in floc composition, alterations to the substrate polysaccharide profiles were also seen. Plant cell wall polymers such as cellulose and hemicelluloses are bound to lignin and structural proteins making cellulose and hemicelluloses less available 
to degrading enzymes (Fry, 2000; Cosgrove, 2005), as well as less susceptible to enzymatic hydrolysis due to their crystalline nature. In aquatic and terrestrial systems lignocellulosic compounds are degraded mostly by certain types of fungi (basidiomycota and some ascomycota). These types of fungi use hyphal growth to enter the pores of the cell wall and deliver cellulases closer to the cellulose complexes enabling degradation (Boer et al. 2004; Chameir, 1985). Our findings show a greater hemicellulose content in Chara spp and paired floc sample EO1 (and to a lesser extent TO3) in the HW and 1M $\mathrm{KOH}$ soluble fractions relative to the emergent macrophytes and control plots. A greater hemicellulose content was observed in the $4 \mathrm{M} \mathrm{KOH}$ soluble fraction of the emergent macrophytes and control floc samples with $T$. domingensis and EC1 being highest. This indicates that there is a greater amount of labile hemicellulosic polymers associated with Chara spp and open plot floc samples relative to the emergent macrophytes and control plot floc samples. Hemicelluloses in emergent macrophytes are likely bound to lignin and structural polymers and thus harder to remove making them less available to fungal and bacterial degradation. This is reflected in the control floc samples as well. In a recent study on bacterial and fungal contents of floc material from WCA-2A (Bellinger et al., 2012), it was found that the mean gram-positive and gram-negative bacteria as well as the fungi contents (from 2007-2009) for the floc in open water plots (EO and TO) were significantly higher than the floc in control plots (EC and TC) with the enriched plot floc (EO) having a greater content than the transitional plot floc. This indicates a greater amount of microbial activity occurring in created open areas. Because of this coupled with the greater labile polysaccharide content of the floc, there is a greater potential for 
microbial OM processing in the open water plots compared to the control plots. This leads to the conclusion that due to the shifting plant community in created open water plots, the polysaccharide profile of the floc layers has been effected and in turn has caused a shift in the microbial community and functions including an increased microbial abundance, decomposition and turnover rates).

\subsubsection{Biomarkers for macrophyte and paired floc sample differentiation}

There were several monoclonal antibodies used in this study that would be useful to differentiate floc and determine the dominant macrophyte in each plot. While AGP has been found in the cell walls of land plants as well as some charophytes (Popper, 2008; Cassab, 1998), it was not found to be present in Chara spp, and was only found present in small amounts in the $\mathrm{NaOH}$ soluble fraction (A) of EO1 and in the insoluble residue of TO3. It was however found to be present in several fractions of T. domingensis, Cladium jamaicense and control floc samples in fractionations A and B. AGP is thought to play a role in growth and development at the cell surface. AGP occurs in many structures of the land plant including leaves, stems, roots and flowering tissues (Showalter, 2001). This may be why AGP was found in several fractions of the emergent macrophytes and control floc samples. One type of AGP consists of repeating $(1,4)-\beta-D$ galactan units and is associated with pectins. This may also be a good biomarker to distinguish macrophytes and associated floc from one another as again, it was present in several fractions of $T$. domingensis, $C$. jamaicense and control floc samples in fractionations A and B but not in any fractions of Chara spp or open water floc samples (except in the 
insoluble residue of TO3). The presence of AGP and $(1,4)-\beta-\mathrm{D}$ galactan in TO3 may be an indication of some residual emergent plant tissue in the floc layer.

The monoclonal antibody to xylan labeled ubiquitously in the macrophytes and paired floc samples and therefore would not be useful in differentiating between samples when using dot blot analysis. Xylan is a highly variable hemicellulosic polymer which acts as a structural polymer in some species (likely the case for Chara spp). The greater (almost $67 \%$ ) $4 \mathrm{M} \mathrm{KOH}$ fraction of $T$. domingensis relative to the other macrophytes indicates that the xylan and xyloglucan found in this fraction are likely tightly associated with the cellulose in the cell wall and indicate an advantage in efficiency and growth ability where water is a limiting factor (Fry, 2000; Popper, 2008). This is especially advantageous to $T$. domingensis growth in the everglades where hydrology can be highly variable due to water control structures and varying hydrologic patterns (Sklar et al., 2008-2013). In a study by Newman et al. in 1998, it was found that $T$. domingensis in WCA-2A as well as another impacted Everglades region (Hoely Land) were able to increase exponentially in area as well as density over the years of 1990-1994 even with water depth varying from less than $0.2 \mathrm{~m}$ (in an especially dry period to over $4.0 \mathrm{~m} . T$. domingensis is able to thrive in high water depths where other species (such as Cladium jamaicense) are likely to drown as well as continue to grow in low water depths as well (Newman et al., 1998)

The monoclonal antibody to unesterified HG was useful in differentiating between Chara spp and emergent macrophytes. The unesterified HG appeared tightly bound in Chara spp with removal possible by treatment with CDTA, while the emergent 
macrophytes showed strong labeling with removal through treatment with hot water as well as CDTA. Unesterified HG appeared to be lost through environmental degradation prior to collection in all floc samples which was expected since $\mathrm{HG}$ is often removed with water (Fry, 2000).

While calcium is important to all plants for particular biochemical processes, it is not usually associated with the plant cell wall as in the charophytes (Hutchinson, 1957; Siong \& Asaeda, 2006). In a 2006 study, it was shown that calcite encrustation on charophytes enhanced the P stored in the plant biomass and increased the potential nutrient sink for P (Siong \& Asaeda, 2006). Our results showed strong $\mathrm{Ca}^{2+}$ labeling in Chara spp as well as unfractionated open water floc samples while only spots of slight $\mathrm{Ca}^{2+}$ labeling in emergent macrophytes and control floc samples. This indicates that $\mathrm{Ca}^{2+}$ associated with Chara spp cell walls can be precipitated into floc OM making calcium a viable biomarker for differentiating Chara spp dominated floc and emergent macrophyte dominated floc. An investigation into the effect of Ca-bound $\mathrm{P}$ on floc will be discussed in chapter 3 .

\subsubsection{Comparison of two methods of cell wall fractionation}

There are both advantages and disadvantages to the two fractionation methods that were used in this study. Fractionation method A is a quicker, more cost-effective fractionation method which may be useful as a preliminary method to distinguish collected macrophyte or floc samples, while fractionation method B may give a more detailed and accurate idea of the polymer content of a given sample. Fractionation 
method A may also be more useful in fractionating floc samples rather than untreated macrophyte samples, as polysaccharides contained in the cell walls of the OM of floc are more liable to removal due to degradation from various environmental sources previous to collection (Webster \& Benfield, 1986). This is shown by the insoluble residue data. The individual polysaccharide analysis shows that fractionation method A removes the polysaccharide being tested for in most of the floc samples (as it is no longer present in the insoluble residue after being fractionated), but many times fractionation method A did not remove the individual polysaccharide being tested for in macrophyte samples. Another disadvantage to using only fractionation method A for polysaccharide analysis is that since there are only $\mathrm{HW}$ and $\mathrm{NaOH}$ fractions, polysaccharides that are not soluble in only $\mathrm{HW}$ or $\mathrm{NaOH}$ will end up in the insoluble residue. Also, since there is no defatting agent included in fractionation method A, non-cell wall components of the sample may end up in insoluble residue. Fractionation method B solves this problem by treating samples with $\mathrm{MeKOH}$ and $\mathrm{DMSO}$ at the beginning of the fractionation which removes amino acids, many organic acids and organic salts as well as starches leaving behind isolated cell walls. HW is again used after the defatting agents which removes pectins including homogalacturonans, rhamnogalacturonans I and II, galactans, arabinans and other polysaccharides (Fry, 2000; Cosgrove, 2005). Treatment with CDTA was also utilized in fractionation method $\mathrm{B}$, which was expected to remove pectic polysaccharides and remaining $\mathrm{Ca}^{2+}$. Finally, treatment with varying strengths of alkali was used to remove alkali soluble pectins and hemicelluloses (Fry, 2000). 


\section{Chapter 3: Chemical analysis of Everglades macrophytes and} paired floc ${ }^{2}$

\subsection{Abstract}

Increases in phosphorous input from urban and agricultural sources, in wetland areas have not only an impact on the aquatic vegetation, but also on detrital flocculent (floc) layers. This in turn may impact complex floc microbial communities which govern much of the nutrient cycling in wetland systems. After two methods of sequential fractionation, the chemical profiles of the dominant macrophytes and paired floc samples of WCA-2A were investigated to gain further insight into how the shift in the dominant aquatic vegetation of WCA-2A may be effecting the chemical profile of floc layers.

The chemical analysis of the samples (post-fractionation methods A and B) showed greater labile carbohydrate and uronic acid content in floc from created open water areas and was correlated with the dominant macrophyte Chara spp.

The results of the chemical profiles from fractionations B showed that Chara spp and paired floc sample EO1 and TO3 contain more easily extractable, carbohydrate-rich polymers. Similarities among the chemical profiles of the four floc samples indicated common macrophyte contributions as well. The greater amount of tightly bound xyloglucan and xylan in the $4 \mathrm{M} \mathrm{KOH}$ fraction of Typha domingensis relative to the other macrophytes indicated an advantage in areas where water may be a limiting factor. Floc

\footnotetext{
${ }^{2}$ The material contained in this chapter is intended to be submitted for publication.
} 
samples, had less carbohydrate, uronic acid and ester sulfate content than the macrophytes due to environmental and microbial degradation prior to collection.

The phosphorus $(\mathrm{P})$ content of the macrophytes and floc samples indicated that Chara spp is contributing a greater amount of Ca-bound $\mathrm{P}$ to floc layers in the open water plots while these plots have a lesser labile P content than the transitional plots. Floc layers reflect the $\mathrm{P}$ contributions of the dominant macrophytes in each study plot, also may be acting as a nutrient source and sink for P. Overall, the results indicated that the creation of open water areas has caused alterations to floc chemical composition, labile and $\mathrm{Ca}$-bound $\mathrm{P}$ and thus probable alterations to nutrient availability and substrate quality due to shifts in vegetation.

\subsection{Introduction}

High levels of nutrient loading from surrounding agricultural areas have resulted in a shift in the plant communities of WCA-2A which resulted in the encroachment of cattails (T. domingensis) into areas that had previously been a ridge and slough landscape populated by native sawgrass (Cladium jamaicense) stands (Davis et al. 1991; Chapters 1 and 2). In order to study ecological management solutions in this area which could be applied to other areas as well, the Cattail Habitat Improvement Project (CHIP) was formed. Fifteen 6.5 ha plots were used to test different methods for controlling the encroachment of cattail as well as ecological restoration. Through burn regimens and the application of herbicide, large open water areas were then formed which then grew populated with SAV such as Chara spp as the dominant macrophyte (Sklar et al., 2008- 
2013). There is little known about how this development will affect the chemical composition of the detrital OM in these study plots. Chapter 2 investigated the polymer and ionic profiles of Chara spp, T. domingensis and Cladium jamaicense and their contributions to detrital floc in the study plots in which they are the dominant macrophytes. In this chapter, I will focus on the chemical analysis and loosely bound phosphorous contribution of the cell walls of submersed (Chara spp) and emergent (T. domingensis and $C$. jamaicense) vegetation and from the floc from the study plots.

Detrital floc is not only an important part of the food chain for aquatic animals; it also supports many algal, fungal and bacterial communities (Webster \& Benfield, 1986; Bellinger et al., 2012). Floc is composed of dead OM and cellular tissue and polymers from plants and algae. Alterations in the chemical composition of floc can thus alter community assemblages as well as food webs. Floc contributes to sediment and peat nutrient accumulation as well, therefore changes in P-binding (due to shifts in plant communities) will alter accumulation rates in sediment and peat derived from emergent or submersed plants (Debusk \& Reddy, 1998; Neto et al., 2006).

The process of detrital floc decomposition leaves cell wall polysaccharides of plant and algal tissues intact (Webster \& Benfield, 1986). Therefore, cell wall composition is an excellent way of investigating floc material in relation to macrophytes. Several major cell wall chemical components were investigated in this study including ester-sulfates, uronic acids and carbohydrates. Uronic acid and ester sulfates are often found associated with the polymers and proteoglycans (heavily glycosylated proteins) outside the cell wall that form the extracellular matrix. The extracellular matrix aids in protection against 
predation and desiccation as well as adhesion, concentrating nutrients and regulating ions at the cell surface (Fazio et al. 1982). Uronic acid is also found in the polysaccharide polymers of higher plant cell walls. In grasses uronic acids are found in two major polysaccharides; the hemicellulosic glucuronoarabinoxylans and galactosyluronic acid rich pectin (Kim \& Carpita, 1992). Galacturonic acid also occurs in the backbone of many major domains of pectins including homogalacturonans, rhamnogalacturonans I and II and xylogalacturonans. Homogalacturonans are also known as polygalacturonic acids. These are thought to be present in all plant species and contribute to cell wall flexibility, expansion, adhesion and porosity (Willats et al. 1998). Because of their negative ionic charge, they may form $\mathrm{Ca} 2+$ crosslinking which forms a stiff gel. If the homogalacturonans are esterified however, they will not form stiff gels and may be helpful in keeping a cell flexible during cell growth. In order to investigate the chemical profile of floc samples and emergent and submersed macrophytes colormetric assays including the total $\%$ Ester sulfate, total $\%$ carbohydrate, total $\%$ uronic acid were utilized.

Plant and algal cell walls are also rich in carbohydrates. The main groups of carbohydrates present in the primary cell wall are celluloses, hemicelluloses and pectins. Cellulose is the most abundant polymer on earth as well as an important cell wall structural component in plants and most algae (Cosgrove, 2005). Hemicelluloses are important in maintaining a structural matrix that aids in cell wall growth and expansion (Marcus at al. 2008). Pectins also contribute to cell wall growth and expansion in 
addition to flexibility, adhesion, cell wall porosity, signaling and ionic control of the cell surface (Willats et al. 1998).

Calcite associated with the cell walls of Chara also allows phosphorous (P) to bind to it as well which may then reduce the bioavailability of $\mathrm{P}$ (Hutchinson, 1975). One study found that the calcification of the cell walls of Chara enhanced it as a nutrient sink for $\mathrm{P}$ which in turn caused bottom up control in phytoplankton (Siong \& Asaeda, 2006). A goal of this study was to gain insight into how the presence of Chara spp in WCA-2A may be affecting the $\mathrm{P}$ content of the associated floc layers by quantifying Ca-bound $\mathrm{P}$ present in the emergent and submersed macrophytes and floc samples from their paired study sites. In order to do this, the molybdenum blue method for P determination was used.

\subsection{Methods}

\subsubsection{Sample collection (as described in chapter 2)}

Sample collection was carried out in study plots EC1, which contain monotypic stands of $T$. domingensis, plot TC3 which contain a mix of $T$. domingensis and Cladium jamaicense, and paired treatment plots $\mathrm{EO} 1$ and $\mathrm{TO} 3$ which have been maintained as open water and are now dominated by Chara spp. The pourable floc samples were collected from above the consolidated sediments. Stems of T. domingensis and Cladium jamaicense were collected by random grab sampling of 5-7 stems in EC1 and TC3, respectively. Chara spp was also collected by random grab sampling from plots EO1 and 
TO3. Sample collection was performed by the SFWMD during the Summer (June) during peak growing season of 2010.

\subsubsection{Isolation and sequential extraction of the cell wall polymers (as} described in chapter 2)

Two methods were used to isolate the cell walls and soluble fractions of samples received from Florida, modified from methods from Fry (2000). Fractionation method A is a simple fractionation method used to create a $\mathrm{HW}$ soluble, $\mathrm{NaOH}$ soluble and insoluble residue fraction used for a relatively quick comparison of macrophytes and paired floc layers, while Fractionation B is a more thorough fractionation.

Fractionation Method A: This fractionation was performed by the SFWMD in June of 2010. In brief, approximately $1 \mathrm{~g}$ (dry weight) of sample was ground under liquid nitrogen. Distilled water was added and the sample was then placed in a $95^{\circ} \mathrm{C}$ water bath for 1 hour. The sample was cooled and the supernatant was collected. This step was repeated two more times. The collected supernatant was the HW soluble fraction. The supernatant was then dialyzed, and freeze-dried. The resulting pellet was then treated with $6 \mathrm{M} \mathrm{NaOH}$ for 1 hour at $21^{\circ} \mathrm{C}$ three times. The resulting supernatant was then collected, dialyzed and freeze-dried. This was the $\mathrm{NaOH}$ (alkali) soluble fraction. The insoluble pellet was then washed extensively with water until neutral and then freeze-dried. The resulting pellet was the insoluble residue fraction.

Fractionation Method B: Untreated, freeze-dried samples were ground to a fine powder. To clean and isolate the cell wall of samples, they were defatted using 
methanolic $\mathrm{KOH}(\mathrm{MeKOH}) . \mathrm{MeKOH}$ was added approximately $0.5 \mathrm{~g}$ (dry weight) of sample and placed in a $90^{\circ} \mathrm{C}$ water bath for 15 minutes. This step was repeated three times, the resulting pellet was then washed extensively with distilled water until neutral. The pellet was then suspended in a solution of $90 \%$ DMSO in ethanol for approximately 16 hours at $25^{\circ} \mathrm{C}$. The supernatant was collected (this was the DMSO soluble fraction) and the resulting pellet was washed extensively with distilled water. The pellet was then suspended in 50mM CDTA solution ( $\mathrm{pH}$ adjusted to 7.5) this was then stirred for approximately 6 hours at $21^{\circ} \mathrm{C}$, and the supernatant was collected (This was the CDTA soluble fraction). This step was repeated two times. The pellet was then washed extensively with distilled water. The resulting pellet was then re-suspended in $0.05 \mathrm{M}$ $\mathrm{Na}_{2} \mathrm{CO}_{3} / 20 \mathrm{mM} \mathrm{NaBH}_{4}$ solution and left to sit in a $1^{\circ} \mathrm{C}$ ice bath for approximately 16 hours. The supernatant was then collected (this was the $\mathrm{Na}_{2} \mathrm{CO}_{3}$ soluble fraction). Please note that the $\mathrm{Na}_{2} \mathrm{CO}_{3}$ soluble fractions of floc samples $\mathrm{TO} 3$ and $\mathrm{TC} 1$ will not be discussed as there were not enough of these fractions recovered for investigation into chemical content. The resulting pellet was then washed extensively and then re-suspended in $1 \mathrm{M}$ $\mathrm{KOH} / 20 \mathrm{mM} \mathrm{NaBH}_{4}$ solution in a $1^{\circ} \mathrm{C}$ ice bath for 2 hours. This step was repeated two times, the supernatant was collected (this was the $1 \mathrm{M} \mathrm{KOH}$ soluble fraction). The resulting pellet was then suspended in $4 \mathrm{M} \mathrm{KOH} / 20 \mathrm{mM} \mathrm{NaBH}_{4}$ solution in a $1^{\circ} \mathrm{C}$ ice bath for 2 hours. This step was repeated two times, the supernatant was collected (this was the 4M KOH soluble fraction). The resulting pellet was washed extensively with distilled water and acetic acid until neutral. The pellet was then freeze-dried (this was the insoluble residue). All soluble fractions were then neutralized to $\mathrm{pH}$ 6-7, dialyzed against 
distilled water (CDTA soluble fraction was dialyzed against $0.5 \mathrm{M}$ imidazole) for approximately 72 hours at $3-5^{\circ} \mathrm{C}$, then freeze-dried.

\subsubsection{Assay for total ester sulfate concentration}

Ester sulfates were detected with methods from Craigie et al. (1984) for samples from fractionation A. A standard curve is generated with potassium sulfate as the standard. All glassware was acid washed in $\mathrm{HCl} .500 \mu \mathrm{g}$ of sample was weighed out using a Cahn C-30 microbalance with a minimum of 4 replicates for each sample. Samples were hydrolyzed with $\mathrm{HCl}\left(5: 1\right.$ in $95 \%$ ethanol) for 2 hours at $100^{\circ} \mathrm{C}$. Hydrolyzed sample is diluted and an aliquot is combined with $0.5 \mathrm{M} \mathrm{HCl}$ and $\mathrm{BaCl}_{2}$ gelatin. The absorbance was read at 550nm using a UV-1201 UV-VIS Spectrophotometer (Shimadzu Scientific Instruments, Inc.).

\subsubsection{Carbazole assay for total uronic acid concentration}

This method for determining the total uronic acid content was measured using the carbazole assay (Bitter \& Muir, 1962). Briefly, the samples were mixed with carbazole reagent $\left(\mathrm{Na}_{2} \mathrm{~B}_{4} \mathrm{O} 7\right.$ and concentrated $\left.\mathrm{H}_{2} \mathrm{SO}_{4}\right)$, allowed to develop and then the absorbance of each was read at 530nm using a UV-1201 UV-VIS Spectrophotometer (Shimadzu Scientific Instruments, Inc.). Glucuronic acid was used to create a standard curve. 


\subsubsection{Phenol-sulfuric assay for total carbohydrate concentration}

Total carbohydrate content was found using the phenol/sulfuric acid assay

outlined by Dubois et al. (1956). The sample was suspended in water and combined with phenol and $\mathrm{H} 2 \mathrm{SO} 4$. The samples were allowed to develop and the absorbance was read at $490 \mathrm{~nm}$ using a UV-1201 UV-VIS Spectrophotometer (Shimadzu Scientific Instruments, Inc.). Glucose was used to create a standard curve.

\subsubsection{Molybdenum blue method for determination of phosphorus}

The P content was determined by using the Molybdenum Blue method as described by Jones (2001). In brief, samples were sequentially extracted with HW to obtain the $\mathrm{HW}$ soluble $\mathrm{P}, \mathrm{NaOH}$ to obtain the organic and Ca-bound $\mathrm{P}$ and concentrated HC1 to obtain the remaining Ca-bound P via methods found in Dou et al. (2000). The sample was then combined with working solution which contained ascorbic acid solution (ascorbic acid and distilled water), sulfuric molybdate solution (ammonium molybdate, antimony potassium tartrate, distilled water and concentrated $\mathrm{H}_{2} \mathrm{SO}_{4}$ ). The sample was then allowed to develop for 20 minutes and the absorbance was read at $880 \mathrm{~nm}$ using a UV-1201 UV-VIS Spectrophotometer (Shimadzu Scientific Instruments, Inc.). Potassium dihydrogen orthophosphate $\left(\mathrm{KH}_{2} \mathrm{PO}_{4}\right)$ was used to create a standard curve. It must be noted that WCA-2A is not a static system and the P content of the macrophytes and floc samples may vary throughout the season. This method of average P content determination is intended to be a snapshot for the comparison of macrophytes and paired floc samples for June of 2010. 
A summary of surface water chemistry from 2007-2009 (table 3.1) was obtained from Chapter 6 of the South Florida Environmental Report (Sklar et al; 2008-2010).

Table 3.1: Mean (standard deviation) of chemical environment of surface water of study plots EC, EO, TC and TO as measured in Jan. 2007, Oct. 2008 and Oct. 2009 for dissolved oxygen content (DO), temperature, $\mathrm{pH}$ and floc total phosphorus (TP) $(\mathrm{n}=3)$. Data obtained from Sklar et al., 2008-2010.

\begin{tabular}{lllll}
\hline Winter 2007 & EC & EO & TC & TO \\
\hline Mean DO $(\mathrm{mg} / \mathrm{L})$ & $1.0(0.36)$ & $1.6(0.99)$ & $1.1(0.13)$ & $1.8(0.84)$ \\
Mean temp. $\left({ }^{\circ} \mathrm{C}\right)$ & $25(0.2)$ & $31(3.3)$ & $27(0.06)$ & $29(2.1)$ \\
Mean pH & $7.39(0.14)$ & $7.46(0.03)$ & $7.47(0.10)$ & $7.59(0.16)$ \\
Mean TP $(\mathrm{mg} / \mathrm{kg})$ & $380(0)$ & $1550(55)$ & $260(4)$ & $560(130)$ \\
\hline & & & & \\
Fall 2008 & EC & EO & TC & TO \\
Mean DO $(\mathrm{mg} / \mathrm{L})$ & $1.6(0.4)$ & $5.2(0.3)$ & $1.8(.04)$ & $7.5(1.3)$ \\
Mean temp. $\left({ }^{\circ} \mathrm{C}\right)$ & $19.1(0.2)$ & $19.7(0.1)$ & $19.7(0.2)$ & $19.1(1.4)$ \\
Mean pH & $7.1(0.1)$ & $7.5(0.1)$ & $7.2(0.1)$ & $7.6(0.3)$ \\
Mean TP $(\mathrm{mg} / \mathrm{kg})$ & $1160(15)$ & $1717(160)$ & $1384(378)$ & $1223(87)$ \\
& & & & TC \\
Fall 2009 & EC & EO & TC & $4.2(3.1)$ \\
Mean DO $(\mathrm{mg} / \mathrm{L})$ & $1.4(1.0)$ & $3.9(3.6)$ & $1.9(1.3)$ & $23.6(5.2)$ \\
Mean temp. $\left({ }^{\circ} \mathrm{C}\right)$ & $22.3(4.9)$ & $23.7(5.1)$ & $22.8(5.1)$ & $7.5(0.3)$ \\
Mean pH & $7.4(0.4)$ & $7.7(0.4)$ & $7.2(0.2)$ & \\
Mean TP $(\mathrm{mg} / \mathrm{kg})$ & & & & \\
\hline & &
\end{tabular}

\subsection{Results}

\subsubsection{Chemical content of fractionation A samples}

The total uronic acid content, carbohydrate concentration, and ester sulfate content are shown below in figure 3.1. In general, the macrophytes tended to show greater concentrations of carbohydrates and uronic acid than in paired floc samples, 
except in the HW soluble fraction of Cladium jamaicense where the uronic acid content was slightly less than in the TC3 HW soluble fraction. The ester sulfate content of the samples was similar in each macrophyte and paired floc sample. The HW soluble fractions of $T$. domingensis and $C$. jamaicense showed higher percentages of ester sulfates than in Chara spp.

Chara spp showed a carbohydrate content in the HW soluble fraction (48.3\%) which was greater than was found in the HW soluble fractions of the emergent macrophytes T. domingensis and Cladium jamaicense. The carbohydrate content of the $\mathrm{NaOH}$ soluble in Chara spp was found to be $60.4 \%$, similar to concentrations found in the $\mathrm{NaOH}$ soluble fractions of $T$. domingensis and $C$. jamaicense. The paired floc samples to Chara spp (EO1 and TO3) were found to contain a lesser carbohydrate content than Chara spp, but showed similar concentrations to each other and the other floc samples. Floc samples EC1 and TC3 showed similar carbohydrate content which was greater than the carbohydrate content of the open area floc samples EO1 and TO3.

The results of the uronic acid content of fractionation A showed that the soluble fractions of Chara spp contained a greater percentage of uronic acid than the other macrophytes. The HW soluble fraction of Chara spp was found contain $31.2 \%$ uronic acid, with a similar percentage in the $\mathrm{NaOH}$ soluble fraction. The $\mathrm{HW}$ soluble fractions of paired floc samples EO1 and TO3 showed less uronic acid content. The uronic acid content of EO1 and TO3 were found to be slightly greater than in the HW soluble fraction. The soluble fractions of $T$. domingensis showed a uronic acid content that was only slightly less than in Chara spp in the $\mathrm{HW}$ and $\mathrm{NaOH}$ soluble fractions. Paired floc 
sample to T. domingensis (EC1) showed $15.4 \%$ uronic acid concentration in the HW soluble fraction and only $8.9 \%$ in the $\mathrm{NAOH}$ soluble fraction. Cladium jamaicense showed the lowest concentrations of uronic acids among the macrophytes with similar percentages in paired floc sample TC3.

Typha domingensis and $C$. jamaicense showed a greater percentage of ester sulfate in the HW soluble fractions than in Chara spp or any of the floc samples. The ester sulfate content of Chara spp soluble fractions was lower than the emergent macrophytes (around a 10\% content in both $\mathrm{HW}$ and $\mathrm{NaOH}$ soluble fractions) with paired floc samples reflecting these results. Typha domingensis showed a greater ester sulfate content of $25.2 \%$ in the HW soluble fraction, and a lower $9.3 \%$ content in the $\mathrm{NaOH}$ soluble fraction. Similarly, Cladium jamaicense showed a $21.1 \%$ concentration of ester sulfate in the HW soluble fraction and a 7.8\% concentration in the $\mathrm{NaOH}$ soluble fraction. All floc samples showed an ester sulfate content around 10\% in both the HW and $\mathrm{NaOH}$ soluble fractions. 


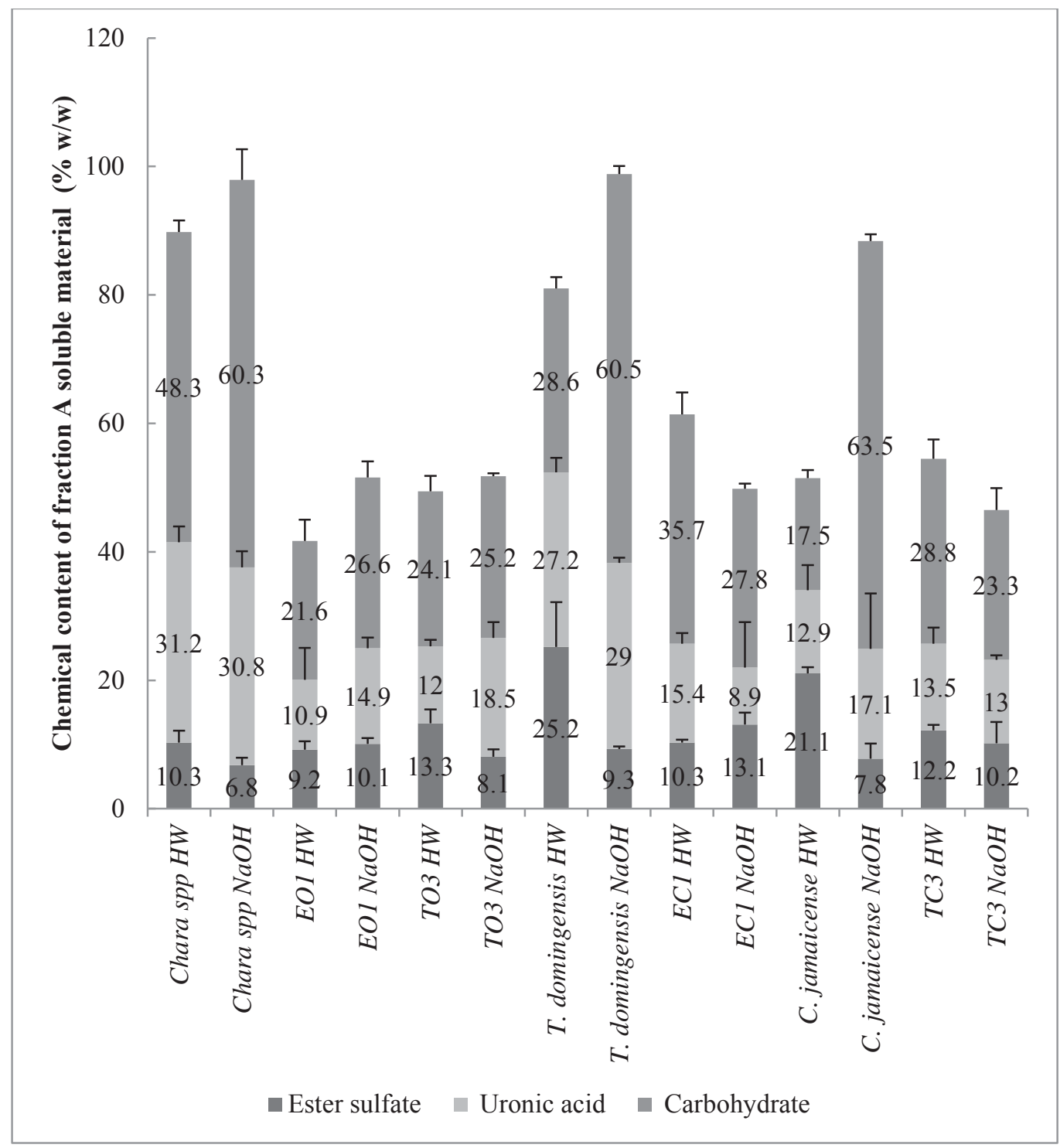

Figure 3.1: Mean carbohydrate, uronic acid and ester sulfate content (error bars showing standard deviation) of macrophyte and paired floc samples $(\% \mathrm{w} / \mathrm{w})$ in $\mathrm{HW}$ soluble and $\mathrm{NaOH}$ soluble fractions via fraction A. $n=3$

\subsubsection{Chemical content of fractionation B samples}

The results of colorimetric analyses of soluble fractions derived from fractionation B are shown below in figures 3.2-3.7. In general, lower carbohydrate 
content and uronic acid were seen in the floc samples than in the macrophytes. The highest concentrations of carbohydrates were found in the HW soluble fractions of macrophytes and paired floc samples (figure 3.3). Chara spp showed a substantial carbohydrate content in the CDTA (figure 3.4) and DMSO (figure 3.2) soluble fractions. Cladium jamaicense showed a substantial percentage of carbohydrate in the DMSO soluble fraction as well. T. domingensis was found to have a lesser carbohydrate content than in the other macrophytes which was also true for the paired floc sample EC1. The greatest uronic acid content was found in the DMSO soluble fraction of Chara spp, while the greatest uronic acid content was seen in the HW soluble fractions of both $T$. domingensis and Cladium jamaicense which is also true for their paired floc samples.

DMSO soluble fractions: In the DMSO soluble fractions (shown in figure 3.2), $C$. jamaicense and paired floc sample TC3 showed the greatest concentrations of carbohydrate with $C$. jamaicense at $35.4 \%$ and TC3 at a slightly higher $38.7 \%$. The DMSO soluble fraction of Chara spp showed a similar, but slightly lower carbohydrate content to T. domingensis (which were both less than in Cladium jamaicense). All floc samples had carbohydrate and uronic acid contents less than their paired macrophytes. EO1, TO3 and EC1 had carbohydrate contents of about 12-18\%, while TC3 had a greater content of $38.7 \%$. The uronic acid content of the DMSO soluble fraction was found to be greatest in Chara spp and paired floc sample TO3. The uronic acid content of the DMSO soluble fraction of Cladium jamaicense was somewhat lesser than the other macrophytes. 
$H W$ soluble fractions: The results of the carbohydrate and uronic acid content of the HW soluble fractions (shown below in figure 3.3) were quite similar between the macrophytes. Chara spp was found to contain a substantial carbohydrate content of 63.6\%. The HW soluble fraction of Cladium jamaicense was also found to contain a greater carbohydrate content at $65.8 \%$. T. domingensis showed slightly less carbohydrate content in the HW soluble fraction at 50.5\%. Floc sample TO3 showed a greater carbohydrate content than any other floc sample. The uronic acid content of the HW soluble fractions was highest in $T$. domingensis compared to the other macrophytes. Chara spp showed a uronic acid concentration that was less than the other macrophytes. Floc samples EO1 and EC1 as well as TO3 and TC3 showed similar uronic acid content.

CDTA soluble fractions: In general, the chemical content of the CDTA soluble fraction (shown below in figure 3.4) of Chara spp had a greater carbohydrate and uronic acid content than the emergent macrophytes. Paired floc samples EO1 and TO3 showed a greater content of carbohydrates and uronic acid than in the other floc samples as well. Cladium jamaicense showed a slightly greater carbohydrate and uronic acid content than T. domingensis while the floc samples paired to emergent macrophytes had similarly low carbohydrate and uronic acid content of about $10.5 \%$ or less.

$\mathrm{Na}_{2} \mathrm{CO}_{3}$ soluble fractions: In the $\mathrm{Na}_{2} \mathrm{CO}_{3}$ soluble fractions (shown in figure 3.5), C. jamaicense showed greater carbohydrate and uronic acid content than in the other macrophyte and floc samples. Chara spp and T. domingensis showed similar results in the carbohydrate and uronic acid content of the $\mathrm{Na}_{2} \mathrm{CO}_{3}$ soluble fraction, with 
comparatively low concentrations of carbohydrates and uronic acid in their paired floc samples.

1M KOH soluble fractions: The carbohydrate and uronic acid content of the $1 \mathrm{M}$ $\mathrm{KOH}$ soluble fractions (shown in figure 3.6) was highly variable. Chara spp and floc sample EO1had similar results to Cladium jamaicense and floc sample TO3 which showed greater carbohydrate uronic acid content in the paired floc sample than in the macrophytes. All samples had a greater uronic acid content than carbohydrate content. The carbohydrate and uronic acid content of $T$. domingensis and paired floc EC1 were quite similar, while $C$. jamaicense had substantially less (about half as much) uronic acid and carbohydrate content than its paired floc sample, TC3. Chara spp had a $14.7 \%$ uronic acid content and a $6.3 \%$ carbohydrate content. Paired floc sample EO1 showed a lesser $6.54 \%$ uronic acid and $1.5 \%$ carbohydrate content, while floc sample TO3 showed substantially greater $24.85 \%$ uronic acid and $12.4 \%$ carbohydrate content.

$4 M \mathrm{KOH}$ soluble fraction: The carbohydrate and uronic acid content of the $4 \mathrm{M}$ $\mathrm{KOH}$ soluble fractions (shown in figure 3.7) were highest in Cladium jamaicense and Chara spp, but much lower in paired floc samples. T. domingensis had carbohydrate and uronic acid concentrations of about half as much as Chara spp and Cladium jamaicense. While floc samples EO1, EC1 and TC3 showed similar results or about $4 \%$ uronic acid content and $0.4 \%$ carbohydrate content, floc sample TO3 showed a greater uronic acid content $(7.8 \%)$ and carbohydrate content $(2.4 \%)$. 


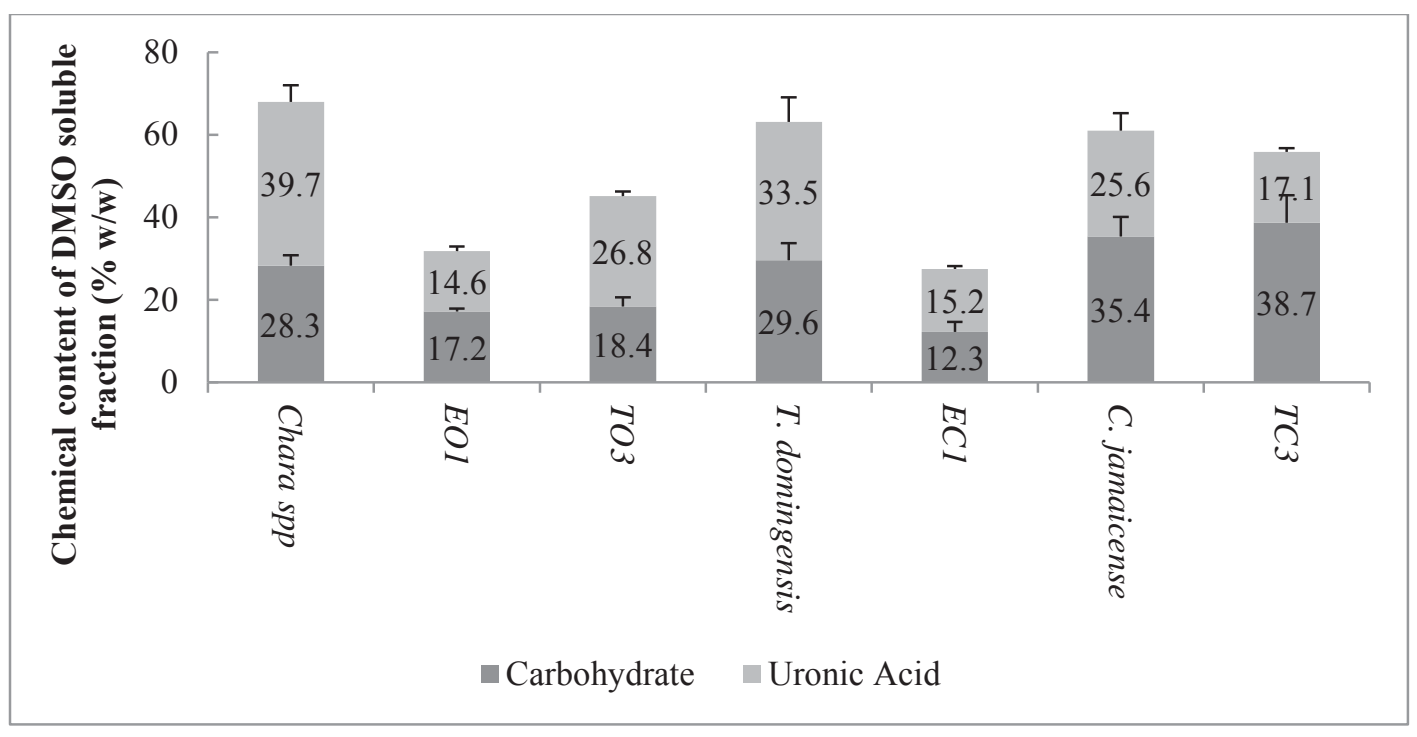

Figure 3.2: Mean carbohydrate and uronic acid concentration $(\% \mathrm{w} / \mathrm{w}$, with error bars showing standard deviation) of the DMSO soluble fraction of macrophytes and paired floc samples (fractionation $B$ ). $n=3$

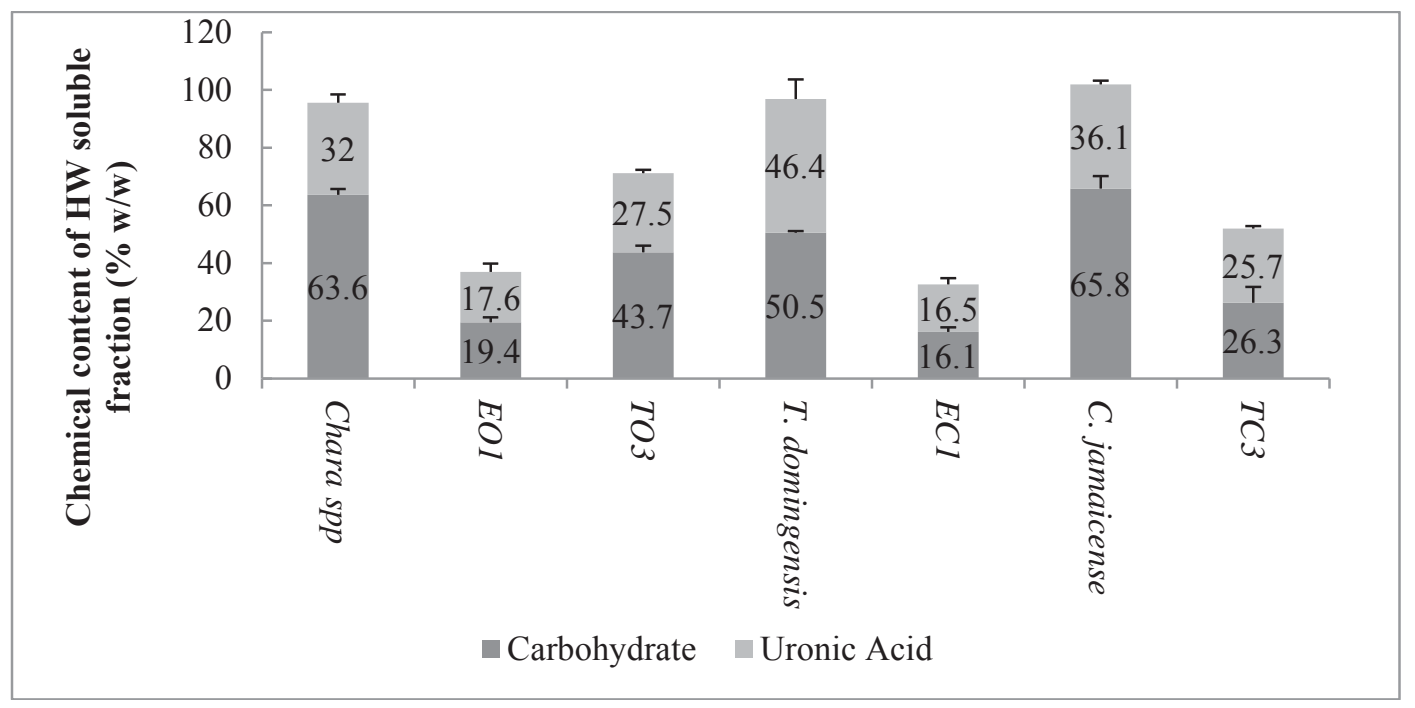

Figure 3.3: Mean carbohydrate and uronic acid concentration ( $\% \mathrm{w} / \mathrm{w}$, with error bars showing standard deviation) of the HW soluble fraction of macrophytes and paired floc samples (fractionation B). $n=3$ 


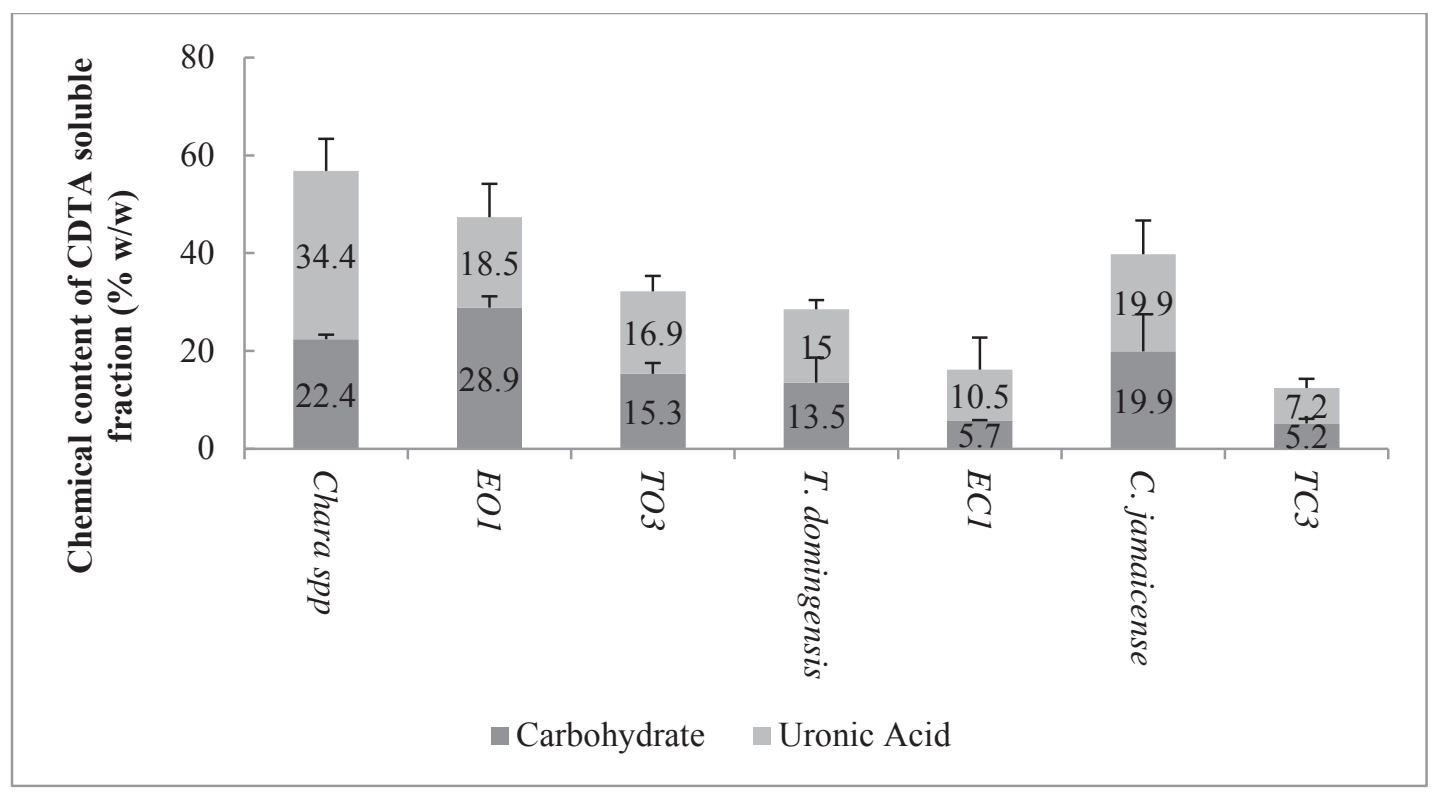

Figure 3.4: Mean carbohydrate and uronic acid concentration (\% w/w, with error bars showing standard deviation) of the CDTA soluble fraction of macrophytes and paired floc samples (fractionation B). $n=3$

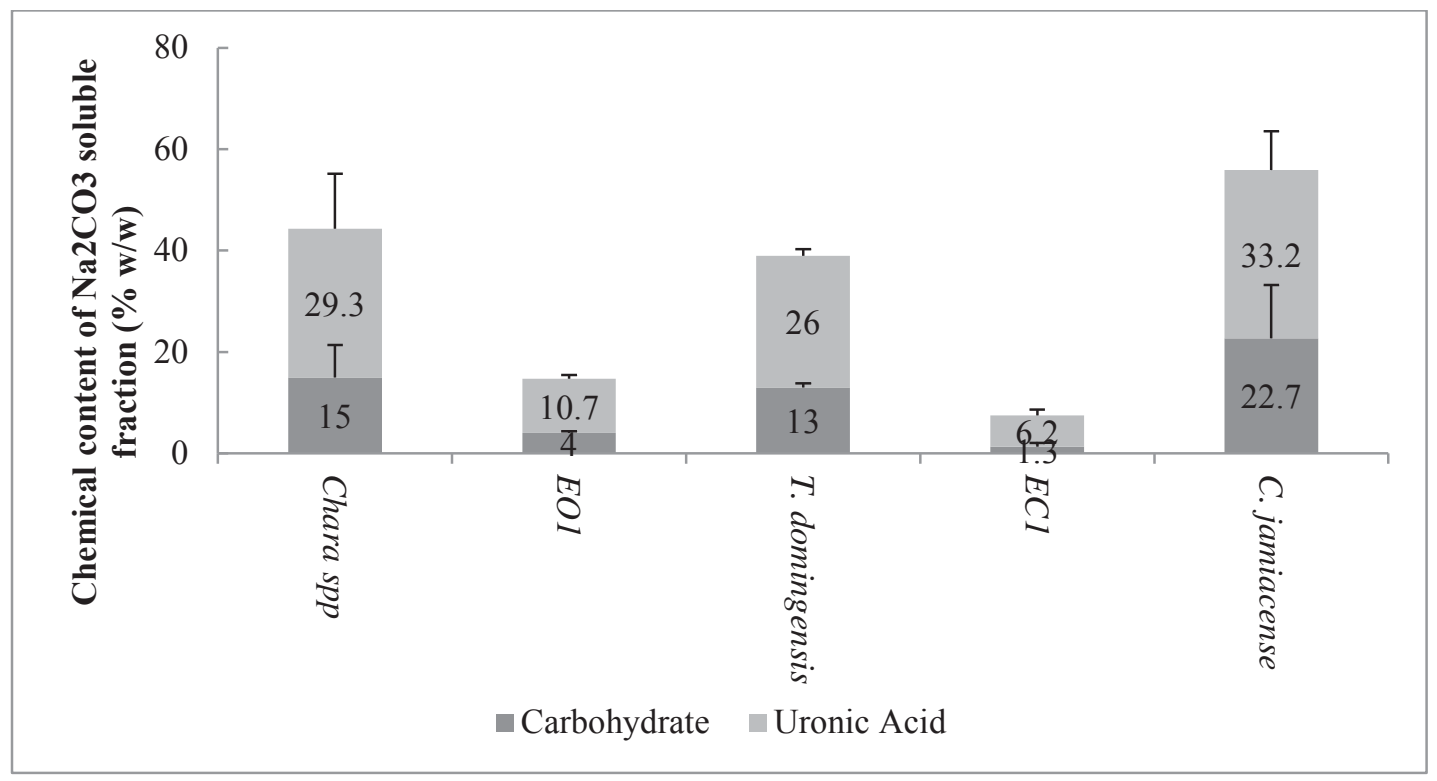

Figure 3.5: Mean carbohydrate and uronic acid concentration (\% w/w with error bars showing standard deviation) of the $\mathrm{Na}_{2} \mathrm{CO}_{3}$ soluble fraction of macrophytes and paired floc samples (fractionation $\mathrm{B}$ ). $\mathrm{n}=3$ 


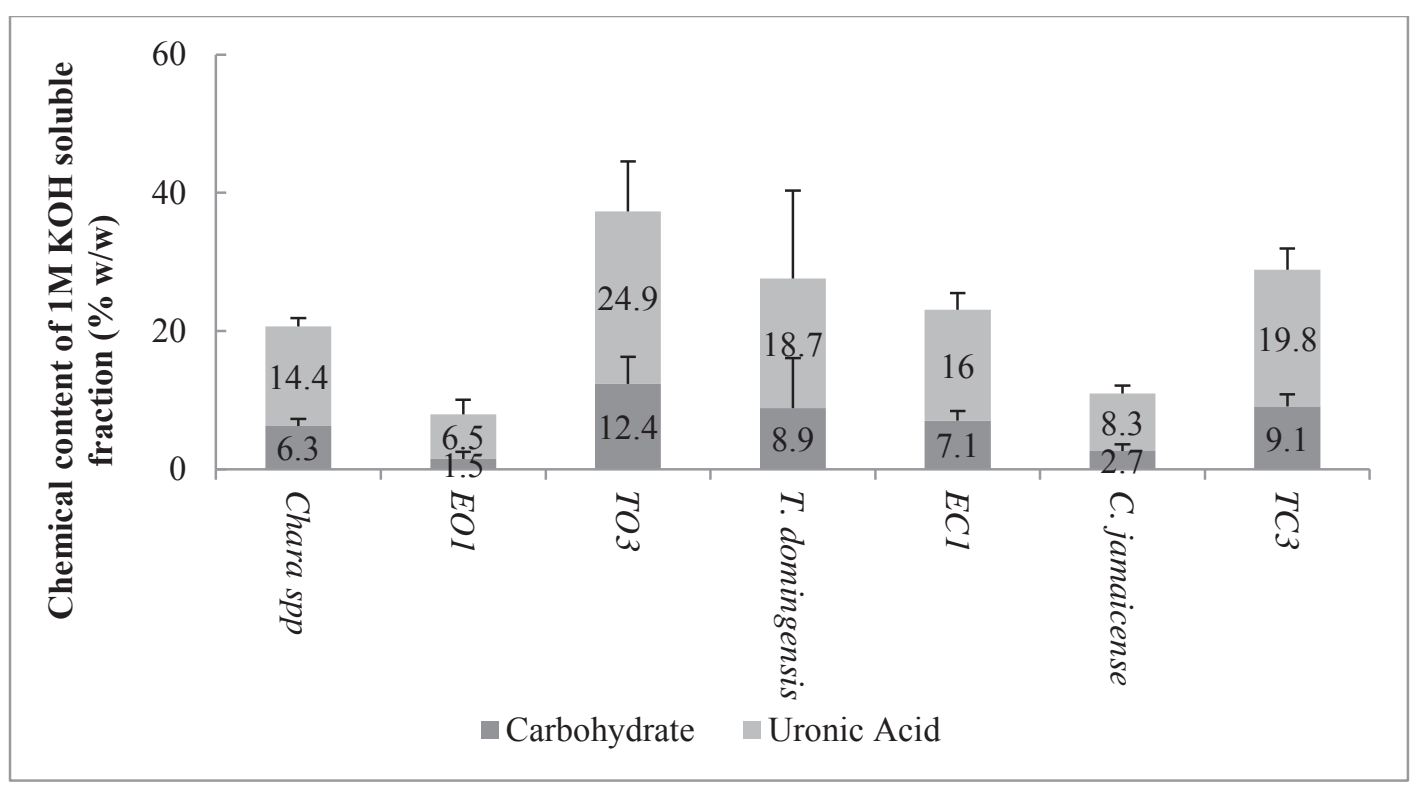

Figure 3.6: Mean carbohydrate and uronic acid concentration $(\% \mathrm{w} / \mathrm{w}$, with error bars showing standard deviation) of the $1 \mathrm{M} \mathrm{KOH}$ soluble fraction of macrophytes and paired floc samples (fractionation $B$ ). $n=3$

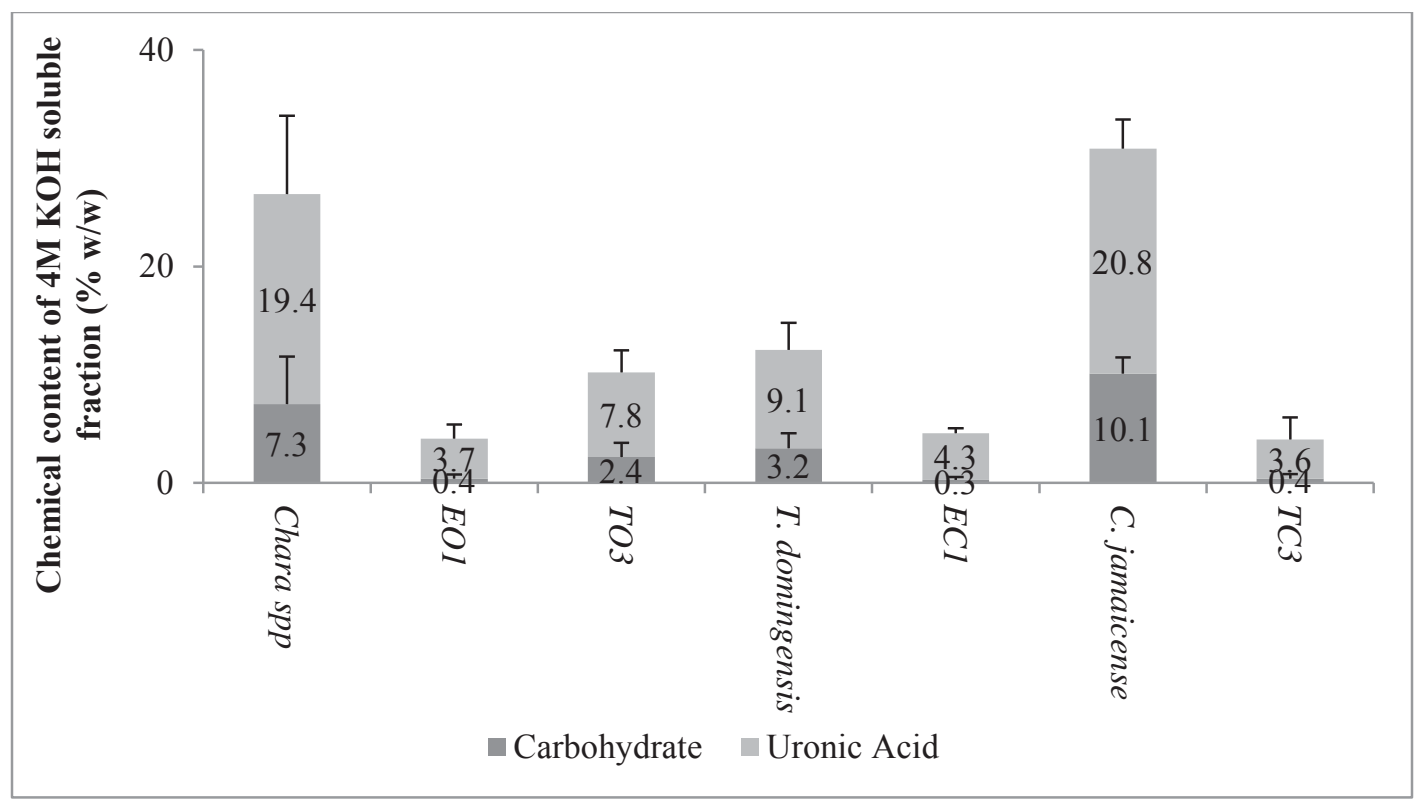

Figure 3.7: Mean carbohydrate and uronic acid concentration ( $\% \mathrm{w} / \mathrm{w}$, with error bars showing standard deviation) of the $4 \mathrm{M} \mathrm{KOH}$ soluble fraction of macrophytes and paired floc samples (fractionation $\mathrm{B}$ ). $\mathrm{n}=3$ 


\subsubsection{Phosphorus content of macrophyte and paired floc samples}

The results from the $\mathrm{P}$ content of the sequential $\mathrm{P}$ fractionation is shown below in figure 3.8. Chara spp had a greater overall soluble P content than the other macrophytes. EO1, EC1 and TO3 had a greater soluble P content than in their paired macrophytes. The floc samples from Chara spp dominated study plots showed greater soluble P content than the other floc samples as well.

Chara spp contained the least amount of HW soluble $\mathrm{P}$ in comparison to $T$. domingensis and Cladium jamaicense. The four floc samples showed similar results in the concentration of HW soluble P with EO1 at an average of about $400-500 \mathrm{mg} / \mathrm{kg}$. Chara spp and its paired floc samples showed much higher average $\mathrm{P}$ concentrations in the $\mathrm{NaOH}$ soluble fractions than in the other samples which had the smallest $\mathrm{P}$ concentrations of the three soluble fractions. The $\mathrm{HCl}$ soluble fraction showed similar results in all samples, around $160-190 \mathrm{mg} / \mathrm{kg}$ on average.

A two-way ANOVA analysis (shown in table 3.2) of soluble P content among the 3 fractions $(\mathrm{HW}, \mathrm{NaOH}$, and $\mathrm{HCl})$ showed a significant difference between all macrophytes and a correlation between macrophytes and their paired floc samples. There was also a correlation found between open plot floc as well as between control plot floc. Interestingly, there was a significant difference found between the enriched open floc sample and both control floc samples but not between the transitional open floc sample and control floc samples. 


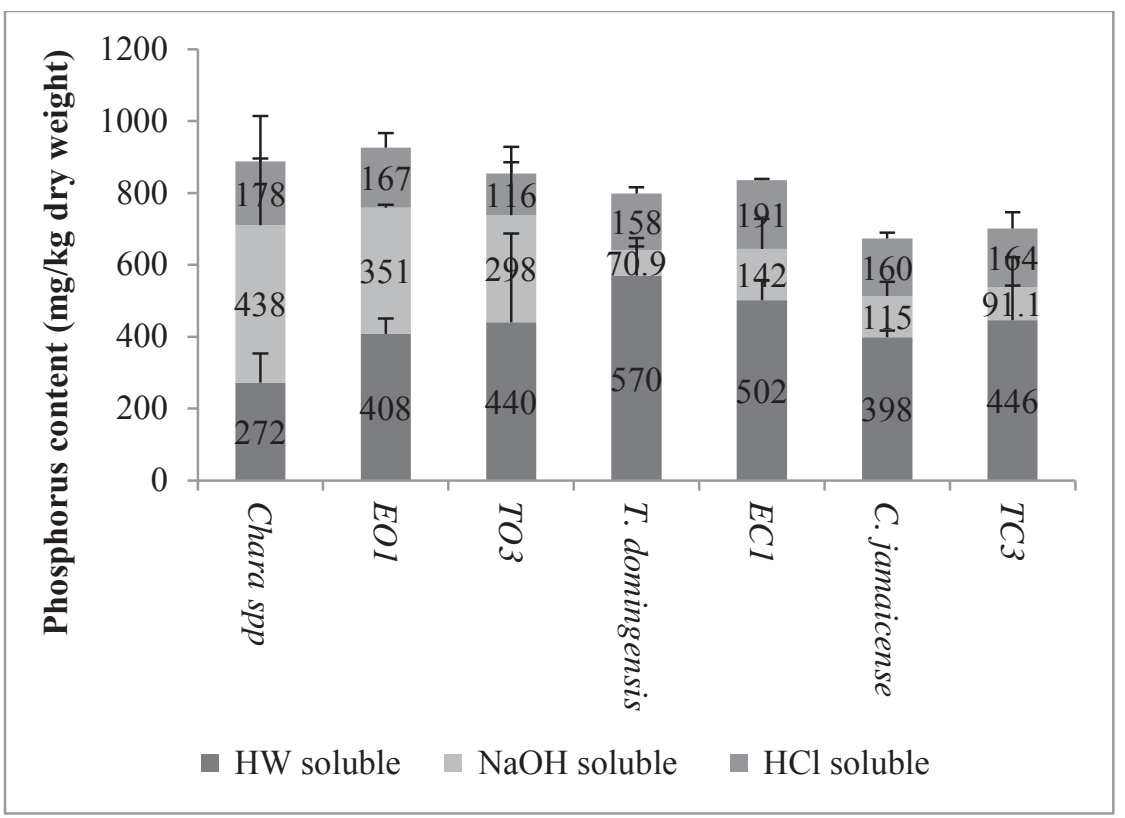

Figure 3.8: Mean phosphorus content (mg/kg dry weight) (error bars showing standard deviation) of HW, $\mathrm{NaOH}$ and $\mathrm{HCl}$ soluble material on Chara spp and paired floc samples EO1 and TO3, T. domingensis and paired floc sample EC1 and Cladium jamaicense and paired floc sample TC3. n=3

Table 3.2: Two-way ANOVA (Soluble $\mathrm{P}$ content of $\mathrm{HW}, \mathrm{NaOH}$ and $\mathrm{HCl}$ fractions). Significant differences are shown in bold $F_{\text {critical }}=3.89 n=3$.

\begin{tabular}{|r|c|c|}
\hline & $\mathrm{F}_{\text {Interaction }}$ & P-Value \\
\hline \hline Chara spp - EO1 & 1.14 & 0.35 \\
Chara spp - TO3 & 1.29 & 0.31 \\
TO3 - EO1 & 0.26 & 3.89 \\
Chara spp - T. domingensis & $\mathbf{9 . 2 9}$ & $\mathbf{0}$ \\
T. domingensis - EC1 & 2.85 & 0.1 \\
EC1 - EO1 & $\mathbf{2 0 . 4 9}$ & $\mathbf{0}$ \\
EC1 - TO3 & 1.7 & 0.22 \\
T. domingensis - Cladium jamaicense & $\mathbf{1 1 . 6 9}$ & $\mathbf{0}$ \\
C. jamaicense - TC3 & 0.59 & 0.57 \\
TC3 - TO3 & 1.7 & 0.22 \\
TC3 - EO1 & $\mathbf{1 1 . 2 6}$ & $\mathbf{0}$ \\
TC3 - EC1 & 0.08 & 0.92 \\
C. jamaicense - Chara spp & $\mathbf{4 . 6 5}$ & $\mathbf{0 . 0 3}$ \\
\hline
\end{tabular}




\subsection{Discussion}

\subsubsection{Chemical content of fractionation A samples}

Plant cell walls are made up cellulose microfibrils with embedded cross-linking glycans within a complex matrix of polysaccharides and structural proteins. The composition of the polysaccharide matrix can vary considerably between species (Fry, 2000; Cosgrove, 2005). Decomposition rate is highly correlated with the chemical composition of the cell wall of plants that contribute to floc, as well as the availability of carbon (Debusk \& Reddy, 1998), therefore the greater percentage of carbohydrates found in Chara spp fractions may mean a higher rate of decomposition in the macrophyte and paired floc.

Our results showed that Chara spp to be rich in hemicelluloses and pectins. The results from chapter 2 showed the xylan epitope was labeled for in the HW soluble fraction of Chara spp. Xylans can act as structural polymers such as cellulose in some species of algae (Cosgrove, 2005). When combining the results from chapters 1 and 2, it is likely that the HW soluble fraction of Chara spp contained loosely bound xylan with glucuronic acid side chains as well as a lesser percentage of pectins associated with ester sulfates. The $\mathrm{NaOH}$ fractions of Chara spp contained a greater percentage of carbohydrates than in the HW soluble fractions but a similar concentration of uronic acids and lower percentage of ester sulfates. This indicates the presence of a moderate percentage of glucuronic and carbohydrate rich polymers such as xyloglucan and xylan (both labeled for in the $\mathrm{NaOH}$ soluble fraction) and a small percentage of ester sulfate associated pectins. This fraction may also include acidic pectins such as arabinans or 
arabinoxylans in concentrations too small to be detected with dot blot analysis. Loss of soluble organic and inorganic material from plant material in detrital OM occurs through initial leaching from immersion in water, degradation by fungi and bacterial species, and fragmentation by primary producers such as aquatic invertebrates (Suberkropp \& Klugg, 1980; Webster \& Benfield, 1986) The results demonstrate this loss of cell wall polysaccharides due to decomposition and degradation from environmental exposure prior to collection; as the two paired floc samples to Chara spp showed similar results to Chara spp but with a lesser carbohydrate, uronic acid and ester sulfate content in both $\mathrm{HW}$ and $\mathrm{NaOH}$ soluble fractions

\section{T. domingensis had almost equal ester sulfate, uronic acid and} carbohydrate contents in the HW soluble fraction. This may indicate the presence of a neutral pectin rich in glucuronic acid such as AGP, (1-4)- $\beta-\mathrm{D}$ galactan, $\mathrm{HG}$, or xylogalactruonan (The presence of AGP, (1-4)- $\beta$-D galactan, xylan and esterified HG were confirmed in the HW soluble fraction with dot-blot analysis). The chemical content may also indicate the presence of Rhamnogalacturonans I and II. Rhamnogalacturonan I contains alternating rhamnose and alternating galacturonic acid with other pectic side chains while rhamnogalacturonan II is a modified HG. Both play a role in strengthening the cell wall (Fry 2000, Cosgrove, 2005; Popper, 2008). However, the presence of these polymers were not tested for with dot blot analysis. The $\mathrm{NaOH}$ soluble fraction of $T$. domingensis was similar to that of Chara spp in that there was a much higher percentage of carbohydrate with lower concentrations of uronic acid and a very low concentration of ester sulfates. This indicating that as in Chara spp, this fraction contains a large 
percentage of hemicelluloses which may be associated with ester sulfates as well as some acidic pectins such as xylan and xyloglucan which were both indicated for in the dot-blot analysis. AGP was also present in this fraction, the backbone of which is linked to uronic acid (Seifert \& Roberts, 2007). The results of the chemical analysis of floc sample EC1 indicate the presence of more loosely bound hemicellulose in the floc sample than in T. domingensis (as well as compared to the other floc samples). Similar to $T$.

domingensis, AGP, xylan, and xyloglucan were indicated in this fraction during dot-blot analysis.

In contrast to both Chara spp and T. domingensis, Cladium jamaicense showed a low carbohydrate and uronic acid concentration in the HW soluble fraction, with a greater ester sulfate content. This indicates the presence a hemicellulose associated with ester sulfates, such as xylan or an HG with ester associated glucuronic acid units (Cosgrove, 2005). This confirms the dot-blot analysis findings which showed the presence of xylan, xyloglucan, and esterified HG. (1-4)- $\beta$-D galactan was also present in this fraction which may be present as an associated side chain. $C$. jamaicense showed a greater carbohydrate content in the $\mathrm{NaOH}$ soluble fraction than uronic acid and ester sulfate content. This indicates a hemicellulosic polymer with glucuronic acid rich side chains and associated polymers such as xylan which occurs in large amounts in the grasses (Fry, 2000; Popper, 2008) as well as xyloglucan (both confirmed as present in the dot-blot analysis). The AGP indicated for in this fraction is likely an AGP with $(1,4) \beta$-D-galactan units and arabinan side chains (Fry, 2000; Popper 2008) (as AGP, (1-4)- $\beta$-D galactan and arabinan were all present in this fraction as well. 
The paired floc sample to $C$. jamaicense (TC3) showed a greater content of carbohydrates in the HW soluble fraction, as well as a slightly greater uronic acid content, and a lower ester sulfate content than in $C$. jamaicense. This indicates the presence of xylans and esterified HG more liable to extraction than in $C$. jamaicense. The $\mathrm{NaOH}$ fraction was found to contain similar hemicelluloses and pectins to $C$. jamaicense but in lesser amounts as with the other floc samples.

\subsubsection{Chemical content of fractionation B samples}

Lignin and cellulose content in plant tissues have been shown to be useful in the determination of the availability of $\mathrm{C}$ compounds and associated nutrients that may be utilized by microbes (often referred to as the substrate quality) (Debusk \& Reddy, 1998). Therefore decomposition rates and wetland $\mathrm{C}$ cycling are known to be affected significantly by the composition of the organic substrate (Debusk \& D'Angelo, 1994). As discussed earlier in this chapter, fractionation of the cell wall can give us insight into the composition of macrophytes and in turn their contribution to the organic substrates (floc layers) of their respective study plots.

Chara spp showed a greater uronic acid content in the DMSO soluble fraction as compared to the other macrophytes. Although the dot blot analysis of this fraction was not found to contain any of the polysaccharides tested for, the large carbohydrate and uronic acid content suggests the presence of manans or starches in this fraction. This is most likely since DMSO is known to extract starches and loosely bound native hemicellulose (Fry, 2000). This may also be true for paired floc samples EO1 and TO3, 
although they were also found to contain xylan and arabinan respectively. The DMSO fraction of T. domingensis had a similar carbohydrate and uronic acid content to Chara spp, but contained AGP, $(1,4)-\beta$-D galactan, xylan and xyloglucan. Both manans and xyloglucans maintain the strength of the cell wall by creating the cell wall matrix (Marcus et al., 2008). Cladium jamaicense contained a greater percentage of carbohydrate than uronic acid and was shown to contain xylan. This may again indicate the presence of starch. The results from this fraction show a difference in the make-up of the cell wall matrix in Chara spp, T. domingensis and Cladium jamaicense.

In the HW soluble fraction, the macrophytes showed high concentrations of carbohydrates suggesting the presence of pectins, which are known to be removed through extraction with HW (Fry, 2000; Cosgrove, 2005). The uronic acid content of the macrophytes was also sizable; suggesting the presence of uronic acid associated pectins. In Chara spp, xylan was the only polysaccharide indicated out of the suite tested in the dot blot analysis. This suggests that the HW soluble fraction contained rhamnogalacturonans I or II which may have had side chains containing xylan or xylogalactruonan which contained xylose branches. Paired floc samples EO1 and EC1 showed similar results with lower concentrations of carbohydrates and uronic acids than in their paired macrophytes and contained xylan as well as xyloglucan. The presence of xyloglucan in Chara spp paired floc samples reflects the contribution of other plant or algal tissues as xyloglucan is not commonly found in significant amounts in the charophytes (Popper \& Fry, 2003) and xyloglucan was not indicated as present in the HW fraction of Chara spp. 
Chara spp had a greater carbohydrate and uronic acid content relative to the other macrophytes in the CDTA soluble fraction. This suggests the presence of uronic acid rich polysaccharides which most likely includes HG (confirmed by dot-blot analysis to be present in this fraction) or galactans. The Charales are known to have unesterified HG bound to the outside of the cell wall which are able to precipitate calcium as well as other ions such as phosphorus loosely bound to the HG (Hutchinson, 1957; Siong \& Asaeda, 2006). It is likely that $\mathrm{HG}$ as well as $\mathrm{Ca}^{2+}$ was contained in the CDTA soluble fraction since CDTA is a calcium chelator. It is also likely that loosely bound unesterified HG was likely removed through decomposition in floc samples prior to collection (Webster \& Benfield, 1986; Fry, 2000). While floc sample TO3 showed similar results to Chara spp, the paired floc sample EO1 contained a greater carbohydrate content and lesser uronic acid content, suggesting the presence of hemicelluloses such as xylans or xyloglucans. Both floc samples showed much higher concentrations of carbohydrate and uronic acid than in the paired floc samples of T. domingensis and Cladium jamaicense which lends evidence to support Chara spp contributing to the floc layers of EO1 and TO3.

The $\mathrm{Na}_{2} \mathrm{CO}_{3}$ soluble fraction showed a similar uronic acid content among the macrophytes and their paired floc samples, with smaller carbohydrate contents. This may indicate the presence of a pectin rich galacturonic acid such as HG (Cosgrove, 2005). Cladium jamaicense showed a larger carbohydrate and uronic acid content as compared to the other macrophytes. This indicates that $C$. jamaicense contains hemicelluloses that are more difficult to extract and possibly more closely associated with the cell wall than in Chara spp or T. domingensis and paired floc samples (Fry, 2000). 
Chara spp and Cladium jamaicense and transitional plot floc samples showed similar chemical content in the $1 \mathrm{M} \mathrm{KOH}$ soluble fraction. Both Chara spp and Cladium jamaicense showed greater uronic acid content than carbohydrate content which suggests the presence of a uronic acid rich hemicellulose. Dot blot analysis confirmed the presence of xylan in Chara spp and paired floc samples and xylan and xyloglucan in $T$. domingensis and Cladium jamaicense and paired floc samples. Xyloglucan has a backbone identical to that of cellulose. It functions in creating a matrix that links cellulose microfibrils together (Marcus et al., 2008). Therefore, the cell walls of the vascular macrophytes $T$. domingensis and $C$. jamaicense may be more rigid and allow them to grow taller than Chara spp.

Chara spp, Cladium jamaicense and T. domingensis showed a uronic acid and carbohydrate content in a ratio of about two to one. This suggests that a tightly bound cell wall associated hemicellulose, rich in uronic acid was removed with $4 \mathrm{M} \mathrm{KOH}$ extraction. Both xylan and xyloglucan was shown to be present in all macrophytes and paired floc samples. As previously mentioned, xylan and xyloglucan work as structural polymers that are able to function similarly to cellulose or by binding to cellulose in vascular plants and allowing macrophytes to reach larger sizes and have more efficient mechanical and vascular tissues. This is a great advantage to vascular macrophytes where water is a limiting factor (Fry, 2000; Popper, 2008). This is interesting to consider because although the all macrophytes and floc samples contained both tightly bound xylan and xyloglucan, Chara spp was shown to contain far less than the emergent macrophytes (less than $1 \%$ of the $4 \mathrm{M} \mathrm{KOH}$ soluble fraction was recovered from the total recovered 
fractions). Cladium jamaicense had a 33\% recovered 4M KOH soluble fraction and $T$. domingensis showed a huge $66.8 \% 4 \mathrm{M} \mathrm{KOH}$ soluble fraction. This gives us more insight into the distinct advantage of $T$. domingensis over the other macrophytes to thrive in an environment such as WCA-2A where water level can be highly variable. $(1,4)-\beta-D$ galactan (useful in promoting cell wall flexibility (Zywinkska et al., 2005)) was also shown to be present in $T$. domingensis and $C$. jamaicense but not in Chara spp or any floc samples. This may indicate that it was a side chain bound to cellulose in the emergent macrophytes (Cosgrove, 2005) and was likely lost during decomposition in the paired floc samples EC1 and TC3.

\subsubsection{Phosphorus content of macrophytes and paired floc samples}

As shown in a similar study done with charophytes in a marl lake, calcite encrustations often enhance $\mathrm{P}$ storage in the plant biomass and can increase the potential nutrient sink of P (Siong \& Asaeda, 2006). Our results show that indeed this is also what is occurring in WCA-2A. The results of the sequential P fractionation showed that while

Chara spp had a greater overall soluble P content than the other macrophytes, the greatest $\mathrm{P}$ content was found in the $\mathrm{NaOH}$ soluble fractions. This indicates that the bulk of the $\mathrm{P}$ contained in the cell walls of Chara spp was Ca-bound while most of the $\mathrm{P}$ in the emergent macrophytes was more loosely bound to cell wall polysaccharides that could be removed by extraction with HW such as HG (Fry, 2000; Cosgrove 2005). This is also true of the paired floc samples. 
All paired floc samples (except for EC1) showed a greater loosely bound P content than their paired macrophytes. This is most likely a reflection of the stored, loosely bound $\mathrm{P}$ from water nutrient enrichment as the $\mathrm{HW}$ soluble $\mathrm{P}$ content was greater in the transitional site floc. This indicates that the floc layers are potentially acting as a nutrient source and sink as well. The enhanced P sink from Ca-bound P can potentially increase the bottom up control of non-emergent vegetation and the floc layers and can therefore be a positive influence in stabilizing Chara spp dominance in aquatic systems (Siong \& Asaeda, 2006).

The two-way ANOVA analysis of the samples and P content of the soluble fractions confirmed that there was no statistical significant differences among the macrophytes and their paired floc samples while there were significant differences when comparing the macrophytes. There was also a significant difference found between the enriched open floc sample and both control floc samples but not between the transitional open floc sample and control floc samples. This is evidence to suggest that there is a correlation between Chara spp and floc EO1 and that Chara spp is contributing to the soluble $\mathrm{P}$ content of $\mathrm{EO} 1$ while floc TO3 is also correlated to Chara spp, it may also contain remnant emergent macrophyte tissues as well.

This study is of course is a "snapshot" of the P content of the macrophytes and floc samples of WCA-2A from June of 2010, but it can be useful in determining trends and correlations between study sites. Soil and floc P content are subject to hydrogeochemical related changes (reflux). Reflux refers to the dispersal of TP in sediment with high TP content into the water column. One study which looked at the 
reflux of TP in WCA-2A sediment found that the removal of $T$. domingensis by treatment with herbicide resulted in a long, slow release of $\mathrm{P}$ from decomposing plant material. Herbicide application and layering the sediment surface with $\mathrm{CaCO}_{3}$ however lowered the outflow of $\mathrm{P}$ (Sklar et al., 2010). This sequestration of $\mathrm{P}$ by $\mathrm{CaCO}_{3}$ is similar to what occurred in open plots with Chara spp growth. Fire and water depth can also effect water and sediment TP. One study by SFWMD in 2011 showed that fires can decrease soil TP levels and fires in a low water depth had a greater decrease of soil TP than fires in higher water depth (Sklar et al., 20012). Another study in WCA-2A, which took place in January of 2007, showed that six months after a fire labile P decreased in floc by a margin of nearly $200 \mathrm{mg} / \mathrm{kg}$ as compared to pre-fire floc samples. Similar to this study, it also showed elevated levels in open site floc where there was known to be increased microbial activity, $\mathrm{P}$ bound to acid hydrolysable minerals (such as $\mathrm{Ca}$ and $\mathrm{Mg}$ ) with the enriched floc sample showing a slightly higher P content than in the control floc sample (Sklar et al., 2008). Both our results and results from 2007 are shown in table 3.3 for comparison. This comparison can be useful in predicting P patterns in open plots versus transitional plots in WCA-2A as well as in other aquatic systems. In general, when $T$. domingensis is removed and open water areas are created, the labile $\mathrm{P}$ content in floc layers is decreased while Ca-bound P is increased. Enriched open plots also tend to have a greater bound $\mathrm{P}$ content than transitional open plots. 
Table 3.3: Mean phosphorus content ( $\mathrm{mg} / \mathrm{kg}$ dry weight) (standard deviation in parenthesis) of $\mathrm{HCl}$ soluble, organic and inorganic phosphorus (Jan, 2007) and $\mathrm{NaOH}$ and $\mathrm{HCl}$ soluble, organic and inorganic $\mathrm{P}$ (Jun. 2010). Jan. 2007 data obtained from (Sklar et al., 2008) $n=3$

\begin{tabular}{lllll}
\hline & EC & EO & TC & TO \\
\hline Bound P (Jan. 2007) & $220(22)$ & $320(27)$ & $99(17)$ & $224(24)$ \\
Bound P (Jun. 2010) & $333(88)$ & $517(48)$ & $255(128)$ & $414(221)$ \\
\hline
\end{tabular}

\section{Chapter 4: Conclusions}

\subsection{Future work}

This study is a good bench mark for how the shifting plant communities are changing the polymeric and chemical content and thus the function of the floc layers in WCA-2A. It would be useful to do a follow up study on these same plots to track these shift so that we may be better able to determine the patterns of the floc biogeochemical processes. This then could be used to determine the outcome of management practices not only in the WCAs, but also other impacted aquatic systems.

It may be useful to perform an assay for determining the $\mathrm{Ca}^{2+}$ content of the macrophyte and floc samples as well. This could tell us how much calcium is actually being precipitated into floc sites dominated by Chara spp growth. This may also let us better elucidate the relationship between Chara spp growth and P cycling. Chara beds have not only shown co-precipitation of $\mathrm{P}$ with calcite, but have also been linked to the release of allelophatic compounds, reduced sediment suspension and slow decomposition on plant senescence (Siong \&Asaeda, 2006). It would be interesting to further study the effects of Chara spp calcium encrustation in WCA-2A in this way. In order to determine 
the amount of $\mathrm{Ca}^{2+}$ actually being contributed to the floc layers by Chara spp, a fractionation method similar to the one used in this study for P determination could be used with a colorimetric assay which uses a chromogenic calcium chelator such as calcium blue (AAT Bioquest, 2012; Bandrowski \& Benson, 1972).

Several monoclonal antibodies to polysaccharides were used to determine the origin of the OM in floc material in this study as well as to find useful biomarkers. This portion of the study could also be expanded to use monoclonal antibodies to manans and extensins. Manans are a storage polysaccharide and is thought to be more abundant in the charophytes than in land plants (Cosgrove, 2005). Extensins are structural hydroxyproline-rich glycoproteins which are abundant in land plants but not the charophytes (Fry, 2000). The extensins enable turgor driven cell expansion and play a role in the development of xylem. It is therefore thought that they are important in the evolution of land plants (Cassab, 1998; Popper, 2008).

It may also be helpful to use conjugated quantum dot labeling in a future study of this sort in place of FITC conjugated labeling. Conjugated quantum dot labeling allows for multi-colored imaging which means we would be able to indicate several polymers at once and get a better indication of where the polymers of interest are relative to each other in the cell wall. Since there are also brighter and more colors available with quantum dot labeling, we would also be able to avoid interference from auto-fluorescence (from chlorophyll and phenolic compounds) that can occur with FITC conjugate labeling. Live samples can also be labeled with quantum dot labeling (Chan \& Shuming, 1998). This could allow for the visualization of cell wall polymer turnover and uptake by species 
in an intact floc sample. This would give us a better idea of biogeochemical processes and floc layer dynamics which is a field of study which has not been extensively researched previously.

Another way we could potentially analyze floc layer dynamics would be to label stomach contents of selected wetland invertebrates and fish in the study plots with selected polysaccharide biomarkers. In one study performed in the Taylor slough of the Everglades used fatty acid labeling on stomach contents of consumers in order to investigate the contributions of periphyton and floc in the study area and to determine the inputs of these substrates to lower trophic-level consumers (Belicka et al. 2012). This could easily be done to stomach contents of lower trophic-level consumers in WCA-2A over a period of several years using polysaccharide biomarkers. This would allow us to elucidate the effects of shifting polysaccharides in floc layer OM on the food web of WCA-2A. This again could be applied to other impacted systems as well.

\subsection{Overall Findings}

A summary of results from fractionation A and B and polysaccharide and chemical data for macrophytes and paired floc samples can be found in tables 4.1 and 4.2. The availability of nutrients as well as electron acceptors plays and important role in wetland C cycling (Debusk \& D'Angelo, 1994). The results of this study reflect highly variable substrate quality due to differences in cell wall composition. Because of shifting plant communities due to agricultural and urban eutrophication, a shift in macrophytic 
communities has taken place. In studying the floc layers of transitional and open study plots of WCA-2A it likely that the source of floc OM is generated in situ by the dominant macrophytes of the plots as well as associated bacterial, fungal and algal sources.

According to recent studies, the decomposition and nutrient turnover rates in open plot floc is higher relative to control plots in WCA-2A (Debusk \& Reddy, 1998; Sklar et al., 2008-2013; Bellinger et al., 2012). The results of this study support these findings as they have shown that Chara spp and associated floc samples are more easily extracted which indicate a higher nutrient and $\mathrm{C}$ availability because of more labile cell wall associated polysaccharides relative to $T$. domingensis and Cladium jamaicense dominated study plots.

The first specific objective of this investigation was to determine if the floc from study plots EO1 and TO3 (open areas which had recently become dominated by Chara spp) were indeed derived from Chara spp or if the detrital OM present is primarily derived from surface peat from the remnant T. domingensis and Cladium jamaicense communities. The results of the polysaccharide and chemical profile as well as the calcium labeling indicate that the floc sample EO1 may have contributions from macrophytes other than Chara spp (the data indicates this is most likely $T$. domingensis), while floc from study site TO3 is primarily derived from TO3. Additionally, EC1 (paired floc sample to $T$. domingensis) may have contributions from algal sources as well as $T$. domingensis. Floc sample TC3 was found to be mainly derived from Cladium jamaicense. 
The second specific objective of this study was to determine effective polysaccharide polymer and calcium probes for possible use as biomarkers for distinguishing macrophytic algal (specifically Chara spp) dominated areas from native, emergent plant dominated areas. Overall, this analysis also shows that anti-AGP and anti $(1,4)$-linked galactan were excellent choices as biomarkers for distinguishing algal and higher plant dominated floc as they are present in HW and alkali extractions of Cladium jamaicense and T. domingensis and their paired floc samples in fractionations A and $\mathrm{B}$, but not in Chara spp or TO3. The presence of minor AGP and arabinan labeling in floc sample EO1 may indicate higher plant contributions in that particular study site. Calcium labeling may also be an effective tool for distinguishing floc layers derived from Chara spp dominated areas from floc layers derived from emergent plants. Although there was minor calcium labeling visible in Cladium jamaicense and T. domingensis and paired floc layers, labeling in Chara spp and paired floc layers was ubiquitous and easily distinguished because of the high amount of $\mathrm{Ca}^{2+}$ associated with Chara spp cell walls.

The third specific objective of this study was to create a polysaccharide polymer profile and chemical analysis of Chara spp and paired floc for comparison with emergent plants and paired floc to assess the shift in polymeric content of floc layers, a summary of which can be found in tables 4.1 and 4.2.

The fourth and final specific objective of this study was to quantify the bound P content of Chara spp and paired floc samples as well as T. domingensis and Cladium jamaicense and paired floc to compare the probable contribution of $\mathrm{P}$ to floc samples from paired macrophytes The amount of phosphorous and calcium being contributed to 
benthic peat layers by Chara spp in WCA-2A has not been explored previously. The findings of the investigation into the soluble $\mathrm{P}$ content of the macrophytes and paired floc samples of WCA-2A showed that the concentrations of soluble P found in the floc samples when compared with their paired macrophytes not only reflect the $\mathrm{P}$ contributions of the dominant macrophytes in each study plot, but may also be acting as a nutrient source or sink for bioavailable P. The two-way ANOVA analysis of the samples and P content of the soluble fractions confirmed that there was no statistical significant differences among the macrophytes and their paired floc samples while there were significant differences when comparing the macrophytes. Therefore open plot floc may act as a source or sink for $\mathrm{P}$. The analysis also suggested that floc from the transitional open plot may have contributions from submersed as well as emergent macrophytes. Chara spp may also be contributing a greater amount of Ca-bound $\mathrm{P}$ to floc layers where it is the dominant macrophyte. This knowledge may lead to a better understanding of Chara spp calcium and phosphorous cycling in relation to detrital flocculent (floc). This information is important not only in terms of potential long-term binding and burial of phosphorus, but combined with the differing cell wall structure of Chara spp, may play a role in rates of microbial activity and decomposition.

These findings support the hypothesis that the shift from native emergent macrophyte communities to submersed macrophyte communities in study sites of the northern Everglades is affecting the ionic content and polymeric/chemical profile of detrital flocculent layers derived from these macrophytic communities. The effects of this shift may contribute to changes in complex flocculent community dynamics. Some 
of these effects may include changes in microbial community composition, changes in food web dynamics, faster decomposition rates due to increased microbial respiration in floc layers, shift in aquatic prey species, changes in carbon quality and availability (Sklar et al., 2008-2013), higher P concentrations in the floc layers and bottom up control of bioavailable P in complex floc communities (Siong \& Asaeda, 2006).

In comparing the two fractionation methods, fractionation $\mathrm{A}$ is less time consuming while fractionation method B shows a more detailed chemical profile of the samples. One drawback to fractionation method B is that polysaccharides that occur in small amounts such as the arabinans may not be detected as well because they are dispersed among several fractions during the sequential extraction rather than extracted in total by $\mathrm{NaOH}$ (Fry, 2000) as in fractionation method A.

\subsection{Broader Impacts}

Our study shows that the shifts in vegetation in WCA-2A are effecting the polysaccharide and chemical profile as well as the soluble $\mathrm{P}$ content of the floc layers, but what are the broader impacts this may have on the ecological processes of WCA-2A? More labile nutrients in the $\mathrm{OM}$ of detrital floc may mean faster decomposition rates relative to plots where emergent macrophytes are dominant. One litter bag study showed twice as much biomass remaining after 24 months in the control study plots when compared to the open study plots of WCA-2A (Newman et al., 2001).

A more labile substrate and increased decomposition rate may also have a great impact on species composition and foraging. A study in 2010 showed that there was an 
increase in the wading bird population in open water plots rather than in transitional plots. However there was more foraging in transitional plots. It was suggested that this was due to shifting fish and invertebrae populations. It was shown in another study that EC sites supported a higher diversity of herbivore and detrivore species including larger bodied fish, while the EO sites only supported small herbivores, shrimp and small bodied fish (Sklar et al., 2011).

Increased P sequestration in Chara spp and paired floc may lead to an increase in floc bioavailable $\mathrm{P}$ (organic $\mathrm{P}$ turnover to inorganic $\mathrm{P}$ which is usable by organisms). This in turn may lead to an increase in algal biomass thus stabilizing Chara spp dominance in these sites as well as further bottom up control of phytoplankton (Siong \& Asaeda, 2006). This could also lead to a decrease in gross primary production. It was found in 2008 that gross primary production was 10 -fold higher in control plots than in the open water plots. A more oxic environment has also been shown in open plots which lead to the rapid growth of gram negative bacteria and fungi (Bellinger et al., 2012). This microbial increase may in turn alter decomposition and turnover rates.

It is important to continue to study floc layer dynamics as this research fills mechanistic gaps in the knowledge of plant-detrital-nutrient pathways. Cattail stands have been expanding throughout the water conservation areas due to an increase in phosphorous input from neighboring agricultural sources, and this is not an uncommon problem for many other aquatic systems. Active management strategies will be necessary for the restoration of function in these areas. Understanding all of the biogeochemical implications of emergent macrophyte removal and subsequent growth of 
submersed macrophytes is therefore essential in predicting the effects of these

management strategies and how best to procede with them.

Table 4.1: Summary of overall results of unfractionated sample and fractionation A soluble and insoluble material.

\begin{tabular}{|c|c|c|c|c|}
\hline & Unfractionated & HW soluble & NaOH soluble & Insoluble residue \\
\hline 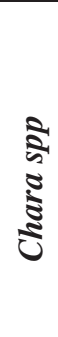 & $\begin{array}{l}\text { Contains: AGP, } \\
(1,4)-\beta-\mathrm{D} \\
\text { galactan, xylan, } \\
\text { unesterified HG, } \\
\text { esterified HG }\end{array}$ & $\begin{array}{ll}\text { - } & 48.8 \% \text { of total } \\
& \text { recovered soluble } \\
\text { - } & 10.3 \% \text { ester } \\
& \text { sulfate } \\
\text { - } & 31.2 \% \text { uronic acid } \\
\text { - } & 48.3 \% \\
& \text { carbohydrate } \\
\text { - } & \text { Contains: xylan }\end{array}$ & $\begin{array}{ll}\text { - } & 51.2 \% \text { of total } \\
& \text { recovered soluble } \\
\text { - } & 6.8 \% \text { ester sulfate } \\
\text { - } & 30.8 \% \text { uronic acid } \\
\text { - } & 60.3 \% \\
& \text { carbohydrate } \\
\text { - } & \text { Contains xylan, } \\
& \text { xyloglucan }\end{array}$ & $\begin{array}{l}\text { - Contains: } \\
\text { xylan, } \\
\text { unesterified } \\
\text { HG, esterified } \\
\text { HG }\end{array}$ \\
\hline$\overline{0}$ & $\begin{array}{l}\text { Contains: AGP, } \\
(1,4)-\beta-\mathrm{D} \\
\text { galactan, xylan, } \\
\text { xyloglucan, } \\
\text { unesterified HG, } \\
\text { esterified HG }\end{array}$ & $\begin{array}{ll}\text { - } & 75.6 \% \text { of total } \\
& \text { recovered soluble } \\
\text { - } & 9.2 \% \text { ester sulfate } \\
\text { - } & 10.9 \% \text { uronic acid } \\
\text { - } & 21.6 \% \\
& \text { carbohydrate } \\
\text { - } & \text { Contains: AGP, } \\
& \text { xylan, esterified } \\
\text { HG }\end{array}$ & $\begin{array}{ll}\text { - } & 24.4 \% \text { of total } \\
& \text { recovered soluble } \\
\text { - } & 10.1 \% \text { ester sulfate } \\
\text { - } & 14.9 \% \text { uronic acid } \\
\text { - } & 26.6 \% \\
& \text { carbohydrate } \\
\text { - } & \text { Contains: AGP, } \\
& \text { xylan, xyloglucan, } \\
\text { esterified HG }\end{array}$ & $\begin{array}{l}\text { - Contains: } \\
\text { unesterified } \\
\text { HG }\end{array}$ \\
\hline ô & $\begin{array}{l}\text { Contains: AGP, } \\
(1,4)-\beta-D \\
\text { galactan, arabinan, } \\
\text { xylan, xyloglucan, } \\
\text { esterified HG }\end{array}$ & $\begin{array}{ll}\text { - } & 34.1 \% \text { of total } \\
& \text { recovered soluble } \\
\text { - } & 13.3 \% \text { ester } \\
& \text { sulfate } \\
\text { - } & 12 \% \text { uronic acid } \\
\text { - } & 24.1 \% \\
& \text { carbohydrate } \\
\text { - } & \text { Contains: xylan }\end{array}$ & $\begin{array}{ll}\text { - } & 66 \% \text { of total } \\
& \text { recovered soluble } \\
\text { - } & 8.1 \% \text { ester sulfate } \\
\text { - } & 18.5 \% \text { uronic acid } \\
\text { - } & 25.2 \% \\
& \text { carbohydrate } \\
\text { - } & \text { Contains: xylan, } \\
& \text { xyloglucan }\end{array}$ & $\begin{array}{l}\text { - Contains: } \\
\text { AGP, }(1,4)-\beta- \\
\text { D galactan, } \\
\text { arabinan, } \\
\text { xylan, } \\
\text { esterified HG }\end{array}$ \\
\hline 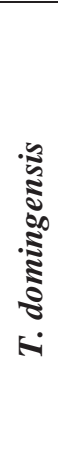 & $\begin{array}{l}\text { Contains: }(1,4)-\beta- \\
\text { D galactan, xylan, } \\
\text { xyloglucan, } \\
\text { esterified } \mathrm{HG}\end{array}$ & $\begin{array}{ll}- & 47.9 \% \text { of total } \\
& \text { recovered soluble } \\
\text { - } & 25.2 \% \text { ester } \\
& \text { sulfate } \\
\text { - } & 27.2 \% \text { uronic acid } \\
\text { - } & 28.6 \% \\
\text { carbohydrate } \\
\text { Contains: AGP, } \\
\text { (1,4)- } \beta-D \\
\text { galactan, xylan, } \\
\text { esterified HG }\end{array}$ & $\begin{array}{ll} & 52.1 \% \text { of total } \\
& \text { recovered soluble } \\
\text { - } & 9.3 \% \text { ester sulfate } \\
\text { - } & 29 \% \text { uronic acid } \\
& 60.5 \% \\
\text { carbohydrate } \\
\text { Contains: AGP, } \\
\text { xylan, xyloglucan, }\end{array}$ & 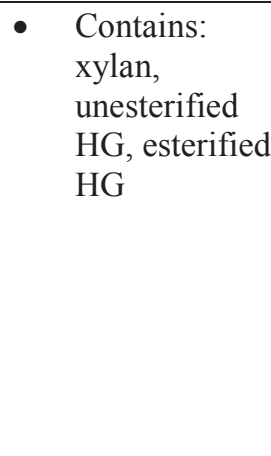 \\
\hline
\end{tabular}




\begin{tabular}{|c|c|c|c|c|}
\hline U & $\begin{array}{l}\text { Contains: AGP, } \\
\text { arabinan, xylan, } \\
\text { xyloglucan, } \\
\text { unesterified HG, } \\
\text { esterified HG }\end{array}$ & $\begin{array}{ll}- & 46.5 \% \text { of total } \\
& \text { recovered soluble } \\
\text { - } & 10.3 \% \text { ester } \\
& \text { sulfate } \\
\text { - } & 15.4 \% \text { uronic acid } \\
\text { - } & 35.7 \% \\
\text { carbohydrate } \\
\text { Contains: AGP, } \\
\text { arabinan, xylan, } \\
\text { unesterified HG }\end{array}$ & $\begin{array}{ll} & 53.5 \% \text { of total } \\
& \text { recovered soluble } \\
\text { - } & 13.1 \% \text { ester sulfate } \\
\text { - } & 8.9 \% \text { uronic acid } \\
\text { - } & 27.8 \% \\
& \text { carbohydrate } \\
\text { - } & \text { AGP, xylan, } \\
& \text { xyloglucan, } \\
& \text { unesterified HG }\end{array}$ & $\begin{array}{l}\text { - Contains: } \\
\text { AGP, } \\
\text { arabinan, } \\
\text { unesterified } \\
\text { HG }\end{array}$ \\
\hline 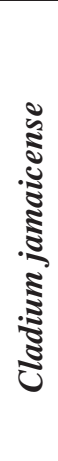 & $\begin{array}{l}\text { Contains: AGP, } \\
(1,4)-\beta-D \\
\text { galactan, arabinan, } \\
\text { xylan, xyloglucan, } \\
\text { unesterified HG, } \\
\text { esterified HG }\end{array}$ & $\begin{array}{ll} & 50 \% \text { of total } \\
& \text { recovered soluble } \\
\text { - } & 21.1 \% \text { ester } \\
& \text { sulfate } \\
\text { - } & 12.9 \% \text { uronic acid } \\
\text { - } & 17.5 \% \\
& \text { carbohydrate } \\
\text { - } & (1,4)-\beta-D \\
\text { galactan, xylan, } \\
\text { xyloglucan, } \\
\text { esterified HG }\end{array}$ & $\begin{array}{ll}\text { - } & 50 \% \text { of total } \\
& \text { recovered soluble } \\
\text { - } & 7.8 \% \text { ester sulfate } \\
\text { - } & 17.1 \% \text { uronic acid } \\
\text { - } & 63.5 \% \\
& \text { carbohydrate } \\
\text { - } & \text { AGP, }(1,4)-\beta-\mathrm{D} \\
& \text { galactan, arabinan, } \\
& \text { xylan, xyloglucan, } \\
\text { esterified HG }\end{array}$ & $\begin{array}{l}\text { Contains: } \\
\text { AGP, }(1,4)-\beta- \\
\text { D galactan, } \\
\text { xylan, } \\
\text { xyloglucan, } \\
\text { unesterified } \\
\text { HG, esterified } \\
\text { HG }\end{array}$ \\
\hline$\ddot{U}$ & $\begin{array}{l}\text { Contains: AGP, } \\
(1,4)-\beta-D \\
\text { galactan, arabinan, } \\
\text { xylan, xyloglucan, } \\
\text { esterified HG }\end{array}$ & $\begin{array}{ll}\text { - } & 55.1 \% \text { of total } \\
& \text { recovered soluble } \\
\text { - } & 12.2 \% \text { ester } \\
& \text { sulfate } \\
\text { - } & 13.5 \% \text { uronic acid } \\
\text { - } & 28.8 \% \\
& \text { carbohydrate } \\
\text { - } & \text { AGP, arabinan, } \\
& \text { xylan, esterified } \\
\text { HG }\end{array}$ & $\begin{array}{ll}\text { - } & 44.9 \% \text { of total } \\
& \text { recovered soluble } \\
\text { - } & 10.2 \% \text { ester sulfate } \\
\text { - } & 13 \% \text { uronic acid } \\
\text { - } & 23.3 \% \\
& \text { carbohydrate } \\
\text { - } & \text { AGP, }(1,4)-\beta-D \\
\text { galactan, arabinan, } \\
\text { xylan, xyloglucan, }\end{array}$ & - Contains: AGP \\
\hline
\end{tabular}

Table 4.2: Summary of overall results of unfractionated sample and fractionation B soluble and insoluble material.

\begin{tabular}{|c|c|c|c|c|}
\hline & МeКОН soluble & DMSO soluble & HW soluble & CDTA soluble \\
\hline 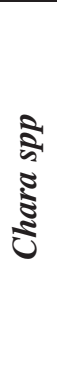 & $\begin{array}{ll}\text { - } & 6.8 \% \text { of total } \\
& \text { recovered } \\
\text { - } & \text { Contains: xylan }\end{array}$ & $\begin{array}{ll}- & 1 \% \text { of total } \\
& \text { recovered } \\
- & 39.7 \% \text { uronic acid } \\
-\quad & 28.3 \% \\
& \text { carbohydrate }\end{array}$ & $\begin{array}{ll} & 4.2 \% \text { of total } \\
& \text { recovered } \\
\text { - } & 32 \% \text { uronic acid } \\
\text { - } & 63.6 \% \\
& \text { carbohydrate } \\
\text { - } & \text { Contains: xylan }\end{array}$ & $\begin{array}{ll} & 2.6 \% \text { of total } \\
\text { - } & 34.4 \% \text { uronic } \\
\text { acid } \\
\text { - } 22.4 \% \\
\text { carbohydrate } \\
\text { - Contains: } \\
\text { unesterified } \\
\text { HG }\end{array}$ \\
\hline
\end{tabular}




\begin{tabular}{|c|c|c|c|c|}
\hline$\overline{0}$ & $\begin{array}{ll} & 21.7 \% \text { of total } \\
& \text { recovered } \\
& \text { Contains: xylan }\end{array}$ & $\begin{array}{ll}- & 2.5 \% \text { of total } \\
& \text { recovered } \\
\text { - } & 14.6 \% \text { uronic acid } \\
\text { - } & 17.2 \% \\
& \text { carbohydrate } \\
\text { - } & \text { Contains: xylan }\end{array}$ & $\begin{array}{l}\text { - } 4.6 \% \text { of total } \\
\text { recovered } \\
17.6 \% \text { uronic acid } \\
\text { - } \quad 19.4 \% \\
\text { carbohydrate } \\
\text { Contains: xylan, } \\
\text { xyloglucan }\end{array}$ & 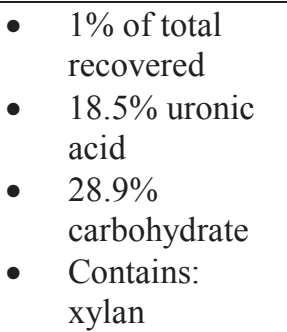 \\
\hline$\stackrel{0}{0}$ & $\begin{array}{l}\text { - } 31.8 \% \text { of total } \\
\text { recovered } \\
\text { Contains: xylan, } \\
\text { xyloglucan }\end{array}$ & $\begin{array}{ll} & 5.2 \% \text { of total } \\
& \text { recovered } \\
\text { - } & 26.8 \% \text { uronic acid } \\
\text { - } & 18.4 \% \\
& \text { carbohydrate } \\
\text { - } & \text { Contains: } \\
& \text { arabinan }\end{array}$ & $\begin{array}{ll}- & 4.2 \% \text { of total } \\
& \text { recovered } \\
& 27.5 \% \text { uronic acid } \\
- & 43.7 \% \\
\text { carbohydrate } \\
\text { Contains: xylan, } \\
\text { xyloglucan, } \\
\text { unesterified HG }\end{array}$ & $\begin{array}{l}\text { - } 3.4 \% \text { of total } \\
\text { recovered } \\
16.9 \% \text { uronic } \\
\text { acid } \\
15.3 \% \\
\text { carbohydrate } \\
\text { Xylan, } \\
\text { xyloglucan, } \\
\text { esterified HG }\end{array}$ \\
\hline 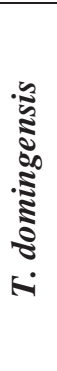 & 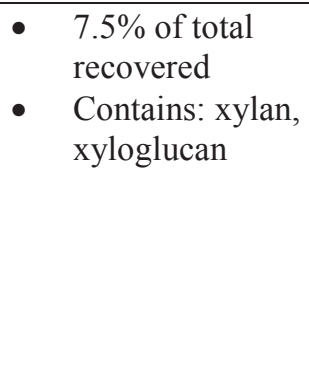 & $\begin{array}{ll}\text { - } & 2.4 \% \text { of total } \\
& \text { recovered } \\
\text { - } & 33.5 \% \text { uronic acid } \\
\text { - } & 29.6 \% \\
& \text { carbohydrate } \\
\text { - } & \text { Contains: AGP, } \\
& (1,4)-\beta-D \\
\text { galactan, xylan, } \\
\text { xyloglucan }\end{array}$ & $\begin{array}{ll} & 1.5 \% \text { of total } \\
& \text { recovered } \\
& 46.4 \% \text { uronic acid } \\
\text { - } & 50.5 \% \\
\text { carbohydrate } \\
\text { Contains: }(1,4)-\beta-\mathrm{D} \\
\text { galactan, xylan, } \\
\text { xyloglucan, } \\
\text { unesterified HG }\end{array}$ & $\begin{array}{ll}-5.5 \% \text { of total } \\
& \text { recovered } \\
& 15 \% \text { uronic } \\
& \text { acid } \\
& 13.5 \% \\
\text { carbohydrate } \\
\text { Contains: } \\
\text { (1,4)- } \beta-\mathrm{D} \\
\text { galactan, xylan }\end{array}$ \\
\hline$\bigcup_{=1}$ & $\begin{array}{ll} & 27.3 \% \text { of total } \\
& \text { recovered } \\
& \text { Contains: xylan }\end{array}$ & $\begin{array}{ll} & 1.6 \% \text { of total } \\
& \text { recovered } \\
\text { - } & 15.2 \% \text { uronic acid } \\
\text { - } & 12.3 \% \\
& \text { carbohydrate } \\
\text { - } & \text { Contains: xylan }\end{array}$ & $\begin{array}{l}\text { - } 3.1 \% \text { of total } \\
\text { recovered } \\
\text { - } 16.5 \% \text { uronic acid } \\
16.1 \% \\
\text { carbohydrate } \\
\text { Contains: xylan, } \\
\text { xyloglucan }\end{array}$ & $\begin{array}{ll} & 3.4 \% \text { of total } \\
\text { recovered } \\
10.5 \% \text { uronic } \\
\text { acid } \\
\text { - } 5.7 \% \\
\text { carbohydrate } \\
\text { Contains: } \\
\text { xylan } \\
\end{array}$ \\
\hline 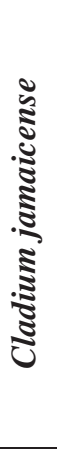 & $\begin{array}{l}\text { - } \quad .6 \% \text { of total } \\
\text { recovered } \\
\text { Contains: xylan, } \\
\text { xyloglucan }\end{array}$ & $\begin{array}{ll}- & 0.6 \% \text { of total } \\
& \text { recovered } \\
- & 25.6 \% \text { uronic acid } \\
\text { - } & 35.4 \% \\
& \text { carbohydrate } \\
\text { - } & \text { Contains: xylan }\end{array}$ & $\begin{array}{l}2 \% \text { of total } \\
\text { recovered } \\
\text { - } \\
36.1 \% \text { uronic acid } \\
65.8 \% \\
\text { carbohydrate } \\
\text { Contains: }(1,4)-\beta-D \\
\text { galactan, arabinan, } \\
\text { xylan, xyloglucan, } \\
\text { unesterified HG }\end{array}$ & $\begin{array}{l}1.8 \% \text { of total } \\
\text { recovered } \\
19.9 \% \text { uronic } \\
\text { acid } \\
19.9 \% \\
\text { carbohydrate } \\
\text { Contains: } \\
(1,4)-\beta-\mathrm{D} \\
\text { galactan, } \\
\text { xylan, } \\
\text { xyloglucan }\end{array}$ \\
\hline
\end{tabular}




\begin{tabular}{|c|c|c|c|c|}
\hline$\ddot{U}$ & $\begin{array}{ll}- & 25.1 \% \text { of total } \\
\text { recovered } \\
\text { Contains: xylan, } \\
\text { xyloglucan }\end{array}$ & $\begin{array}{ll} & 6.1 \% \text { of total } \\
& \text { recovered } \\
\text { - } & 17.1 \% \text { uronic acid } \\
\text { - } & 38.7 \% \\
& \text { carbohydrate }\end{array}$ & $\begin{array}{ll} & 2.7 \% \text { of total } \\
& \text { recovered } \\
& 25.7 \% \text { uronic acid } \\
-\quad & 26.3 \% \\
\text { carbohydrate } \\
\text { Contains: AGP, } \\
(1,4)-\beta-D \text { galactan, } \\
\text { xylan, xyloglucan }\end{array}$ & $\begin{array}{ll} & 4.3 \% \text { of total } \\
& \text { recovered } \\
& 7.2 \% \text { uronic } \\
& \text { acid } \\
\text { - } & 5.2 \% \\
\text { carbohydrate } \\
\text { - } \\
\text { Contains: } \\
\text { xylan, } \\
\text { xyloglucan, } \\
\text { esterified HG }\end{array}$ \\
\hline & $\mathrm{Na}_{2} \mathrm{CO} 3$ soluble & 1M КОН soluble & 4M КОН soluble & Insoluble residue \\
\hline$\frac{0}{0}$ & $\begin{array}{ll}\text { - } & 1.5 \% \text { of total } \\
& \text { recovered } \\
\text { - } & 29.3 \% \text { uronic acid } \\
\text { - } & 15 \% \text { carbohydrate } \\
\text { - } & \text { Contains: xylan, } \\
& \text { unesterified HG }\end{array}$ & $\begin{array}{ll}\text { - } & 33.6 \% \text { of total } \\
& \text { recovered } \\
\text { - } & 14.4 \% \text { uronic acid } \\
\text { - } & 6.3 \% \\
& \text { carbohydrate } \\
\text { - } & \text { Contains: xylan }\end{array}$ & $\begin{array}{ll}\text { - } & 0.1 \% \text { of total } \\
& \text { recovered } \\
\text { - } & 19.4 \% \text { uronic acid } \\
\text { - } & 7.3 \% \text { carbohydrate } \\
\text { - } & \text { Contains: xylan, } \\
& \text { xyloglucan }\end{array}$ & $\begin{array}{l}\text { - } 50.3 \% \text { of total } \\
\text { recovered } \\
\text { Contains: } \\
\text { Xylan, } \\
\text { unesterified } \\
\text { HG, esterified } \\
\text { HG }\end{array}$ \\
\hline$\overline{0}$ & $\begin{array}{ll}\text { - } & 3 \% \text { of total } \\
& \text { recovered } \\
\text { - } & 10.7 \% \text { uronic acid } \\
\text { - } & 4 \% \text { carbohydrate }\end{array}$ & $\begin{array}{ll} & 7.9 \% \text { of total } \\
& \text { recovered } \\
- & 6.5 \% \text { uronic acid } \\
- & 1.5 \% \\
& \text { carbohydrate } \\
\text { - } & \text { Contains: xylan } \\
\end{array}$ & $\begin{array}{ll} & 27.2 \% \text { of total } \\
& \text { recovered } \\
- & 3.7 \% \text { uronic acid } \\
\text { - } & 0.4 \% \text { carbohydrate } \\
\text { - } & \text { Contains: xylan, } \\
& \text { xyloglucan } \\
\end{array}$ & $\begin{array}{l}32.2 \% \text { of total } \\
\text { recovered }\end{array}$ \\
\hline 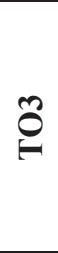 & $\begin{array}{l}1.5 \% \text { of total } \\
\text { recovered }\end{array}$ & $\begin{array}{ll}- & 2.7 \% \text { of total } \\
& \text { recovered } \\
\text { - } & 24.9 \% \text { uronic acid } \\
\text { - } & 12.4 \% \\
& \text { carbohydrate } \\
\text { - } & \text { Contains: xylan }\end{array}$ & $\begin{array}{ll} & 12.2 \% \text { of total } \\
& \text { recovered } \\
\text { - } & 7.8 \% \text { uronic acid } \\
\text { - } & 2.4 \% \text { carbohydrate } \\
\text { - } & \text { Contains: xylan, } \\
& \text { xyloglucan }\end{array}$ & $\begin{array}{l}\text { 38.8\% of total } \\
\text { recovered } \\
\text { Contains: } \\
\text { AGP, xylan, }\end{array}$ \\
\hline 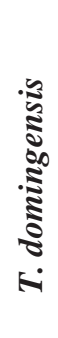 & $\begin{array}{l}\text { - } 2.4 \% \text { of total } \\
\text { recovered } \\
\text { - } \quad 26 \% \text { uronic acid } \\
\text { - } \quad \text { Contains: }(1,4)-\beta \text { - } \\
\text { D galactan, } \\
\text { arabinan, xylan, } \\
\text { xyloglucan }\end{array}$ & $\begin{array}{ll}\text { - } & 0.1 \% \text { of total } \\
& \text { recovered } \\
\text { - } & 18.7 \% \text { uronic acid } \\
\text { - } & 8.9 \% \\
\text { carbohydrate } \\
\text { - Contains: }(1,4)-\beta- \\
\text { D galactan, xylan, } \\
\text { xyloglucan }\end{array}$ & $\begin{array}{ll}\text { - } & 66.8 \% \text { of total } \\
& \text { recovered } \\
- & 9.1 \% \text { uronic acid } \\
- & 3.2 \% \text { carbohydrate } \\
\text { - } & \text { Contains: }(1,4)-\beta-D \\
& \text { galactan, xylan, } \\
& \text { xyloglucan }\end{array}$ & $\begin{array}{l}\text { - } 13.8 \% \text { of total } \\
\text { recovered } \\
\text { Contains: } \\
\text { xylan }\end{array}$ \\
\hline 已 & $\begin{array}{ll}\text { - } & 2.9 \% \text { of total } \\
& \text { recovered } \\
\text { - } & 6.2 \% \text { uronic acid } \\
\text { - } & 1.3 \% \\
& \text { carbohydrate }\end{array}$ & $\begin{array}{ll}\text { - } & 3.8 \% \text { of total } \\
& \text { recovered } \\
\text { - } & 16 \% \text { uronic acid } \\
\text { - } & 7.1 \% \\
& \text { carbohydrate } \\
\text { - } & \text { Contains: } x y l a n\end{array}$ & $\begin{array}{ll}\text { - } & 46.1 \% \text { of total } \\
& \text { recovered } \\
\text { - } & 4.3 \% \text { uronic acid } \\
\text { - } & 0.3 \% \text { carbohydrate }\end{array}$ & $\begin{array}{l}\text { - } 11.9 \% \text { of total } \\
\text { recovered } \\
\text { - } \quad \text { Contains: AGP }\end{array}$ \\
\hline
\end{tabular}




\begin{tabular}{|c|c|c|c|c|}
\hline 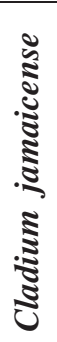 & 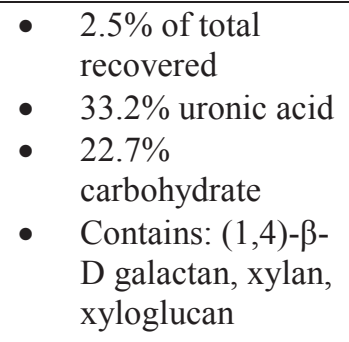 & $\begin{array}{ll}- & 30.4 \% \text { of total } \\
& \text { recovered } \\
- & 8.3 \% \text { uronic acid } \\
- & 2.7 \% \\
& \text { carbohydrate } \\
\text { - } & \text { Contains: xylan, } \\
& \text { xyloglucan }\end{array}$ & $\begin{array}{ll} & 33 \% \text { of total } \\
& \text { recovered } \\
- & 20.8 \% \text { uronic acid } \\
- & 10.1 \% \\
& \text { carbohydrate } \\
\text { - } & \text { Contains: }(1,4)-\beta-D \\
& \text { galactan, xylan, } \\
& \text { xyloglucan }\end{array}$ & $\begin{array}{ll} & 20.2 \% \text { of total } \\
& \text { recovered } \\
\text { - } & \text { Contains: } \\
& \text { AGP, xylan }\end{array}$ \\
\hline$\bigcup_{\theta}^{0}$ & $\begin{array}{ll}-1.8 \% \text { of total } \\
\text { recovered }\end{array}$ & $\begin{array}{ll}- & 2.1 \% \text { of total } \\
& \text { recovered } \\
- & 19.8 \% \text { uronic acid } \\
- & 9.1 \% \\
& \text { carbohydrate } \\
\text { - } & \text { Contains: xylan }\end{array}$ & $\begin{array}{ll}\text { - } & 37.2 \% \text { of total } \\
& \text { recovered } \\
- & 3.6 \% \text { uronic acid } \\
\text { - } & 0.4 \% \text { carbohydrate } \\
\text { - } & \text { Contains: xylan, } \\
& \text { xyloglucan }\end{array}$ & $\begin{array}{l}20.8 \% \text { of total } \\
\text { recovered } \\
\text { Contains: } \\
\text { xylan }\end{array}$ \\
\hline
\end{tabular}




\section{Literature Cited (a-z)}

Aronson JM, Lin CCL. 1978. Hyphal cell wall chemistry of Leptomitus lacteus. Mycologia. 70: 363-369.

ATT Bioquest (Producer). 2012. Amplite colorimetric calcium quantitation kit. Product technical information sheet. 1-4.

Bandrowski JF, Benson CL. 1972. Investigation of the use of calcein in the ultramicro Fluorometric Determination of Calcium in Serum. Clinical Chemistry. 18: 11.

Belika LL, Sokol ER, Hoch M, Jaffe R, Trexler JC. 2012. A molecular stable isotopic approach to investigate algal and detrital energy pathways in a freshwater marsh.

Wetlands. 32: 531-542.

Benner R, Newell SY, Maccubbin AE, Hodson RE. 1984. Relative contributions of bacteria and fungi to rates of degradation of lignocellulosic detritus in salt-marsh sediments. Applied Environmental Microbiology. 48(1): 36-40.

Bhaskar PV, Narayan BB. 2005. Microbial extracellular polymeric substances in marine biogeochemical processes. Current Science. 88(1): 45-53.

Boer W, Folman LB, Summerbell RC, Boddy L. 2004. Living in a fungal world: impact of fungi on soil bacterial niche development. FEMS Microbiology Reveiws. 29: 795811.

Bitter T, Muir HM. 1962. A modified uronic acid carbozole reaction. Analytical Biochemistry. 4: 330-334.

Bradford MM. 1976. A rapid and sensitive method for the quantitation of microgram quantities of protein utilizing the principle of protein-dye binding. Analytical Biochemistry. 72: 248-54.

Carpita NC, Gibeaut DM. 1993. Structural models of the primary cell walls in flowering plants: consistency of molecular structure with the physical properties of the walls during growth. Plant Journal. 3: 1-30.

Carpita NC. 1996. Structure and biogenesis of the cell walls of grasses. Annual Review of Plant Physiology and Plant Molecular Biology. 47: 445-476.

Carpita NC, McCann M. 2000. The cell wall. In: Buchanan B B, Gruissem W, Jones R L (ed) Biochemistry and Molecular Biology of Plants. American Society of Plant Physiologists. Rockville, Md. 52-108.

Cassab GI. 1998. Plant cell wall proteins. Annual Review of Plant Physiology and Plant Molecular Biology. 49: 281-309. 
Chiang C, Craft CB, Rogers DW, Richardson CJ. 2000. Effects of 4 years of nitrogen and phosphorus additions on Everglades plant communities. Aquatic Botany. 68(1): 6178.

Chameir AC. 1985. Cell-wall-degradaing enzymes of aquatic hyphomycetes: a review. Botanical Journal of the Linnean Society. 91(1-2): 67-81.

Chandler DE, Roberson RW. 2009. Bioimaging: Current techniques in light and electron microscopy. Jones and Bartlett Publishers. Sudburry, MA.

Chan WCW, Shuming N. Quantum dot bioconjugates for ultrasensitive detection. 1998. Science. 281(5385): 2016-2018.

Cleckner LB, Gilmour CC, Hurley JP, Krabbenhoft DP. 1999. Mercury methylation in periphyton of the Florida Everglades. Limnology and Oceanography. 44(7): 1815-1825.

Cook ME, Graham LE, Lavin CA. 1998. Cytokinesis and nodal anatomy in the charophycean green alga Chara zeylanica. Protoplasma. 203(1-2): 65-74.

Cook ME. 2004. Cytokinesis in Coleochaete orbicularis (Charophyceae): an ancestral mechanism inherited by plants. American Journal of Botany. 91: 313-320.

Corstanje R, Reddy KR, Prenger JP, Newman S, Ogram AV. 2007. Soil microbial ecophysiological response to nutrient enrichment in a sub-tropical wetland. Ecological Indicators. 7: 277-289.

Cosgrove DJ. 2005. Growth of the plant cell wall. Nature Reviews Molecular Cell Biology. 6: 850-861.

Cosgrove DJ. 2005. Loosening of plant cell walls by expansins. Nature. 407: 321-326.

Craigie JS, Wen ZCL, Van de Meer JP. 1984. Interspecific, intraspecific and nutritionally-determined variation in the composition of agars from Gracilaria spp. Botanica Marina. 27: 55-61.

Davis SM. 1991. Growth, decoposition and nutrient retention of Cladium jamaicense Crantz and Typha domingensis Pers. in the Florida Everglades. Aquatic Botany. 40: 203224.

Davis SM, Ogden JC. 1994. Towards ecosystem restoration. P. 769-796. In: Davis SM, Ogden JC (eds.) Everglades, the ecosystem and its restoration. St. Lucie Press. Delaray Beach, FL.

Debusk WF and Reddy KR. 1998. Turnover of detrital organic carbon in a nutrientimpacted Everglades marsh. American Journal of Soil Science. 62: 1460-1468. 
Domozych DS, Kort S, Benton S, Yu T. 2005. The extracellular polymeric substance of the green alga Penium margaritaceum and its role in biofilm formation. Biofilms. 2: 129144.

Domozych DS, Serfis A, Kiemle SN. 2007. The structure and biochemistry of charophycean cell walls: I. Pectins of Penium margaritaceum. Protoplasma. 230: 99-115.

Domozych DS, Sørensen I, Willats WG. 2009. The distribution of cell wall polymers during antheridium development and spermatogenesis in the Charophycean green alga, Chara corallina. Annals of Botany. 104: 1045-1056.

Domozych DS, Ciancia M, Fangel JU, Mikkelsen MD, Ulvskov P, Willats WGT. 2012. The Cell Walls of Green Algae: A Journey through Evolution and Diversity. Frontiers in Plant Science. 3: 82.

Dou Z, Toth JD, Galligan DT, Ranberg CF, Ferguson JD. 2000. Laboratory procedures for characterizing manure phorsorus. Journal of Environmental Quality. 29: 508-514.

Dubois M, Gilles KA, Hamiltion JK, Rebers PA, Smith F. 1956. Colormetric method for determination of sugars and related substances. Analytical Chemistry. 28: 350-56.

Fazio SA, Uhlinger DJ, Parker JH, White DC. 1982. Estimations of Uronic Acids as Quantitative Measures of Extracellular and Cell Wall Polysaccaride Polymers from Environmental Samples. Applied Environmental Microbiology. 43(5): 1151.

Fry SCL. 2000. The growing plant cell wall: chemical and metabolic analysis. Blackburn Press. Caldwell, NJ.

Grimshaw H J, et al. 1997. Shading of periphyton communities by wetland emergent macrophytes: decoupling of algal photosynthesis from microbial nutrient retention. Archiv für Hydrobiologie 139(1): 17-27.

Graham SA, Mendelsshon IA. 2010. Multiple levels of nitrogen applied to an oligohaline marsh identify a plant community response sequence to eutrophication. Marine Ecology Progress Series. 417: 73-82.

Grynkiewicz G, Poenie M, Tsien RY. 1985. A new generation of Ca2+ indicators with greatly improved fluorescence properties. Biological Chemistry. 260: 3440-3450.

Gutknecht LM, Goodman RM, Balser TC. 2006. Linking soil process and microbial ecology in freshwater wetland ecosystems. Plant Soil. 289: 17-34.

Hagerthey SE, Newman S, Rutchey K, Smith EP, Godin J. 2008. Multiple regime shifts in subtropical peatland: community specific thresholds to eutrophication. Ecological Monographs. 78(4): 547-565. 
Harris PJ, Henry RJ, Blakeney AB, Stone BA 1984. An improved procedure for the mehtylation analysis of oligosaccharides and polysaccharides. Carbohydrate Research. 127: 59-73.

Howarth RW, Marino R, Lane J. 1988. Nitrogen fixation in freshwater, estuarine and marine ecosystems. Limnology and Oceanography. 33: 669-687.

Hutchinson GE. 1957. A Treatise on Limnology, volume 1. Geography, Physics and Chemistry. Wiley. NY.

Hutchinson GE. 1975. A Treatise on Limnology, volume 3. Limnological Botany. John Wiley \& Sons. NY.

Jeffree CE. 1993. Immobilization of pectin, xyloglucan and other soluble plant polysaccharides on blotting membranes. New Phytology. 125: 695-706.

Jones JB. 2001. Laboratory Guide for Conducting Soil Tests and Plant Analysis. CRC Press. New York. 76-78.

Kiemle SN. 2010. The extracellular matrix of the charophycean green algae. 2010. Michigan Technological University. Houghton, MI.

Kim JB, Carpita NC. 1992. Changes in Esterification of the Uronic Acid Groups of Cell Wall Polysaccharides During Elongation of Maize Coleoptiles. Plant Physiology. 98(2): 646-653.

Knox JP, et al. 1990. Pectin Esterification is spatially regulated both within cell walls and between developing tissues of root apices. Planta. 184(4): 512-521.

Knox PJ. 2008. Revealing the structural and functional diversity of plant cell walls. Current Opinion in Plant Biology. 11(3): 308-313.

Kufel L, Kufel I. 2002. Chara beds acting as nutrient sinks in shallow lakes - A review. Aquatic Botany. 72(3-4): 249-260.

Lodge TE. 2010. The Everglades Handbook, $3^{\text {rd }}$ edition. CRC Press. Boca Ranton, FL.

Lorenzen B, Brix H, Mendelssohn IA, McKee KL, Miao SL. 2001. Growth, biomass allocation and nutrient use efficiency in Cladium jamaicense and Typha domingensis as affected by phosphorus and oxygen availability. Aquatic Botany. 70: 117-133.

Lorenzen B, Brix H, McKee KL, Mendelssohn IA, Miao SL. 2000. Seed germination of two Everglades species, Cladium jamaicense and Typha domingensis. Aquatic

Botany. 66: 169-180.

Loveless CM. 1959. A study of the vegetation in the Florida Everglades. Ecology. 40: $1-9$. 
Marcus SE, Verhertbruggen Y, Hervé C, Ordaz-Ortiz JJ, Farkas V, Pedersen HL, Willats GTW, Knox JP. 2008. Pectic homogalacturonan masks abundant sets of xyloglucan epitopes in plant cell walls. BMC Plant Biology. 8(60). doi:10.1186/14712229-8-60.

Mattox KR and Stewart KD. 1984. Classification of the green algae: a concept based on comparative cytology. In: Systematics of of the Green Algae. Academic Press. London. 29-72.

McCormick PV, O’Dell MB. 1996. Quantifying periphyton responses to phosphorus in the Florida Everglades: a synoptic-experimental approach. Journal of American Benthological Society. 15: 450-468.

McCormick PV, Newman S, Payne GG, Miao SL, Reddy KR, Fontaine TD. 2000. Ecological effects of phosphorus enrichment in the Everglades IN: Everglades Consolidated Report. South Florida Water Management District, West Palm Beach, FL, USA.

Miao SL, Sklar FH. 1998. Biomass and nutrient allocation of sawgrass and cattail along a nutrient gradient in the Florida Everglades. Wetland Ecological Management. 5: 245263.

Mitsch WJ, Gosselink JG. 1993. Wetlands. $2^{\text {nd }}$ edition. Van Nostrand Reinhold. NY.

Mitsch WJ, Gosselink JG. 2000. The value of wetlands: importance of scale and landscape setting. Ecological Economics. 35(200): 25-33.

Mohnen D. 2008. Pectin structure and synthesis. Current Opinion Plant Biology 11: 266-277.

Murphey J, Riley J. 1962. A modified single solution method for the determination of phosphate in natural waters. Analytica Chimica Acta. 27: 31-36.

Neto RR, Mead RN, Louda JW, Jaffe R. 2006. Organic biogeochemistry of detrital flocculent material (floc) in subtropical, coastal wetland. Biogeochemistry. 77: 283-304.

Newman S, Grace JB, Koebel JW. 1996. Effects of nutrients and hydroperiod on Typha, Cladium and Eleocharis: implications for Everglades restoration. Ecological Applications. 6: 774-783.

Newman S, Hagerthy S, Cook M, Manna M, Jacoby M, Bellinger B, Wheeler K, Kobza RM, Shuford R. 2008-2010. Cattail Habitat Improvement Project. "Ecosystem Ecology" in: Chapter 6: Ecology of the Everglades Protection Area, South Florida Environmental Report. South Florida Water Management District. West Palm Beach, Fl.

Newman S, Kumf H, Liang JA, Kennedy WC. 2001. Decomposition responses to phosphorus enrichment in an Everglades slough. Biogeochemistry. 54: 229-250. 
Newman S, Reddy KR, DeBusk WF, Wang Y, Shih G, Fisher MM. 1997. Spatial distribution of soil nutrients in a northern Everglades marsh: Water Conservation Area 1. Soils Science Society of America. 61: 1275-1283.

Newman S, Schuette J, Grace JB, Rutchey K, Fontaine T, Reddy KR, Pietrucha M. 1998. Factors influencing cattail abundance in the northern everglades. Aquatic Botany. 60: 265-280.

Nichols HW. 1973. Growth media-freshwater. In: Stein JR (ed) Handbook of phycological methods: Culture methods and growth measurements. Cambridge University Press. NY. 39-78.

Ogden JC. 2005. Everglades ridge and slough conceptual ecological model. Wetlands. 25(4): 8101-831.

Popper ZA, Fry SC. 2003. Primary cell wall composition of bryophytes and charophytes. Planta. 91(1): 1-12.

Popper ZA. 2008. Evolution and diversity of green plant cell walls. Current Opinion in Plant biology. 11(3): 286-292.

Reddy KR, D’Angelo. 1994. Diagenesis of Organic Matter in a Wetland Receiving Hypereutrophic Lake Water: I. Distribution of Dissolved Nutrients in the Soil and Water Column. Journal of Environmental Quality. 23(5): 928-936.

Reddy KR, DuLaune RD. Biogeochemistry of Wetlands: Science and Applications. 2008. CRC Press. Boca Raton, FL. 1-5.

Reddy KR, White JR, Wright A, Chua T. 1999. Influence of phosphorus loading on microbial processes in the soil and water column of wetlands. In: Reddy KR, O'Connor GA, Schlske CL (Eda) Phosphorus Biogeochemistry in Subtropical Ecosystems. Lewis Publishers. Boca Ratan, FL. 249-273.

Richardson CJ, Vaithiyanathan P. 1995. Phosphorus Sorption Characteristics of Everglades Soils along a Eutrophication Gradient. Soils Science Society of America. 59(6): 1782-1788.

Richardson JC, Marshall PE. 1986. Processes controlling movement, storage, and export of phosphorus in a fen peatland. Ecological Monographs. 56: 279-302.

Seifert GJ, Roberts K. 2007. The biology of arabinogalactan proteins. Annual Review of Biology. 58: 137-161.

SFWMD. 1992. Surface water improvement and management plan for the Everglades. South Florida Water Management District, West Palm Beach, FL, USA. 
Showalter AM. 2001. Arabinogalactan-proteins: structure, expression and function. Cellular and Molecular Life Sciences. 58: 1399-1417.

Siong K, Aseada T. 2006. Does calcification in Chara provide a phosphorous nutrient sink? Journal of Environmental Quality. 35: 490-494.

Siong K, Aseada T. 2009. Calcite encrustation in macro-algae Chara and its implication to the formation of carbonate-bound cadmium. Journal of Hazardous Materials. 167: 1237-1241.

Sklar F, Dreschel T, Warren K. 2008-2013. Chapter 6: Ecology of the Everglades Protection Area, South Florida Environmental Report. South Florida Water Management District. West Palm Beach, F1. 1-91.

Sorensen I, Pettolino FA, Bacic A, Ralph J, Lu F, O’Neill MA, Fei Z, Rose JK, Domozych DS, Willats WGT. 2011. The charophycean green algae provide insights into the early origins of plant cell walls. The Plant Journal. 68: 201-211.

Steward KK, Ornes WH. 1975. Assessing a marsh environment for wastewater renovation. Journal of Water Pollution Control Federation. 47(7): 1880-1891.

Suberkropp K, Klugg MJ. 1980. The maceration of deciduous leaf litter by aquatic hyphomycetes. Canadian Journal of Botany. 58(9): 1025-1031.

United States Environmental Protection Agency. 2001. Functions and Values of Wetlands. <http://water.epa.gov/type/wetlands/funtions.cfm>. September, 2011.

United States Environmental Protection Agency. 2012. Wetlands Status and Trends. < http://water.epa.gov/lawsregs/guidance/wetlands/status.cfm>. September, 2012.

Verhertbruggen Y, Marcus SE, Haeger A, Ordaz-Ortiz JJ, Knox P. 2009. An extended set of monoclonal antibodies to pectic homogalacturonan. Carbohydrate Research. 344: $1858-1862$.

Vogel J. 2008. Unique aspects of the grass cell wall. Current Opinion in Plant Biology. 11(3): 301-307.

Webster JR, Benfield EF. 1986. Vascular Plant Breakdown in Freshwater Ecosystems. Annual Review of Ecological Systems. 17: 567-94.

Westerman P. 1993. Wetland and swamp microbiology. Aquatic Microbiology. Blackwell Scientific, Cambridge, MA. 215-238.

Willats GT, Marcus SE, Knox JP. 1998. Generation of a monoclonal antibody specific to (1-5)- $\alpha$-L-arabinan. Carbohydrate Research. 308: 149-152.

Willats WG, McCartney L, Mackie W, Knox JP. 2001. Pectin: cell biology and prospects for functional analysis. Plant Molecular Biology. 47: 9-27. 
Wustman BA, Gretz MR, Hoagland KD. 1997. Extracellular matrtix assembly in diatoms (Bacillariophyceae). I. A model of adhesives based on chemical characterization and localization of polysaccharides from the marine diatom Achnanthes longipes and other diatoms. Plant Physiology. 113: 1059-1069

Zak DR, Holmes WE, White DC, Peacock AD, Tilman D. 2003. Plant diversity, soil microbial communities and ecosystem function: are there any links? Ecology. 84: 20422050 .

Zedler JB, Kercher S. 2005. Wetland resources: status, trends, ecosystem services and restorability. Annual Review of Environmental Resources. 30: 39-74.

Zykwinska AW, Ralet MC, Garnier CD and Thibault JF. 2005. Evidence for in vitro binding of pectin side chains to cellulose. Plant Physiology 139: 397-407.

\section{Appendices}

\section{Methods:}

\section{Fractionation Method A}

\section{HW Soluble Fraction}

1. Grind approximately $1 \mathrm{~g}$ of sample to fine powder under liquid nitrogen

2. Add $50 \mathrm{~mL}$ of $\mathrm{dH}_{2} \mathrm{O}$ to sample

3. Vortex thoroughly

4. Place in hot water bath $\left(95^{\circ} \mathrm{C}\right)$ for 1 hour

5. Remove allow to cool and centrifuge, collect supernatant

6. Repeat steps 1-4 twice more (total of 3 times)

\section{NaOH Soluble Fraction}

1. Add $50 \mathrm{~mL} 6 \mathrm{M} \mathrm{NaOH}$ to $\mathrm{HW}$ pellet

2. Vortex thouroughly

3. Let sit for 1 hour at $21^{\circ} \mathrm{C}$

4. Remove allow to cool and centrifuge, collect supernatant

5. Repeat steps 1-4 twice more (total of 3 times)

*Store all samples in the refrigerator, neutralize samples and dialize for 36 hours at $5^{\circ} \mathrm{C}$ freeze dry samples and record weight. Methods modified from Fry (2000).

\section{Fractionation Method B}




\section{Methanolic KOH Extraction}

1. Make solutions as follows:

- $5 \% \mathrm{KOH}$ in $80 \%$ methanol: $25 \mathrm{~g} \mathrm{KOH}, 256 \mathrm{~mL} \mathrm{MeOH}$, and $64 \mathrm{~mL}$ $\mathrm{dH}_{2} \mathrm{O}$

- $\quad 0.5 \mathrm{~N}$ acetic acid: $5.8 \mathrm{~mL}$ of glacial acetic acid and $200 \mathrm{~mL} \mathrm{dH}_{2} \mathrm{O}$

2. Grind samples to fine powder under liquid nitrogen

3. Add $25 \mathrm{~mL}$ of $\mathrm{MeKOH}$ to $50 \mathrm{~mL}$ tube containing sample

4. Vortex thoroughly

5. Place in $90^{\circ} \mathrm{C}$ water bath for 15 mins. (watch the the samples don't bubble over)

6. Centrifuge on medium high setting for 5 minutes.

7. Repeat steps 2-6 two more times (total 3 times).

8. Add $\mathrm{dH}_{2} \mathrm{O}$, vortex, and centrifuge

9. Pour off supernatant and repeat step 8 twice more.

10. Add $0.5 \mathrm{~N}$ acetic acid, vortex and centrifuge.

11. Add $\mathrm{dH}_{2} \mathrm{O}$, vortex, and centrifuge. Repeat this step three times.

\section{Hot Water Soluble Fraction}

1. Add $20 \mathrm{~mL}$ of $\mathrm{dH}_{2} \mathrm{O}$ to $\mathrm{MeKOH}$ pellet.

2. Vortex thoroughly

3. Place in hot water bath $\left(95^{\circ} \mathrm{C}\right)$ for 1 hour

4. Remove allow to cool and centrifuge, collect supernatant

5. Repeat steps 1-4 twice more (total of 3 times)

\section{CDTA Soluble Fraction}

1. Make solutions as follows:

- $0.05 \mathrm{M}$ CDTA: $1.822 \mathrm{~g}$ in $100 \mathrm{~mL}$ of $\mathrm{dH}_{2} \mathrm{O}$

- $\quad 0.5 \mathrm{M}$ imidazole: $34.04 \mathrm{~g}$ in $1000 \mathrm{~mL}$ of $\mathrm{dH}_{2} \mathrm{O}$

2. Add $20 \mathrm{~mL}$ of $0.05 \mathrm{M}$ CDTA to HW pellet

3. Vortex thoroughly

4. Let sit at room temperature for 6 hours

5. Centrifuge and collect supernatant

6. Wash 3 times with $\mathrm{dH}_{2} \mathrm{O}$ and collect supernatant

7. Combine washes and CDTA supernatant

\section{$\mathrm{Na}_{2} \mathrm{CO}_{3}$ Soluble Fraction}

1. Make solution as follows:

- $\quad 0.05 \mathrm{M} \mathrm{Na}_{2} \mathrm{CO}_{3} / 20 \mathrm{mM} \mathrm{NaBH}_{4}: 0.53 \mathrm{~g} \mathrm{Na}_{2} \mathrm{CO}_{3}$ and $75.6 \mathrm{mg} \mathrm{NaBH}_{4}$ in $100 \mathrm{~mL}$ of $\mathrm{dH}_{2} \mathrm{O}$

2. Add $20 \mathrm{~mL}$ of $0.05 \mathrm{M} \mathrm{Na}_{2} \mathrm{CO}_{3} / 20 \mathrm{mM} \mathrm{NaBH}_{4}$ (on shelf) to CDTA pellet

3. Vortex thoroughly

4. Let sit in ice bath at $1^{\circ} \mathrm{C}$ for 16 hours

5. Centrifuge and collect supernatant

6. Wash 3 times with $\mathrm{dH}_{2} \mathrm{O}$ and collect supernatant 
7. Combine washes and supernatant

\section{M KOH Soluble Fraction}

1. Make solution as follows:

- $1 \mathrm{M} \mathrm{KOH} / 20 \mathrm{mM} \mathrm{NaBH}_{4}$ : $5.6 \mathrm{~g} \mathrm{KOH}$ and $75.6 \mathrm{mg} \mathrm{NaBH}_{4}$ in $100 \mathrm{~mL}$ of $\mathrm{dH}_{2} \mathrm{O}$

2. Add $20 \mathrm{~mL}$ of $1 \mathrm{M} \mathrm{KOH} / 20 \mathrm{mM} \mathrm{NaBH}_{4}$ to $\mathrm{Na}_{2} \mathrm{CO}_{3}$ pellet

3. Vortex thoroughly

4. Let sit in ice bath at $1^{\circ} \mathrm{C}$ for 2 hours

5. Centrifuge and collect supernatant

6. Repeat steps 2-4 one more time

7. Wash 3 times with $\mathrm{dH}_{2} \mathrm{O}$ and collect supernatant

8. Combine washes and supernatant

\section{$4 \mathrm{M} \mathrm{KOH} \mathrm{Soluble} \mathrm{Fraction}$}

1. Make solutions as follows:

- $4 \mathrm{M} \mathrm{KOH} / 20 \mathrm{mM} \mathrm{NaBH}_{4}$ : 22.4g KOH and $75.6 \mathrm{mg} \mathrm{NaBH}_{4}$ in $100 \mathrm{~mL}$ of $\mathrm{dH}_{2} \mathrm{O}$

2. Add $20 \mathrm{~mL}$ of $4 \mathrm{M} \mathrm{KOH} / 20 \mathrm{mM} \mathrm{NaBH}_{4}$ to $1 \mathrm{M} \mathrm{KOH}$ pellet

3. Vortex thoroughly

4. Let sit in ice bath at $1^{\circ} \mathrm{C}$ for 2 hours

5. Centrifuge and collect supernatant

6. Repeat steps 2-5 one more time

7. Wash 3 times with $\mathrm{dH}_{2} \mathrm{O}$ and collect supernatant

8. Combine washes and supernatant

*Store all samples in the refrigerator, neutralize samples and dialize for 36 hours at $5^{\circ} \mathrm{C}$ freeze dry samples and record weight. Methods modified from Fry (2000).

\section{Immuno-cytochemical Dot Blot Analysis}

1. Make solutions as follows:

\section{X Phosphate Buffered Saline (PBS)}

1. Dissolve $8 \mathrm{~g} \mathrm{NaCl}, 0.2 \mathrm{~g} \mathrm{KCl}, 1.44 \mathrm{~g} \mathrm{Na}_{2} \mathrm{HPO}_{4}$, and $0.24 \mathrm{~g} \mathrm{KH}_{2} \mathrm{PO}_{4}$ in $800 \mathrm{~mL}$ $\mathrm{dH}_{2} \mathrm{O}$

2. Adjust to $\mathrm{pH} 7.4$

3. Adjust to $1 \mathrm{~L}$ with $\mathrm{dH}_{2} \mathrm{O}$

4. Sterilize by autoclaving

Powdered Milk Block (MP/PBS)

1. Add $2.5 \mathrm{~g}$ powdered milk to $50 \mathrm{~mL}$ PBS 


\section{$1^{0}$ Antibody Solution}

1. Add $10 \mu \mathrm{l}$ antibody to $0.5 \mathrm{~mL}$ PBS for $1 / 50$ solution

2. Add $10 \mu 1$ antibody to $1 \mathrm{~mL}$ PBS for $1 / 100$ solution

\section{$2^{\circ}$ Antibody Solution}

1. Add $10 \mu 1$ anti-rat $I g G$ antibody to $0.5 \mathrm{~mL}$ PBS for $1 / 50$ solution

2. Mark out grid and label square of nitrocellulose membrane (label one column as 0 to use as control)

3. Apply dilution series of $1 \mu \mathrm{l}$ aliquots of test compound dissolved in $\mathrm{H}_{2} \mathrm{O}$ or buffer to membrane and allow to dry overnite in covered petri dish.

4. Incubate sheet in $\mathrm{mp} / \mathrm{PBS}$ for 1 hour on shaker to block binding sites

5. Incubate in primary antibody diluted 10 -fold $\mathrm{mp} / \mathrm{PBS}$ for 1.5 hours

6. Wash 5 times in $\mathrm{dH}_{2} \mathrm{O}$

7. Wash 3 times in PBS (incubate 5 minutes in between each wash)

8. Incubate in secondary antibody diluted 1000 -fold in $\mathrm{mp} / \mathrm{PBS}$ for 1.5 hours

9. Repeat steps 6 and 7

10. Prepare HRP substrate $(25 \mathrm{~mL}$ de-ionized $\mathrm{H} 2 \mathrm{O}, 5 \mathrm{~mL}$ methanol containing $10 \mathrm{mg} / \mathrm{mL}$ 4-chloro-1-napthonol)

11. Add $2 \mathrm{~mL} \mathrm{HRP}$ substrate and $60 \mu \mathrm{l} 6 \% \mathrm{H}_{2} \mathrm{O}_{2}$ at the same time to membrane sheet on shaker

12. Incubate until sheet until developed

\section{FITC Cell Labeling Procedure}

1. Add $50 \mu \mathrm{l}$ of sample and $400 \mu \mathrm{lmp} / \mathrm{PBS}$ to Eppendorf tube and incubate for 1 hour

2. Cetrifuge and remove PBS

3. Add primary antibody diluted 10 -fold in $\mathrm{mp} / \mathrm{PBS}$

4. Incubate for 1.5 hours on shaker

5. Wash 3 times in PBS

6. Add secondary antibody (FITC conjugate) diluted 1000 -fold in $\mathrm{mp} / \mathrm{PBS}$

7. Incubate 1.5 hours

8. Repeat step 6

9. Observe and image with microscope under UV

*Method from Domozych (2007) and Wustman (1997)

\section{Calcium Labeling Procedure}

1. Place cells in Eppendorf tube

2. Make $1 \mathrm{~mm}$ stock solution of Fura- 2 AM in DMSO $(1 \mathrm{~mL} / 1 \mathrm{~mL})$ 
3. Dilute Fura-2 AM 100 fold in buffer (PBS)

4. Add to cells and vortex

5. Incubate cells $15-60$ minutes at $25^{\circ} \mathrm{C}$ to $37^{\circ} \mathrm{C}$

6. Wash in buffer 2 times

7. View under UV

*Method from Grynkiewicz (1985)

\section{Phenol-sulfuric Assay for \% Total Carbohydrates (w/w)}

1. Make $100 \mathrm{~mL}$ of stock solution by dissolving $1 \mathrm{~mL}$ glucose stock in $99 \mathrm{ml}$ of $\mathrm{dH}_{2} \mathrm{O}$.

2. In the hood, make $5 \%$ phenol solution by dissolving $5 \mathrm{~g}$ of phenol in $100 \mathrm{~mL}$ of $\mathrm{dH}_{2} \mathrm{O}$ (store in dark container).

\section{Standard Curve}

3. In clean tubes, add glucose solution with 4 replicates of each concentration. Bring to $1 \mathrm{~mL}$ as shown in table A.1.

4. To $1 \mathrm{~mL}$ of aqueous solution, add $0.5 \mathrm{~mL}$ of $5 \%$ phenol solution. Vortex.

5. Jet $2.5 \mathrm{~mL}$ conc $\mathrm{H}_{2} \mathrm{SO}_{4}$ into each tuble (5 pumps). This reaction is exothermic and may boil up (be cautious!).

6. Allow tubes to cool for 30 minutes.

7. Pour solution into cuvettes and measure the absorbance at $485 \mathrm{~nm}$ with spectrophotometer. Blank against $\mathrm{dH}_{2} \mathrm{O}$ ( $0 \%$ conc.) standard. The color remains stable up to 4 hours.

8. Use Excel to plot the absorbance and concentration as a scatter plot. Find the $\mathrm{r}^{2}$ value for the trend line, it should be as close to $100 \%$ as possible.

\section{For Samples}

1. Measure close to $0.250 \mathrm{mg}$ of sample and put into clean tubes. Use at least 3 replicates. Be sure to label tubes to ensure accurate results.

2. Bring samples to $1 \mathrm{~mL}$ by adding $\mathrm{dH}_{2} 0$.

3. Proceed as above, steps 4-7.

Table A.1: $\mu \mathrm{L}$ of glucose and $\mathrm{dH}_{2} \mathrm{O}$ for various concentrations for the glucose standard curve

\begin{tabular}{|l|l|l|}
\hline \multicolumn{3}{|c|}{ Glucose Standard Curve } \\
\hline Concentration (\%) & $\mu$ L Glucose & $\mu{\mathrm{L} \mathrm{H}_{2} \mathrm{O}}^{-1}$ \\
\hline 0 & 0 & 1000 \\
\hline 10 & 100 & 900 \\
\hline 20 & 200 & 800 \\
\hline 40 & 400 & 600 \\
\hline 60 & 600 & 400 \\
\hline 80 & 800 & 200 \\
\hline 100 & 1000 & 0 \\
\hline
\end{tabular}


*Methods from Dubois (1956)

\section{Carbazole Assay for \% Total Uronic Acid (w/w)}

1. Weigh out $0.277 \mathrm{~g}$ of sodium tetraborate.

2. Add $55 \mathrm{ml}$ of concentrated $\mathrm{H}_{2} \mathrm{SO}_{4}(0.025 \mathrm{M})$.

3. Pipete $5 \mathrm{ml}$ of $\mathrm{H}_{2} \mathrm{SO}_{4}$ reagent in 10 test tubes with screw caps and freeze at -80 ${ }^{\circ} \mathrm{C}$.

4. Weigh out $1 \mathrm{~g}$ of carbazole.

5. Add $100 \mathrm{ml}$ of absolute ethanol (stable for 12 weeks at $4{ }^{\circ} \mathrm{C}$ in the dark).

\section{Standard Curve}

1. Weigh out $500 \mu \mathrm{g}$ of standard and bring to volume, $5 \mathrm{ml}$.

2. Create tubes for standard curve as shown in table A.2.

3. Add $1 \mathrm{ml}$ of standard or sample to each of the frozen test tubes with $\mathrm{H}_{2} \mathrm{SO}_{4}$ on ice.

4. Vortex. Mix gently at first, then more vigorously.

5. Heat in boiling water bath for $12 \mathrm{~min}$.

6. Remove and cool to room temp on ice.

7. Add $200 \mu \mathrm{l}$ of carbazole reagent to each tube.

8. Mix by vortexing

9. Heat in boiling water bath for $15 \mathrm{~min}$.

10. Remove and cool on ice to room temp.

11. Transfer to $2.5 \mathrm{ml}$ cuvettes

12. Read absorbance in Spec at $530 \mathrm{~nm}$.

\section{For Samples}

1. Weigh out four $100 \mu \mathrm{g}$ samples and bring each to volume, $1 \mathrm{ml}$.

2. Repeat steps 8-17 as above.

Table A.2: $\mu \mathrm{L}$ of standard and $\mathrm{dH}_{2} \mathrm{O}$ for various concentrations for the uronic acid standard curve

\begin{tabular}{|l|l|l|}
\hline \multicolumn{3}{|c|}{ Uronic acid standard curve } \\
\hline Concentration (\%) & $\mu \mathrm{L}$ standard & $\mu \mathrm{L} \mathrm{dH}_{2} \mathrm{O}$ \\
\hline 0 & 0 & 1000 \\
\hline 10 & 100 & 900 \\
\hline 20 & 200 & 800 \\
\hline 40 & 400 & 600 \\
\hline 60 & 600 & 400 \\
\hline 80 & 800 & 200 \\
\hline 100 & 1000 & 0 \\
\hline
\end{tabular}


*Methods from Bitter and Muir (1962)

\section{Sulfate Assay for \% Total Ester Sulfate (w/w)}

1. Clean all glassware including pipet tips, reactivials, and cuvettes by rinsing with $2 \% \mathrm{HCl}, 2$ times with $\mathrm{dH}_{2} \mathrm{O}$ and $1 \mathrm{x}$ with $\mathrm{ddH}_{2} \mathrm{O}$. (You may want to clean extras as well)

2. Prepare $\mathrm{BaCl}_{2}$ gelatin by dissolving $0.6 \mathrm{~g}$ Difco Bacto gelatin in $200 \mathrm{ml}$ warm $\mathrm{ddH}_{2} \mathrm{O}$. Allow solution to stand in refrigerator overnight (about 16 hours).

Before use, bring to room temperature, add $2 \mathrm{~g} \mathrm{BaCl}_{2} \cdot 2 \mathrm{H}_{2} \mathrm{O}$ (AR grade) stir until dissolved.

3. Prepare $0.5 \mathrm{M}$ and $2 \mathrm{M} \mathrm{HCl}$ solutions.

4. Prepare stock solution: Disolve $0.5434 \mathrm{~g}$ dry $\mathrm{K}_{2} \mathrm{SO}_{4}$ (AR grade) in $100 \mathrm{ml} \mathrm{ddH_{2 } \mathrm { O }}$ (conc. $=3 \mathrm{mg} \mathrm{SO}_{4}^{-2} / \mathrm{mL}$ )

\section{Standard Curve}

5. Prepare standards: pipet volumes of reagents into cleaned test tubes according to table A.3. (4 replicates of each).

6. Hydrolysis: in reactive vial add $20 \mu \mathrm{l} 95 \% \mathrm{EtOH}, 100 \mu \mathrm{l} 2 \mathrm{M} \mathrm{HCl}$ and briefly sonicate.

7. Incubate at $100^{\circ} \mathrm{C}$ for $2 \mathrm{~min}$, sonicate and tighten cap.

8. Heat at $100^{\circ} \mathrm{C}$ for $2 \mathrm{~h}$, cool, add $900 \mu \mathrm{ddd} \mathrm{d}_{2} \mathrm{O}$ and mix. Centrifuge if necessary.

9. Precipitate development: Transfer $0.2 \mathrm{ml}$ of sample or standards to clean test tubes.

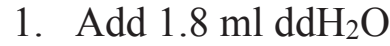

2. Add $0.2 \mathrm{ml} 0.5 \mathrm{M} \mathrm{HCl}$

3. Add $0.1 \mathrm{ml} \mathrm{BaCl} 2$ gelatin

4. Mix well, cover with parafilm

5. Let develop for 30 minutes

10. Transfer to cuvettes and read absorbance at $\lambda=550$

\section{For Sample}

1. Weigh out close to $500 \mu \mathrm{g}$ of sample and place in reactivial.

2. Repeat steps 6-10.

Table A.3: $\mu \mathrm{L}$ of standard, $\mathrm{dH}_{2} \mathrm{O}$ and $2 \mathrm{M} \mathrm{HCl}$ for various concentrations for the ester sulfate standard curve

\begin{tabular}{|l|l|l|l|}
\hline \multicolumn{4}{|c|}{ Ester sulfate standard curve } \\
\hline Concentration (\%) & $\mu \mathrm{L}$ standard & $\mu \mathrm{L} \mathrm{dH}_{2} \mathrm{O}$ & $\begin{array}{l}\mu \mathrm{L} \\
\mathrm{HCl}\end{array}$ \\
\hline 0 & 0 & 900 & 100 \\
\hline 30 & 10 & 890 & 100 \\
\hline 60 & 20 & 880 & 100 \\
\hline
\end{tabular}




\begin{tabular}{|l|l|l|l|}
\hline 90 & 30 & 870 & 100 \\
\hline 120 & 40 & 860 & 100 \\
\hline 150 & 50 & 850 & 100 \\
\hline 300 & 100 & 800 & 100 \\
\hline
\end{tabular}

*Methods from Craigie (1981)

\section{Sequential Fractionation of Soluble Phosphorus}

\section{HW Soluble Fraction}

1. Grind approximately $1 \mathrm{~g}$ of sample to fine powder under liquid nitrogen

2. Add $30 \mathrm{~mL}$ of $\mathrm{dH}_{2} \mathrm{O}$ to sample

3. Vortex thoroughly

4. Place in hot water bath $\left(95^{\circ} \mathrm{C}\right)$ for 30 minutes

5. Remove allow to cool and centrifuge, collect supernatant

6. Repeat steps 1-4 twice more (total of 3 times)

\section{$\mathrm{NaOH}$ soluble fraction (organic $\mathrm{P}$ and $\mathrm{Ca}-\mathrm{bound} \mathrm{P}$ )}

1. Add $50 \mathrm{~mL} 6 \mathrm{M} \mathrm{NaOH}$ to $\mathrm{HW}$ pellet

2. Vortex thouroughly

3. Let sit for 20 hours at $21^{\circ} \mathrm{C}$ on stir plate

4. Remove and centrifuge, collect supernatant

\section{HCl soluble fraction (remaining Ca-bound P)}

1. Add $50 \mathrm{~mL} 1 \mathrm{M} \mathrm{HC} 1$ to $\mathrm{NaOH}$ pellet

2. Vortex thouroughtly

3. Let sit for 1 hour on stir plate

4. Remove and centrifuge, collect supernatant

*Methods from Dou et al. (2000)

\section{Molybdenum Blue Method for \% Total Phosphorus (w/w)}

1. Make solutions as follows:

\section{Sulfuric molybdate solution}

1. Add $10 \mathrm{~g}$ ammonium molybdate, $0.2425 \mathrm{~g}$ antimony potassium tartrate and

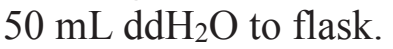

2. Slowly add $140 \mathrm{~mL}$ concentrated $\mathrm{H}_{2} \mathrm{SO}_{4}$ (mix on stir plate)

3. Let cool to room temperature and bring to $200 \mathrm{~mL}$ with $\mathrm{ddH}_{2} \mathrm{O}$ 


\section{Ascorbic Acid Solution}

1. Add $17.6 \mathrm{~g}$ ascorbic acid to $200 \mathrm{~mL} \mathrm{H} 2 \mathrm{O}$

2. Mix on stir plate

\section{Working Solution}

1. Mix $2 \mathrm{~mL}$ ascorbic acid solution with $4 \mathrm{~mL}$ sulfuric molybdate solution

2. Bring to $200 \mathrm{~mL}$ with $\mathrm{ddH}_{2} \mathrm{O}$

3. Mix on stir plate and allow to stand for 1 hour before use (good for 3 days)

\section{Phosphate Standard Solution $(1000 \mathrm{mg} / \mathrm{L})$}

1. Add 0.430 potassium dihydrogen orthophosphate $\left(\mathrm{KH}_{2} \mathrm{PO}_{4}\right)$ to $100 \mathrm{~mL}$ $\mathrm{dd}_{2} \mathrm{O}$

2. Mix on stir plate

\section{Stock Standard Solution (10mg/L)}

1. Add $1 \mathrm{~mL}$ phosphate standard solution to $99 \mathrm{~mL} \mathrm{ddH}_{2} \mathrm{O}$

2. Mix on stir plate

2. Prepare standards: pipet the volumes shown in table A.4 of reagents into cleaned test tubes (4 replicates of each).

3. Add $2 \mathrm{~mL}$ of standard or sample to $23 \mathrm{~mL}$ working solution.

4. Vortex thouroughly

5. Let stand 20 minutes

6. Read absorbance at $880 \mathrm{~nm}$.

7. Repeat steps 3-6 for samples.

Table A.4: $\mu \mathrm{L}$ of standard and $\mathrm{dH}_{2} \mathrm{O}$ for various concentrations for the phosphorus standard curve

\begin{tabular}{|l|l|l|}
\hline \multicolumn{3}{|c|}{ Phosphorus standard curve } \\
\hline Concentration $(\%)$ & $\mu \mathrm{L}$ standard & $\mu \mathrm{L} \mathrm{dH}_{2} \mathrm{O}$ \\
\hline 0 & 0 & 1000 \\
\hline 10 & 100 & 900 \\
\hline 20 & 200 & 800 \\
\hline 40 & 400 & 600 \\
\hline 60 & 600 & 400 \\
\hline 80 & 800 & 200 \\
\hline 100 & 1000 & 0 \\
\hline
\end{tabular}

*Method from Jones (2001) 


\section{Standard Curves for Assays}

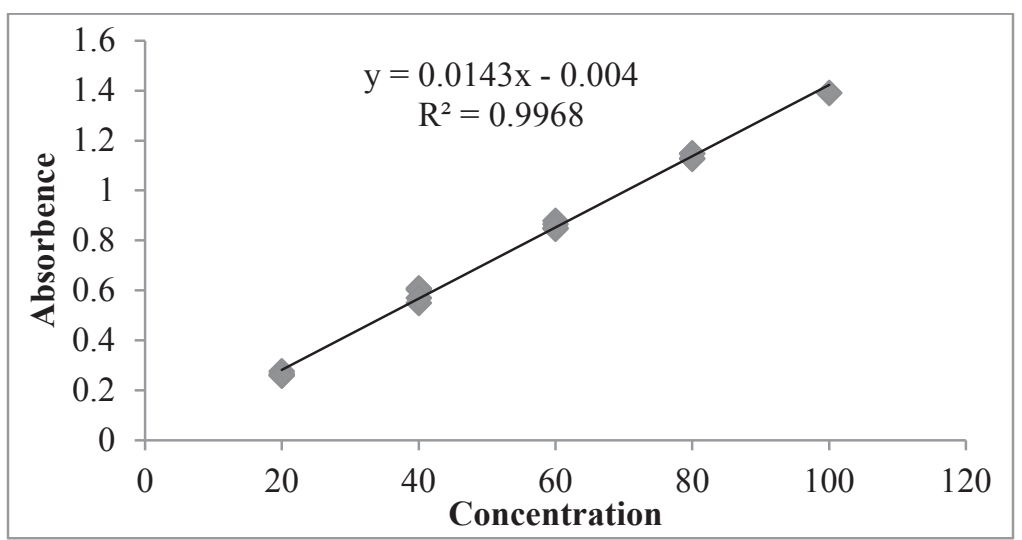

Figure A.1: Standard curve obtained for carbazole assay (total \% uronic acid w/w) of fractionation A samples using glucuronic acid as a standard $n=3$

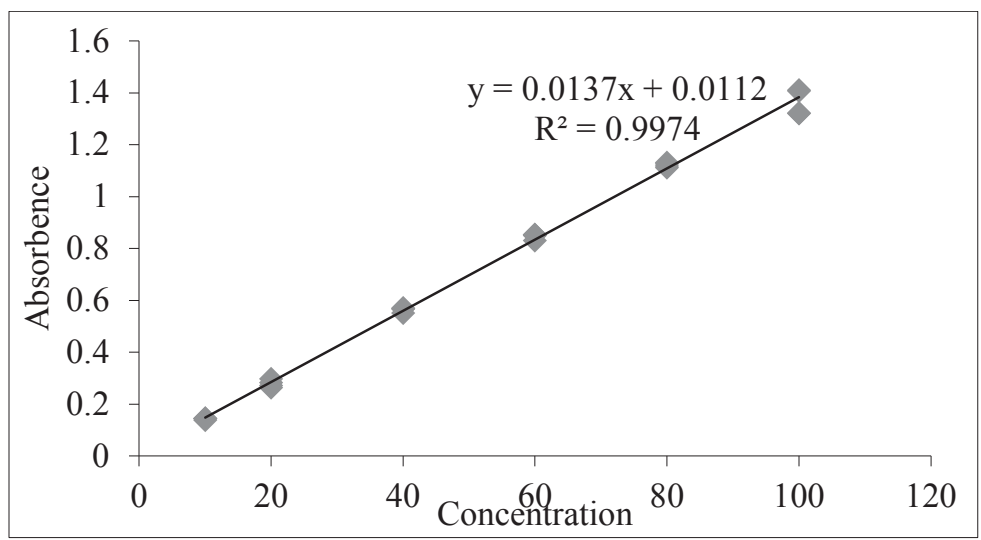

Figure A.2: Standard curve obtained for phenol assay (total \% carbohydrate w/w) of fractionation A samples using glucose as a standard $n=3$ 


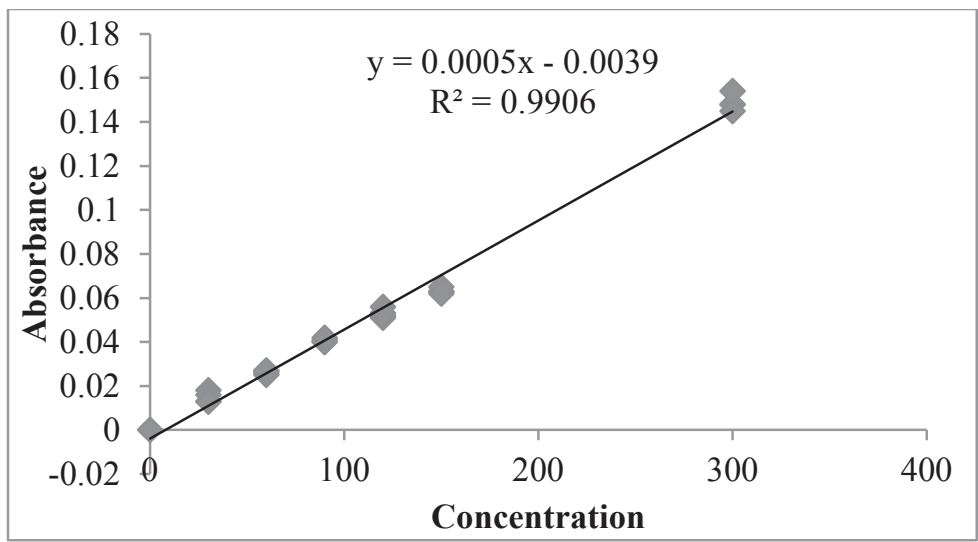

Figure A.3: Standard curve obtained for sulfate assay (total $\%$ ester sulfate w/w) of fractionation A samples using potassium sulfate as a standard $n=3$

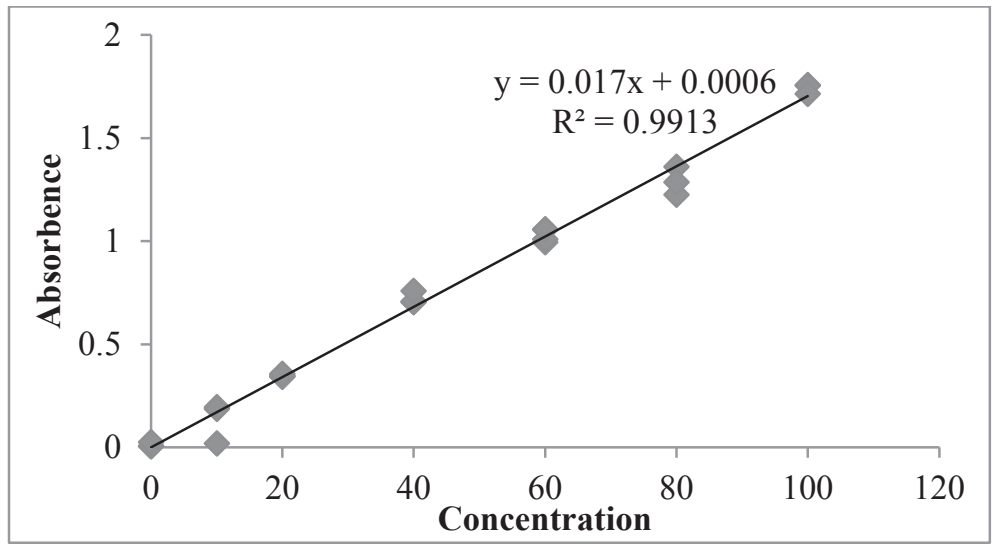

Figure A.4: Standard curve obtained for phenol Assay (total $\%$ glucose w/w) fractionation B samples using glucose as a standard $n=3$

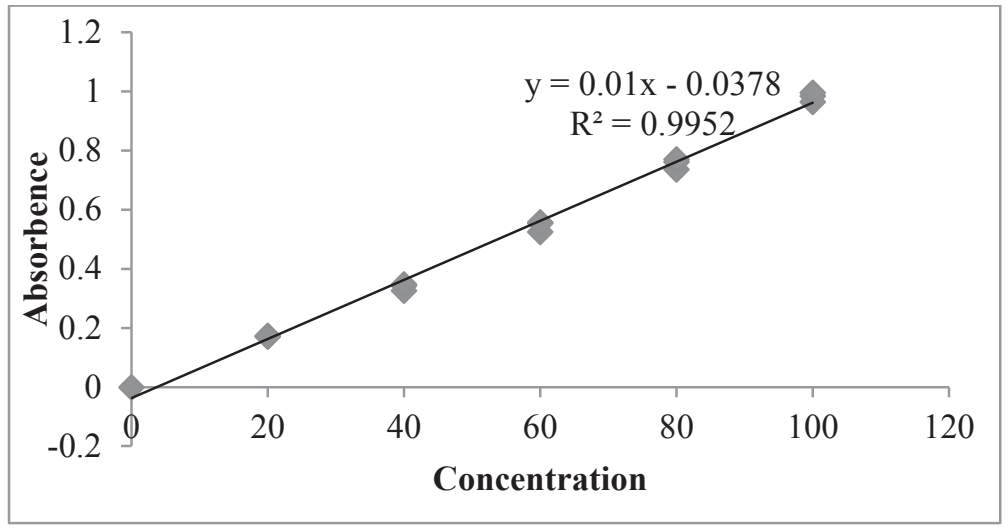

Figure A.5: Standard curve for Carbazole Assay (total \% uronic acid w/w) fractionation B samples using glucuronic acid as a standard $n=3$ 


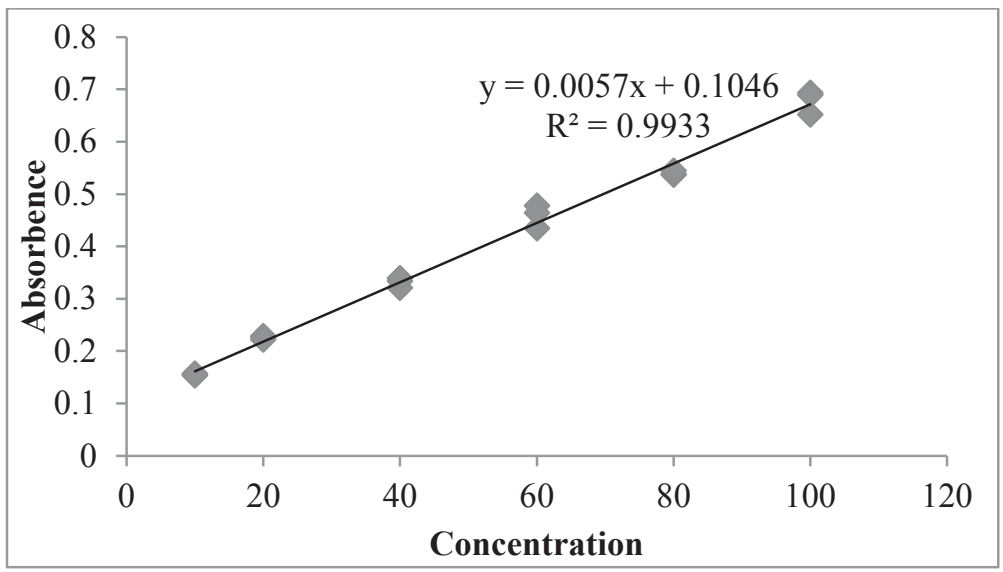

Figure A.6: Standard curve for phosphate assay (total $\%$ phosphorus $w / w$ ) using potassium dihydrogen orthophosphate as a standard $n=3$ 